WSRC-TR-2004-00436

REVISION 0

\title{
EVALUATION OF MIXING IN THE SLURRY MIX EVAPORATOR AND MELTER FEED TANK (U)
}

\author{
A.R. Marinik \\ M.E. Stone
}

August 2004

Immobilization Technology Section

Savannah River National Laboratory

Savannah River National Laboratory

Aiken, SC 29808 
This document was prepared in conjunction with work accomplished under Contract No. DE-AC09-96SR18500 with the U. S. Department of Energy.

\section{DISCLAIMER}

This report was prepared as an account of work sponsored by an agency of the United States Government. Neither the United States Government nor any agency thereof, nor any of their employees, makes any warranty, express or implied, or assumes any legal liability or responsibility for the accuracy, completeness, or usefulness of any information, apparatus, product or process disclosed, or represents that its use would not infringe privately owned rights. Reference herein to any specific commercial product, process or service by trade name, trademark, manufacturer, or otherwise does not necessarily constitute or imply its endorsement, recommendation, or favoring by the United States Government or any agency thereof. The views and opinions of authors expressed herein do not necessarily state or reflect those of the United States Government or any agency thereof.

This report has been reproduced directly from the best available copy.

Available for sale to the public, in paper, from: U.S. Department of Commerce, National Technical Information Service, 5285 Port Royal Road, Springfield, VA 22161, phone: (800) 553-6847, fax: (703) 605-6900

email: orders@ntis.fedworld.gov

online ordering: http://www.ntis.gov/help/index.asp

Available electronically at http://www.osti.gov/bridge

Available for a processing fee to U.S. Department of Energy and its contractors, in paper, from: U.S. Department of Energy, Office of Scientific and Technical Information, P.O. Box 62, Oak Ridge, TN 37831-0062,

phone: (865)576-8401,

fax: (865)576-5728

email: $\underline{\text { reports@ adonis.osti.gov }}$ 
Key Words:

DWPF, Mixing, Vortex, Xanthan Gum, Scaling Mixing Tanks

Retention:

Permanent

\title{
EVALUATION OF MIXING IN THE SLURRY MIX EVAPORATOR AND MELTER FEED TANK (U)
}

\author{
A.R. Marinik \\ M.E. Stone
}

August 2004

Immobilization Technology Section Savannah River National Laboratory Savannah River National Laboratory Aiken, SC 29808 
This page was intentionally left blank 
WSRC-TR-2004-00436

REVISION 0

\section{EXECUTIVE SUMMARY}

The Savannah River National Laboratory (SRNL) performed $1 / 6^{\text {th }}$ scale mixing tests using Xanthan Gum and Frit 418 slurries to evaluate the impact of removing the helical cooling coils from the Melter Feed Tank, and to evaluate the minimum agitator speed necessary in the Slurry Mix Evaporator (SME) tank and the Melter Feed Tank (MFT) to maintain solids suspension and fluid motion throughout the tank. Testing was conducted with three slurries having Bingham Plastic yield stresses of Five, Ten, and Twenty Pascals.

Testing was performed at three different tank levels, 6 gallons (full scale equivalent: 1500 gallons), 25 gallons (6000 gallons), and 40 gallons (9500 gallons). Each slurry was tested at each tank level with the helical coils in the vessel and with the helical coils removed from the vessel. Each test consisted of various agitation speeds, including 220 revolutions per minute (RPM), 330 RPM, and 420 RPM (full scale equivalent: 67, 103, and 130 RPM, respectively using the Ekato sizing correlation).

\section{Conclusions}

Vortex formation increased significantly when the coil was removed, especially for the $5 \mathrm{~Pa}$ test fluid. Vortex formation can cause process upsets by entraining air into the process ${ }^{1}$ and can cause uneven mechanical loading on the agitator shaft and subsequent failure. It should be noted that scaling of the vortex phenomena is extremely uncertain and the $1 / 6^{\text {th }}$ scale results may not accurately reflect the severity of the problems that will occur in the full scale tank. However, removal of the coil did improve surface motion and solids distribution.

The $1 / 6^{\text {th }}$ scale test results showed good surface motion for the $5 \mathrm{~Pa}$ and $10 \mathrm{~Pa}$ fluids at 25 gallons for the 330 RPM tests (scales to 6000 gallons and 103 RPM), but the 20 Pa fluid indicated borderline results with small areas of stagnation around the wall. Cavern formation was noted for all fluids at 40 gallons (9500 gallons) at this speed, both with the coils in and out. Sample results from the homogeneity samples did not indicate that the $5 \mathrm{~Pa}$ fluid was uniform at 40 gallons and 330 RPM with the coils in the tank.

The power per unit volume sizing method yielded significant cavern formation at higher volumes and at lower volumes with high yield stress materials. Comparisons between the $1 / 6^{\text {th }}$ Scale SRAT and the Full Scale homogeneity study indicate that Equal Tip Speed may be a more appropriate scaling method. Utilizing Equal Tip Speed as a scaling method would lead to significant changes in the results given the much higher agitator speeds required.

\footnotetext{
${ }^{1}$ Stone, M.E., Marinik. A.R., Small Scale Mixing Tests for the DWPF Chemical Process Cell Vessels (U). March 2004. WSRC-TR-2004-00074.
} 
WSRC-TR-2004-00436

REVISION 0

The DWPF MFT agitator is currently configured at a high speed setting of 103 RPM with no operational difficulties noted to date. Sample results from the MFT have agreed with sample results from the SME, indicating that adequate mixing has been maintained in the MFT at the lower agitator speed.

\section{Recommendations}

A plan should be developed to address vortex formation prior to removal of the MFT coil assembly.

The CFD models developed for the MFT and SME vessels should be validated versus the $1 / 6^{\text {th }}$ scale results. Validation of the model will lead to improved results from the model and will allow better representation of the DWPF process by the model.

The rheological properties of actual DWPF process slurries should be measured. A flow curve would be ideal, but even a single point measurement of apparent viscosity could lead to valuable insight into process conditions and aid in the evaluation of process upsets. The amount of variability in the process could be determined if the analysis is performed on routine process samples.

The MFT and SME agitators should not operate continuously at the low speed setting (67 RPM) when the vessels are above 6000 gallons to reduce the potential for cavern formation.

Alternative means of reducing the erosion rate on the cooling/heating coils due to the irregular shaped frit are:

- Conversion of irregular shaped frit to spherical shaped frit which is processed from the irregular shaped frit.

- Raising the lower section of the cooling/heating coils above the discharge of the bottom impeller. Raising the coils would likely improve mixing in the vessel. 


\section{TABLE OF CONTENTS}

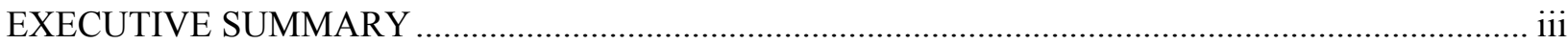

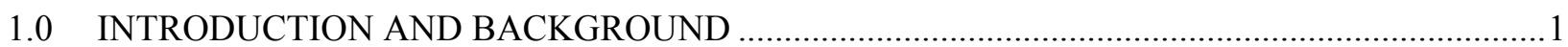

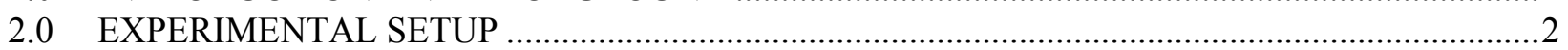

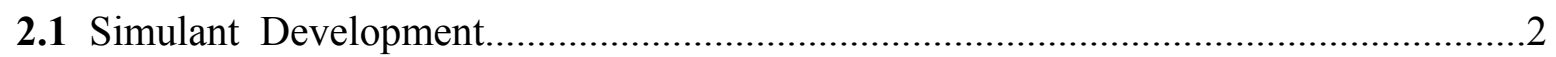

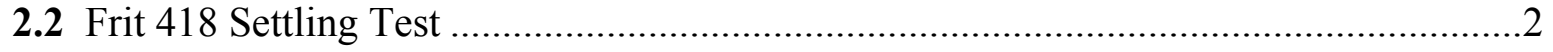

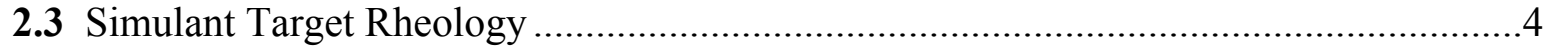

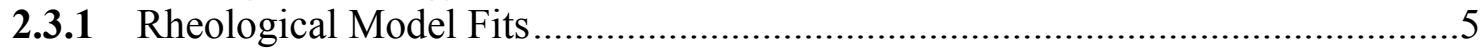

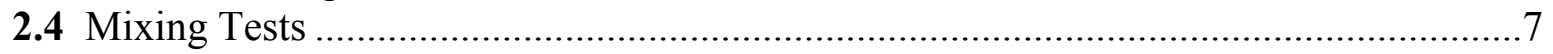

2.4.1 Instrumentation and Equipment Setup ......................................................

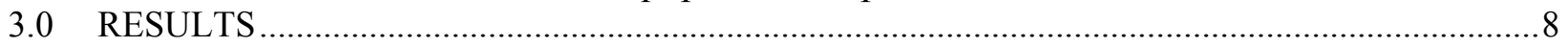

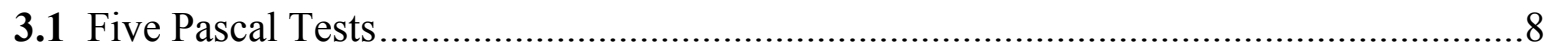

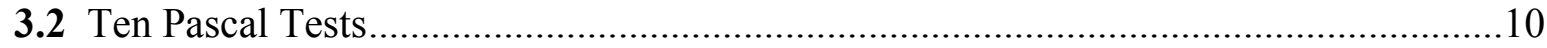

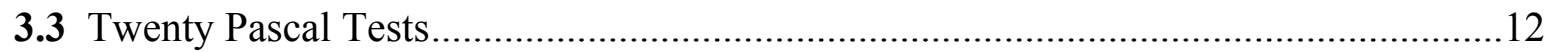

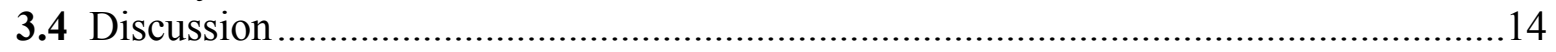

3.4.1 Impact of Coils on Solids Suspension ........................................................ 14

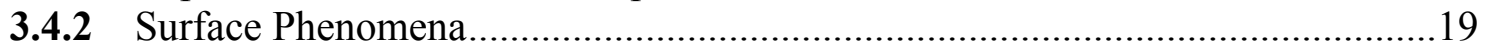

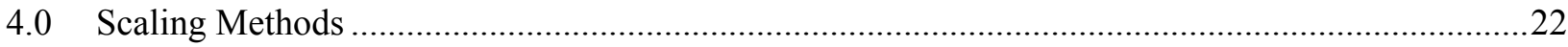

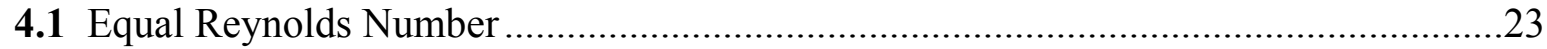

4.2 Equal Cavern Diameter Ratio .........................................................................24

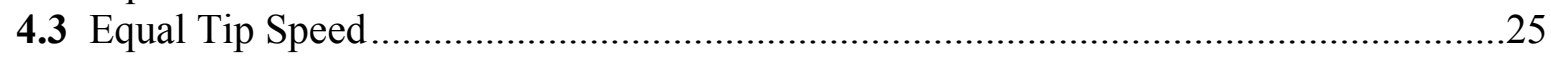

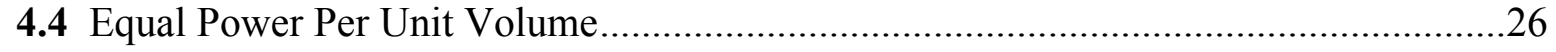

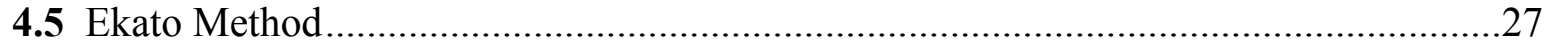

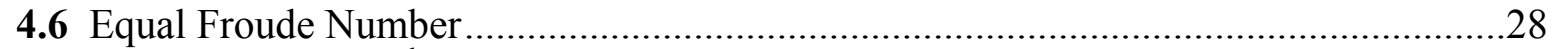

4.7 Comparison of $1 / 6^{\text {th }}$ Scaled Mixing to TNX Homogeneity Study..............................29

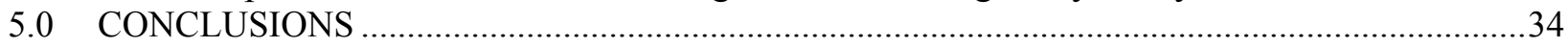

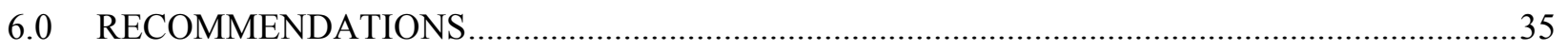

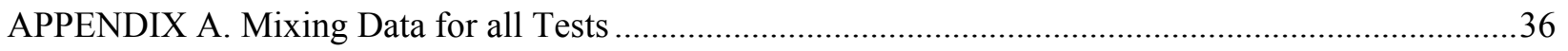

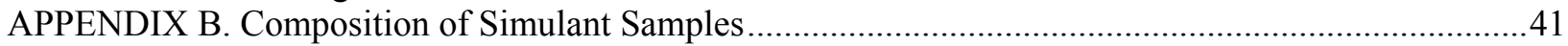

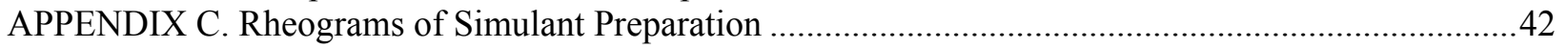

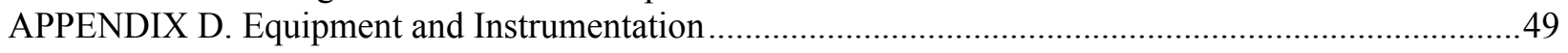

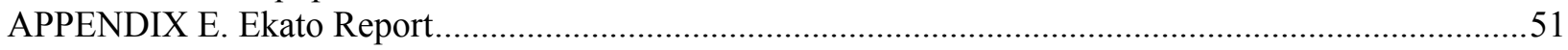

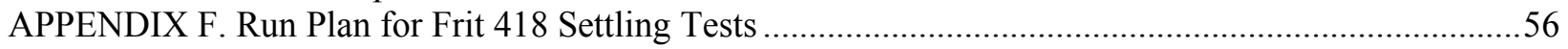




\section{LIST OF FIGURES}

Figure 2-1. Experimental Setup ................................................................................. 2

Figure 2-2. Settling of One Wt \% Frit After 5 Days of Settling .......................................... 3

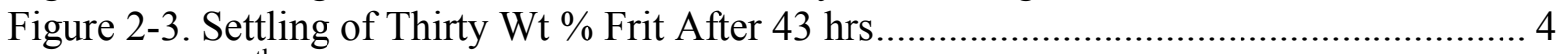

Figure 2-4. $1 / 6^{\text {th }}$ Scale SRAT/SME/MFT Diagram ........................................................... 7

Figure 2-5. 1/6 ${ }^{\text {th }}$ Scale Mixing Tank, Coil and Agitator ...................................................... 8

Figure 3-1. 25 Gallon, 5 Pa, Visible Upper Impeller Hub at 330 RPM with Coils Out .......... 9

Figure 3-2. 25 Gallon, 10 Pascal Fluid Mixing at 330 RPM with Coils In ......................... 10

Figure 3-3. 6 Gallons, 10 Pa, Extreme Surface Motion At 330 RPM with Coils Out............ 11

Figure 3-4. 25 Gallons, 20 Pa Reverse Vortex With Coils................................................. 12

Figure 3-5. Histogram of Wt\% TS Distribution for Five Pascal Mixing Tests at 40 Gallons 15

Figure 3-6. Histogram of Wt\% TS Distribution for Ten Pascal Mixing Tests with Coils Out at 40 Gallons

Figure 3-7. Histogram of Wt\% TS Distribution for Ten Pascal Mixing Tests with Coils In at 40 Gallons 19

Figure 3-8. Impact of Coils on Vortex Depth at 220 RPM For 25 Gallon 5 Pa Slurry ......... 20

Figure 3-9. Impact of Coils on Vortex Depth at 330 RPM For 25 Gallon 10 Pa Slurry ....... 20

Figure 4-1. Ekato Test Results.................................................................................... 28

Figure 4-2. Comparison to TNX Homogeneity Study ..................................................... 30

\section{LIST OF TABLES}

Table 2-1 Settling Test Simulant Makeup ....................................................................... 3

Table 2-2 Batching Quantities of Xanthan Gum/Frit 418 for Mixing Tests......................... 5

Table 3-1 Results for Initial Five Pascal Fluid Samples.................................................. 14

Table 3-2 Physical Properties from the 40 Gallon Five Pascal Fluid Mixing Tests............. 16

Table 3-3 Physical Properties from the 40 Gallon Ten Pascal Fluid Mixing Tests.............. 17

Table 4-1 Scaling Agitator Speeds Using Equal Reynolds Number ................................. 24

Table 4-2 Scaling Agitator Speed Using Equal Cavern Diameter Method To Reach the Wall

of the Mixing Tank ..................................................................................................... 25

Table 4-3 Scaling Agitator Speed Using Equal Tip Speed Method ................................... 26

Table 4-4 Scaling Agitator Speed Using Equal Power Per Unit Volume............................ 27

Table 4-5 Scaling Agitator Speed Using Ekato Method..................................................... 28

Table 4-6 Scaling Agitator Speed Using Equal Froude Number...................................... 29

Table 4-7 Dynamic/Kinematic Properties of $1 / 6^{\text {th }}$ Scale Using Various Sizing Methods -5 Pa

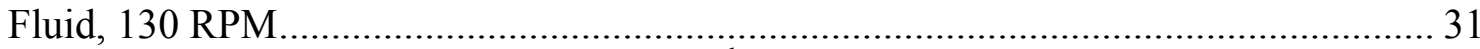

Table 4-8 Dynamic/Kinematic Properties of $1 / 6^{\text {th }}$ Scale Using Various Sizing Methods -5 Pa Fluid, 67 RPM.................................................................................................... 31

Table 4-9 Dynamic/Kinematic Properties of $1 / 6^{\text {th }}$ Scale Using Various Sizing Methods -10

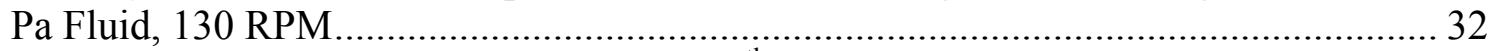

Table 4-10 Dynamic/Kinematic Properties of $1 / 6^{\text {th }}$ Scale Using Various Sizing Methods -10

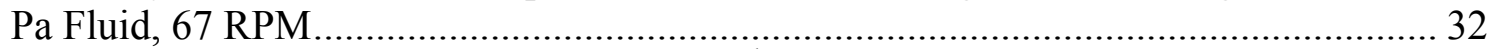

Table 4-11 Dynamic/Kinematic Properties of $1 / 6^{\text {th }}$ Scale Using Various Sizing Methods -20

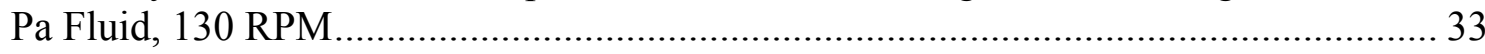


WSRC-TR-2004-00436

REVISION 0

Table 4-12 Dynamic/Kinematic Properties of $1 / 6^{\text {th }}$ Scale Using Various Sizing Methods -20

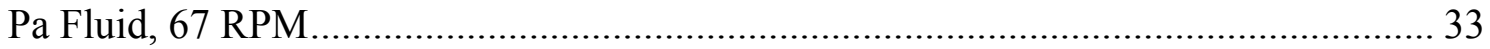




\section{LIST OF ACRONYMS}

$\begin{array}{ll}\text { ACTL } & \text { Aiken County Technology Laboratory } \\ \text { CFD } & \text { Computational Fluid Dynamics } \\ \text { CPC } & \text { Chemical Process Cell } \\ \text { DWPF } & \text { Defense Waste Processing Facility } \\ \text { HLW } & \text { High Level radioactive Waste } \\ \text { MFT } & \text { Melter Feed Tank } \\ \text { RPM } & \text { Revolutions Per Minute } \\ \text { SME } & \text { Slurry Mix Evaporator } \\ \text { SRAT } & \text { Sludge Receipt and Adjustment Tank } \\ \text { SRNL } & \text { Savannah River National Laboratory } \\ \text { SRS } & \text { Savannah River Site }\end{array}$


WSRC-TR-2004-00436

REVISION 0

\subsection{INTRODUCTION AND BACKGROUND}

The Defense Waste Processing Facility (DWPF) vitrifies High Level radioactive Waste (HLW) currently stored in underground tanks at the Savannah River Site (SRS). The HLW currently being processed is a waste sludge composed primarily of metal hydroxides and oxides in caustic slurry. These slurries are typically characterized as Bingham Plastic fluids.

The HLW undergoes a pretreatment process in the Chemical Process Cell (CPC) at DWPF. The processed HLW sludge is then transferred to the Sludge Receipt and Adjustment Tank (SRAT) where it is acidified with nitric and formic acid then evaporated to concentrate the solids. Reflux boiling is utilized to strip mercury from the waste and then the waste is transferred to the Slurry Mix Evaporator tank (SME). Glass formers are added as a frit slurry to the SME to prepare the waste for vitrification. This mixture is evaporated in the SME to the final concentration target. The frit slurry mixture is then transferred to the Melter Feed Tank (MFT) to be fed to the melter.

The irregular shaped frit slurry is extremely abrasive and is currently causing failure of the heating and cooling coil assembly in the SME vessel after approximately two years of continuous operations. The agitator on the SME has two speed settings: 130 revolutions per minute (RPM) and 67 RPM. The higher speed is used by DWPF to maintain homogeneity in the SME. Operating at the higher speed increases the erosion rate, therefore DWPF is evaluating reducing this speed to 103 RPM.

The MFT contains a coil assembly similar to the coil assembly in the SME, but the coils are not currently required to maintain tank temperatures. DWPF is evaluating the removal of the coil assembly from the MFT to reduce the maintenance required on the tank.

DWPF Engineering has developed a Computational Fluid Dynamics (CFD) model of the SRAT, SME and MFT to evaluate the above proposed process changes. Small-scale mixing tests were conducted by the Savannah River National Laboratory (SRNL) to evaluate the proposed process changes and to verify the results of the CFD model. The tests were conducted in response to a Technical Task Request ${ }^{2}$ from DWPF Engineering and conducted in accordance with a Task Technical and Quality Assurance Plan. ${ }^{3}$

\footnotetext{
2 Technical Task Request, "Develop Scale Model Testing of the SME and MFT Mixing Process." HLW/DWPF/TTR-2004-0009

${ }^{3}$ Technical Task Plan, "Scale Model Testing of the SME and MFT Mixing Process (U)." WRSC-RP2004-00407.
} 
WSRC-TR-2004-00436

REVISION 0

\subsection{EXPERIMENTAL SETUP}

\subsection{Simulant Development}

Physical simulants were developed to provide rheological properties similar to the actual waste having Bingham Plastic yield stresses of 5, 10, and 20 Pascals (Pa). The simulants contained 30 weight percent (wt \%) Frit 418. Xanthan Gum solutions were used in place of precipitated hydroxide simulants because the Xanthan Gum solutions are more cost effective, somewhat transparent and yield the necessary rheological properties. Kathon CG-ICP was utilized as a preservative for the Xanthan Gum solutions. The frit and Kathon CG-ICP concentrations were held constant while the Xanthan Gum concentrations were varied to obtain the targeted yield stresses. The particle size distribution of the Frit 418 used during this study met the requirements specified for use in DWPF: greater than $70 \mathrm{wt} \%$ of Frit will be between 80 and 140 mesh, less than $2 \mathrm{wt}$ $\%$ Frit will be greater than 80 mesh, and less than $10 \mathrm{wt} \%$ Frit less than 200 mesh. The rheology of Xanthan Gum / Kathon CG-ICP / Frit 418 slurries were measured using the rheometer at the Aiken County Technology Laboratory (ACTL) and the rheological properties evaluated for suitability based upon engineering judgment.

\subsection{Frit 418 Settling Test}

Initially a settling test was performed to determine the settling characteristics of the different slurries, indicating the approximate time required for complete settling. Seven graduated cylinders were setup according to SRT-GPD-2004-00075 (as seen in Appendix F) and shown in Figure 2-1. The composition of the slurry in each cylinder is described in Table 2-1. Frit was added to Tests 1.1 through 2.3 just as testing began, however, the Frit had already been added to the slurries in Tests 3.1 through 3.3 prior to testing. Therefore, cylinders for each test were shaken vigorously just prior to testing. The entire test was recorded by time lapse video.

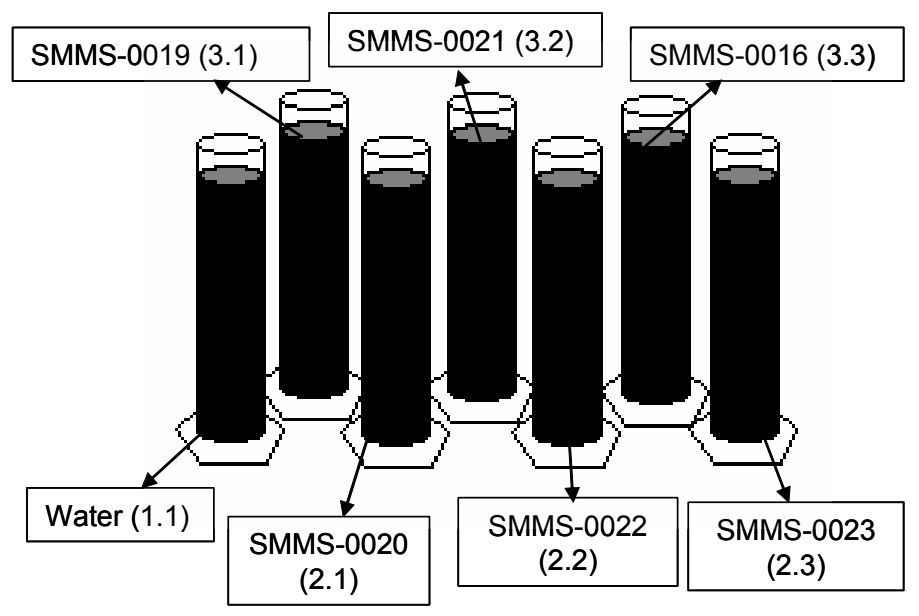

Figure 2-1. Experimental Setup 
The water test (Test 1.1) showed all the frit settling in less than 10 seconds. The $5 \mathrm{~Pa}$ Xanthan Gum 1\% Frit (Test 2.1) completely settled in approximately 43 hours. The 10 Pa Xanthan Gum 1\% Frit (Test 2.2) showed very little settling during the five day test. The $20 \mathrm{~Pa}$ Xanthan Gum 1\% Frit (Test 2.3) showed no settling during the five day test. The $20 \mathrm{~Pa}$ Xanthan Gum (Test 2.3) contained air bubbles that were entrained in the slurry during the addition of the Xanthan Gum slurry to the cylinder prior to testing. This entrained air remained stagnant in the cylinder throughout the testing. Test 1.1 through Test 2.3 cylinders, after testing was complete, are shown in Figure 2-2.

Table 2-1 Settling Test Simulant Makeup

\begin{tabular}{cccccc}
\hline Test \# & $\begin{array}{c}\text { Frit 418 } \\
(\mathbf{w t} \%)\end{array}$ & $\begin{array}{c}\text { Frit 418 } \\
(\mathbf{g})\end{array}$ & $\begin{array}{c}\text { Slurry Yield } \\
\text { Stress }\end{array}$ & $\begin{array}{c}\text { Slurry Mass } \\
(\mathbf{g})\end{array}$ & Sample \# \\
\hline 1.1 & 1.0 & 0.5 & $0 \mathrm{~Pa}$ & 50 & Water \\
2.1 & 1.0 & 0.5 & $5 \mathrm{~Pa}$ & 50 & SMMS-0020 \\
2.2 & 1.0 & 0.5 & $10 \mathrm{~Pa}$ & 50 & SMMS-0022 \\
2.3 & 1.0 & 0.5 & $20 \mathrm{~Pa}$ & 50 & SMMS-0023 \\
3.1 & 30 & $\mathrm{~N} / \mathrm{A}^{4}$ & $5 \mathrm{~Pa}$ & 50 & SMMS-0019 \\
3.2 & 30 & $\mathrm{~N} / \mathrm{A}^{4}$ & $10 \mathrm{~Pa}$ & 50 & SMMS-0021 \\
3.3 & 30 & $\mathrm{~N} / \mathrm{A}^{4}$ & $20 \mathrm{~Pa}$ & 50 & SMMS-0016 \\
\hline
\end{tabular}

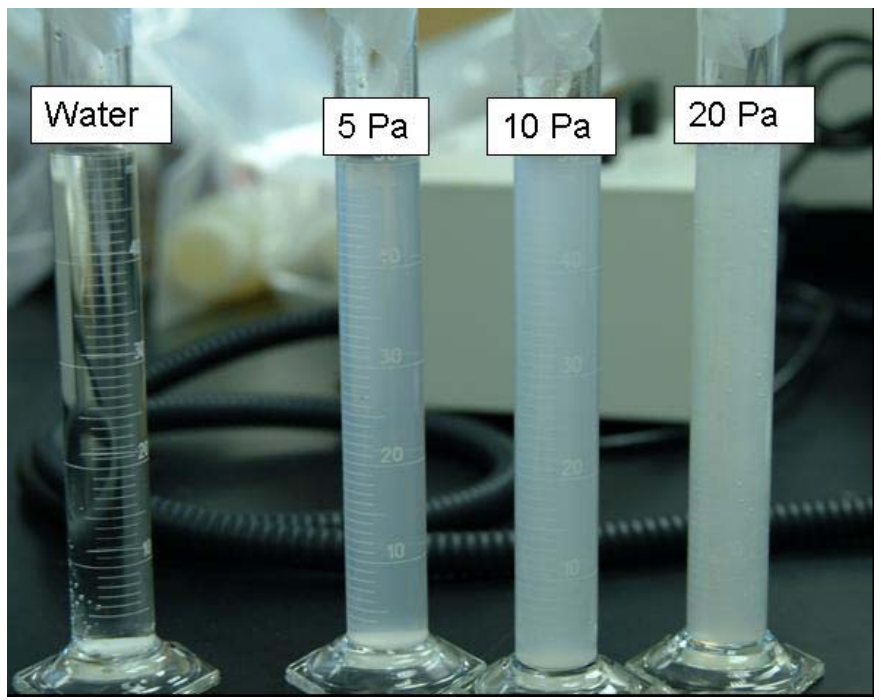

Figure 2-2. Settling of One Wt \% Frit After 5 Days of Settling

The $5 \mathrm{~Pa}$ Xanthan Gum 30\% Frit (Test 3.1) clearly showed settling within 43 hours and is shown in Figure 2-3. The $10 \mathrm{~Pa}$ Xanthan Gum 30\% Frit (Test 3.2) showed some settling of the larger frit particles, however, most of the frit remained suspended in the slurry.

\footnotetext{
${ }^{4}$ Frit was already added to these slurries.
} 
The 20 Pa Xanthan Gum 30\% Frit (Test 3.3) showed no settling during the entire five days of testing. Figure 2-3 shows the amount of settling for Test 3.1 through Test 3.3.

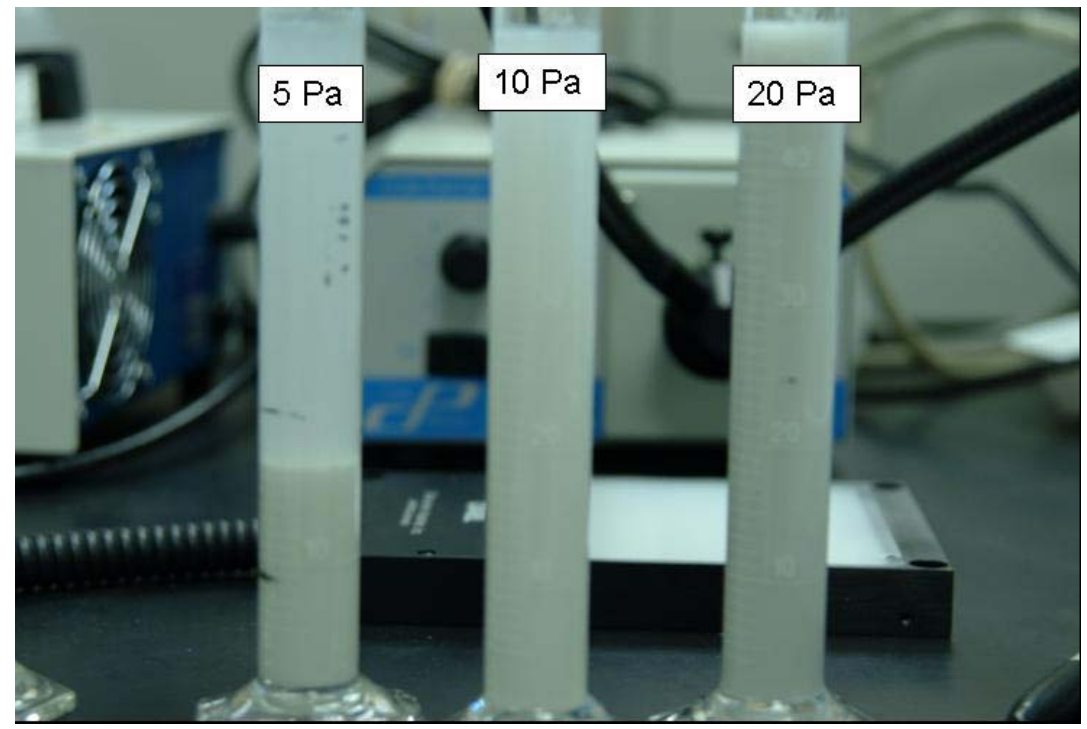

Figure 2-3. Settling of Thirty Wt \% Frit After 43 hrs

As a result of the very slow settling nature of the $10 \mathrm{~Pa}$ and $20 \mathrm{~Pa}$ fluids, it was unlikely that either would settle during the mixing tests. The decision of whether or not to perform solids sampling was made during the mixing portion of this testing.

\subsection{Simulant Target Rheology}

It was important during testing that the rheological properties of the simulants were representative of the rheology in the SME and MFT. Since the SME and MFT have an operating range of rheological properties, the targeted rheological property was that of the bounding conditions in the SME and MFT. ${ }^{3}$ Initial simulant preparation was based on previous mixing studies utilizing Xanthan Gum. ${ }^{5}$ Each simulant was prepared with Xanthan Gum, Frit 418, Kathon CG-ICP, and Deionized water. The Xanthan Gum concentration was varied to achieve the targeted yield stress.

Simulant development required determining the Xanthan Gum concentrations for simulants that have yield stresses of 5, 10, and 20 Pascals. Eighteen test solutions were prepared and analyzed rheologically using the Haake RS600 Rheometer. The Z38 bob/cup (concentric cylinder geometry) was used to produce the flow curves. After adjustments to the test solutions were finalized to determine the blending ratios of the additives required for the targeted yield stresses, the batching quantities for the mixing tests for the 5,10 and $20 \mathrm{~Pa}$ mixing simulants were determined and the results are shown in Table 2-2. The rheogram and the Bingham Plastic regression for each of the test simulants are in Appendix C.

\footnotetext{
${ }^{5}$ Stone, M.E., Marinik. A.R., Small Scale Mixing Tests for the DWPF Chemical Process Cell Vessels (U). March 2004. WSRC-TR-2004-00074.
} 
WSRC-TR-2004-00436

REVISION 0

Table 2-2 Batching Quantities of Xanthan Gum/Frit 418 for Mixing Tests

\begin{tabular}{||c|c|c|c|c|c|c||}
\hline \multirow{2}{*}{$\begin{array}{c}\text { Simulant } \\
\text { Yield } \\
\text { Stress } \\
\text { Target }\end{array}$} & $\begin{array}{c}\text { Xanthan } \\
\text { Gum }\end{array}$ & Frit 418 & $\begin{array}{c}\text { Kathon } \\
\text { CG- } \\
\text { ICP }\end{array}$ & Water & $\begin{array}{c}\text { Calculated } \\
\text { Solids } \\
\text { Content }\end{array}$ & Sample \# \\
\cline { 2 - 6 } & Grams & Kilograms & Grams & Kilograms & Wt\% & \\
\hline $5 \mathrm{~Pa}$ & 585.5 & 73.8 & 344.4 & 171.3 & 30.4 & SMMS-0024 \\
\hline $10 \mathrm{~Pa}$ & 947.2 & 73.8 & 344.4 & 170.9 & 30.5 & SMMS-0025 \\
\hline $20 \mathrm{~Pa}$ & 1550.0 & 73.8 & 344.4 & 170.3 & 30.8 & SMMS-0026 \\
\hline
\end{tabular}

\subsubsection{Rheological Model Fits}

Slow settling slurries can be modeled as a single phase fluid. This produces certain simplifications over dealing with a two-phase solid-liquid transport model in the analysis of pumps, pipeline flow, and tank mixing. Various empirical and semi-theoretical models have been proposed to relate the shear stress and the shear rate of non-Newtonian slow settling slurries. One of the simplest of these rheological models is the Bingham Plastic fluid, which is generally used when characterizing SRS waste slurries. This is a two parameter model that is used to relate shear stress and shear rate data and is shown below.

where: $\tau=$ shear stress $(\mathrm{Pa})$

$$
\tau=\tau_{B P}+\mu_{\infty} \cdot \dot{\gamma}
$$

$\tau_{B P}=$ Bingham Plastic yield stress $(\mathrm{Pa})$

$\mu_{\infty}=$ Bingham Plastic consistency or infinite viscosity $(\mathrm{Pa} \cdot \mathrm{sec})$

$\dot{\gamma}=$ shear rate $\left(\sec ^{-1}\right)$

The two fitted parameters are the yield stress and consistency and both are constants for a given sample that is time-independent. The Bingham Plastic model or any other rheological model must be fitted to only the laminar region of a flow curve. The Bingham Plastic model is a linear fit of the rheological data, where the intercept is the yield stress, and the slope is the consistency. If the yield stress is zero, then the fluid is a Newtonian fluid and the consistency is equivalent to the viscosity of a Newtonian fluid. When the yield stress is not zero, the consistency is no longer analogous to the viscosity of a Newtonian fluid. The difference between a Newtonian and non-Newtonian fluid is that the non-Newtonian fluid is shear rate dependent. This shear rate dependence can be expressed as the apparent viscosity of the non-Newtonian fluid and is calculated by taking the ratio of the shear stress to shear rate and is shown below for a Bingham Plastic fluid:

$$
\mu_{\text {apparent }}=\frac{\tau}{\dot{\gamma}}=\frac{\tau_{B P}+\mu_{\infty} \cdot \dot{\gamma}}{\dot{\gamma}}=\frac{\tau_{B P}}{\dot{\gamma}}+\mu_{\infty}
$$

where: $\mu_{\text {apparent }}=$ Apparent viscosity $(\mathrm{Pa} \cdot \mathrm{sec})$ 
The apparent viscosity of a Bingham Plastic fluid decreases with increasing shear rate and approaches that of the infinite viscosity as shown above. This type of rheological behavior is called shear thinning. The apparent viscosity goes to infinity as the shear rate goes to zero. The apparent viscosity of other non-Newtonian models can also be calculated in this fashion.

The Bingham Plastic properties are presumed to be time independent. Not all slurries are time independent. Time-dependence is a potential issue when dealing with slurries containing colloidal solid particles. Colloidal solids are in the range of 1 micron in diameter. ${ }^{8}$ Colloidal solids can exhibit unusual behavior because the size of the particles is small enough that the inter-particle surface forces can become an appreciable fraction of the total force acting on a given particle. SRS waste slurries and corresponding simulants contain particles in this size range. The Bingham Plastic model is not appropriate for fluids that are highly time-dependent. DWPF frit particles are larger than a majority of the sludge particles. An issue with SME product frit slurries is keeping the frit uniformly suspended, so that the slurry can be classified as slow settling ${ }^{6}$ at the point of rheological measurement.

\footnotetext{
${ }^{6}$ Koopman, D.C., A Comparison of Rheology Data for Radioactive and Simulant Savannah River Site Waste (U). March 2004. WSRC-TR-2004-00044.
} 
WSRC-TR-2004-00436

REVISION 0

\subsection{Mixing Tests}

\subsubsection{Instrumentation and Equipment Setup}

The $1 / 6^{\text {th }}$ scale SRAT/SME/MFT vessel has an internal diameter of 23.19 inches and has coils, impellers, pump dip legs, and a bubbler geometrically scaled from the full scale vessel. The agitator motor and other equipment installed during the mixing tests are listed in Appendix D. A diagram of the tank and installed equipment is shown in Figure $2-4$.

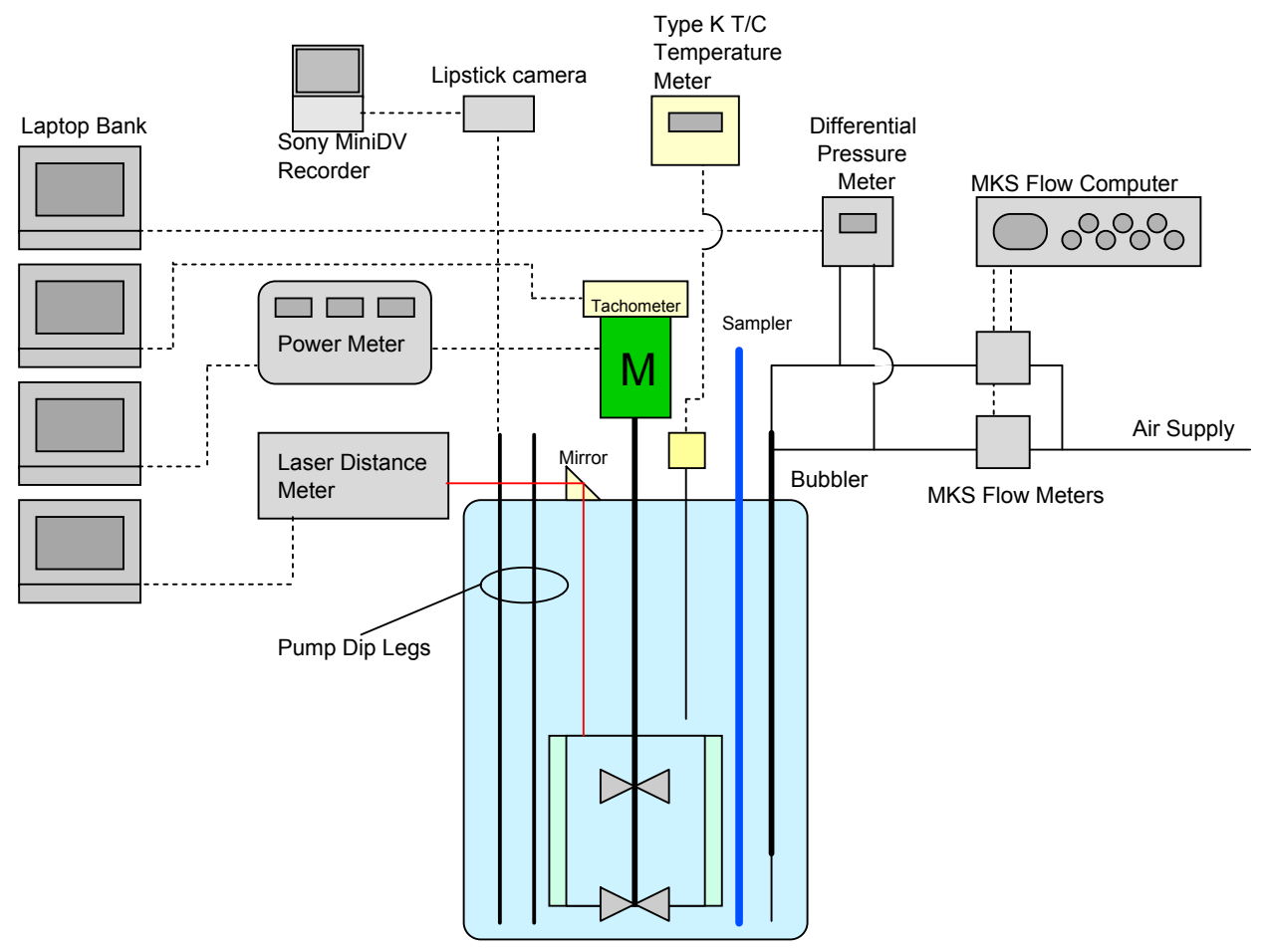

Figure 2-4. $1 / 6^{\text {th }}$ Scale SRAT/SME/MFT Diagram

The $1 / 6^{\text {th }}$ scale SRAT/SME/MFT vessel was fitted with a variety of instruments to monitor each test. These instruments measured agitator speed, vessel temperature, slurry density, agitator power, and vortex depth. In addition, video cameras recorded surface phenomena (e.g. motion) during the test and were used to monitor the tank bottom for settled solids. Details of the instruments used during the testing are provided in Appendix D. Three different motors were used for agitation during this testing. Originally a direct drive motor was used (Lightnin EV1P50M), however, it failed during the Five Pascal fluid testing. Secondly, a motor using a gear reducer was used (Lightnin EV5P50M), which limited the rotational speed. Therefore, a third motor was used (Caframo BDC3030), however , it was only capable of limited duration tests, and thus was only used to agitate at high speeds (i.e. 360 RPM - 450 RPM). Figure 2-5 shows the $1 / 6^{\text {th }}$ Scale Vessel, Coils, and Agitator Blades. Agitator speeds tested and the subsequent data collected are located in Appendix A. 


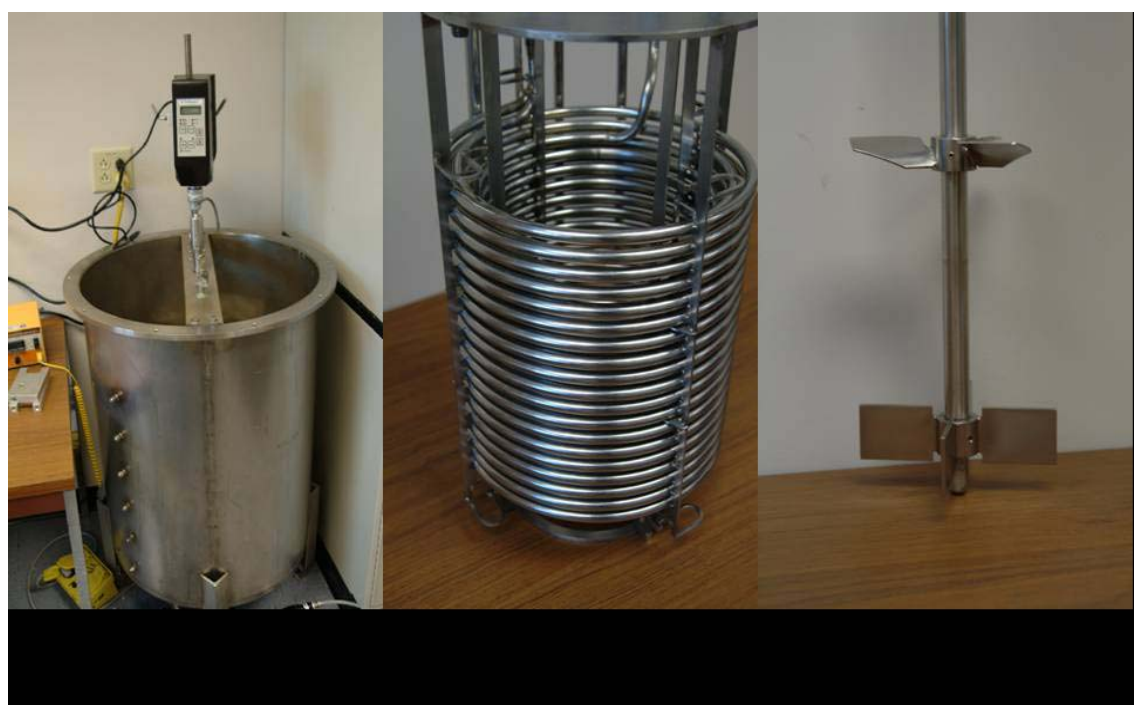

Figure 2-5. 1/6 ${ }^{\text {th }}$ Scale Mixing Tank, Coil and Agitator

\subsection{RESULTS}

\subsection{Five Pascal Tests}

\section{Gallon Test Coils In}

The minimum agitator speed required to suspend solids was 76 RPM as evident through the Lipstick Camera, which is located $1 / 4$ " off the bottom of the tank. Surface motion was not evident at 220 RPM, however, slight motion was observed at 300RPM. Full surface motion without vortexing occurred at 378 RPM. Full motion and vortexing occurred at 420 RPM.

\section{Gallon Test Coils Out}

Mixing at 200 RPM showed no surface motion, however, mixing at 330 RPM produced surface movement nearly to the tank wall. Complete surface motion occured at 360 RPM and a vortex existed, but did not reach the bottom impeller. At 420 RPM full surface motion and vortexing was observed, as well as, a constant gurgling noise from the vortex, indicating that the vortex had reached the lower impeller.

\section{Gallon Test Coils In}

Slight surface movement occurred at 60 RPM with areas along the wall being stagnant. The surface movement was more pronounced at 150 RPM. At 220 RPM a slight vortex occurred, and surface movement is nearly to the wall. There is full surface motion and a pronounced vortex above the upper impeller hub when mixing at 330 RPM. Mixing at 390 RPM, the surface motion was completely to the tank wall moving towards the center in a swirling fashion. The vortex at 390 RPM was slightly deeper than that of 330 RPM, and oscillated around the agitator shaft rather than centrally located about the shaft. 


\section{Gallon Test Coils Out}

Minimum agitator speed required for movement at a distance of $1 / 4$ " from the bottom (as seen through the Lipstick Camera) was 98.2 RPM, however, there was no visible surface motion at this speed. Relatively no surface motion and no vortex were observed while mixing at 150 RPM. Full surface motion was evident, with the vortex reaching and air entrainment occurring at the upper impeller blade at 220 RPM. At 330 RPM an extreme vortex impacting the upper impeller and significant surface motion occurred. The vortex exposed the upper impeller hub, and periodically the upper impeller itself as shown in Figure 3-1. Significant amounts of air were entrained at this agitator speed and the surface was in a swirling motion. Visually there was little change at $360 \mathrm{RPM}$, an extreme vortex entrained air and full surface movement continued in a swirling motion with no stagnant areas. At 420 RPM, there was a large vortex with rapid fluid motion throughout the tank.

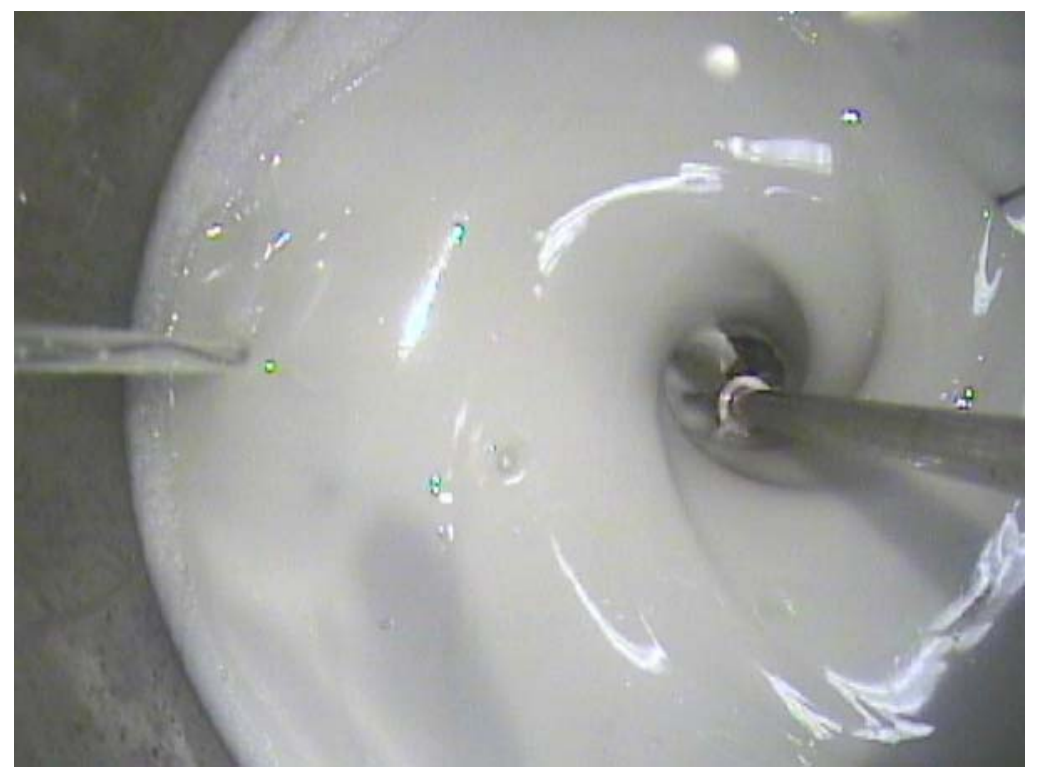

Figure 3-1. 25 Gallon, 5 Pa, Visible Upper Impeller Hub at 330 RPM with Coils Out

\section{Gallon Test Coils In}

Incomplete surface movement was observed at 150 RPM with stagnant areas near the tank walls. Full surface movement and significant air entrainment occurred at 220 RPM. At 330 RPM the surface was obscured by bubbles as the agitator entrained air at an extremely high rate. There was very little change at 420 RPM, due to the high volume of air being entrained and the surface continued to be obscured by bubbles. The vigor at which the slurry was thrown from the impellers increased significantly.

\section{Gallon Test Coils Out}

Minimum agitator speed required for movement at a distance of $1 / 4$ " from the bottom (as seen through the Lipstick Camera) was 154 RPM. At 220 RPM, surface motion is 
complete with a vortex revealing the lower impeller. Surface motion increases at 330 RPM violently throwing the slurry onto the tank walls.

\subsection{Ten Pascal Tests}

40 Gallon Test Coils In

With agitator speeds of 75 RPM, 100 RPM, 150 RPM, 200 RPM, and 250 RPM, no surface motion occurred. At speeds of 275 RPM, 300 RPM, 330 RPM, and 350 RPM, surface motion was limited to that with immediate contact to the agitator shaft. No surface motion was observed at 420 RPM with the exception of slight oscillations around the agitator shaft.

\section{Gallon Test Coils Out}

Surface motion was again limited in this test for 220 RPM, 330 RPM, and 348 RPM to the area immediately contacting the agitator shaft. At 420 RPM, significant surface motion was observed, however, no vortexing occurred.

\section{Gallon Test Coils In}

Surface motion was limited to the interior of the coils at speeds of 75 and 150 RPM. However, at 200 RPM the surface motion was observed outside of the coils as well as inside, but not extending to the tank walls. Surface motion outside the coils was more pronounced at 220 RPM, again with stagnant areas at the tank walls. Surface motion was nearly to the walls at 300 RPM, and completely to the walls at both 330 (Figure 3-2) and 352 RPM. A slight vortex was observed at both 330 RPM and 352RPM. At 420 RPM, the vortex increased and surface motion continued throughout the tank.

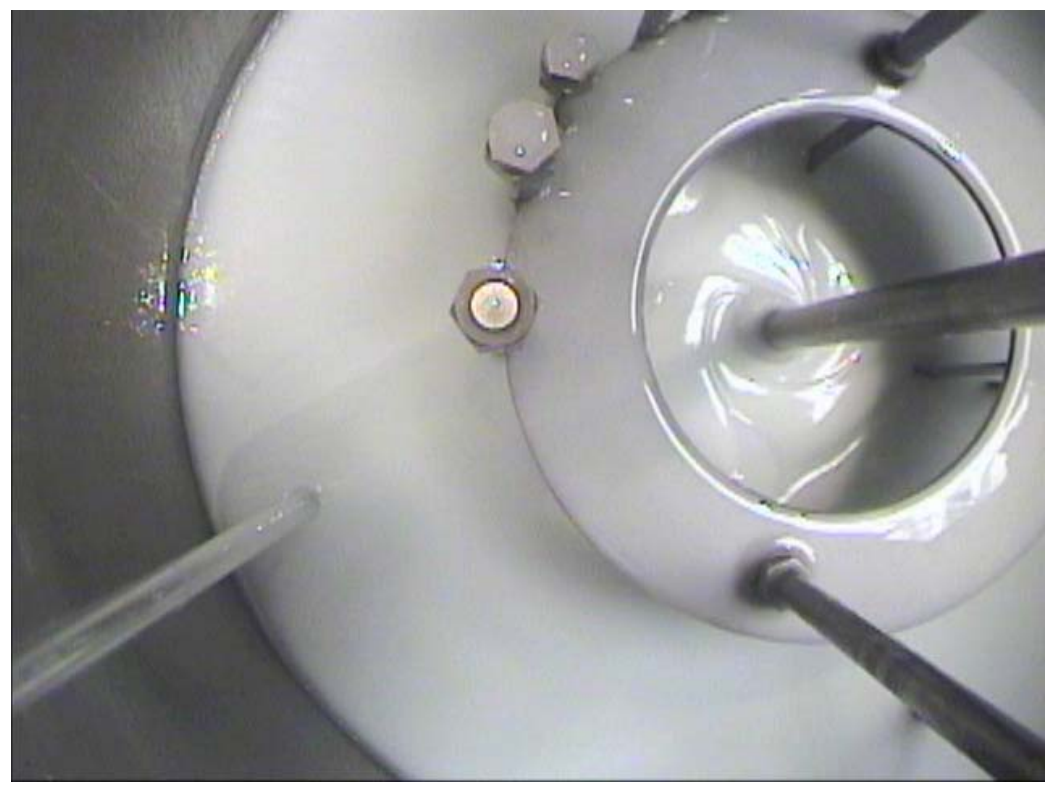

Figure 3-2. 25 Gallon, 10 Pascal Fluid Mixing at 330 RPM with Coils In 


\section{Gallon Test Coils Out}

Surface motion, at 150 RPM, was observed extending to approximately three inches from the tank wall. Some surface motion was noted at 220 RPM, however, the surface areas near the wall remained stagnant, and there was no vortex. Full surface motion with the exception of some small stagnant areas at the tank wall occurred at 330 RPM with a vortex slightly off-centered. At 360 RPM, the off-centered vortex remained, and full surface motion was observed. Both surface motion and the vortex increased at 420 RPM with the vortex revealing the upper impeller.

\section{Gallon Test Coils In}

Slight surface motion was observed outside the coils at 220 RPM with only a slight increase in motion near the tank wall. Mixing at 275 RPM produced a large amount of bubbles pushing toward the tank wall with greater vigor than previously seen. Both 300 RPM, and 330 RPM showed increase bubble production outside the coils, and surface motion increased slightly towards the tank wall as speed increased. There was little difference between 330 RPM and 354 RPM with respect to visual appearance of bubbles and surface motion. Mixing at speeds of 275 RPM and greater produced obvious air entrainment, however, coils and agitator blades obscured view of actual vortex depth.

\section{Gallon Test Coils Out}

Agitation at 75 RPM produced surface movement approximately five inches in diameter centered around the agitator shaft. A slight depression around the shaft formed at 75 RPM. Some surface motion was noted at 150 RPM, however, no motion occurred within two inches of the tank wall. Full mixing occurred at 220 RPM with complete surface motion throughout the tank. Rapid and irregular surface motion occurred at 330 RPM, the slurry was thrown to the tank wall as evident in Figure 3-3.

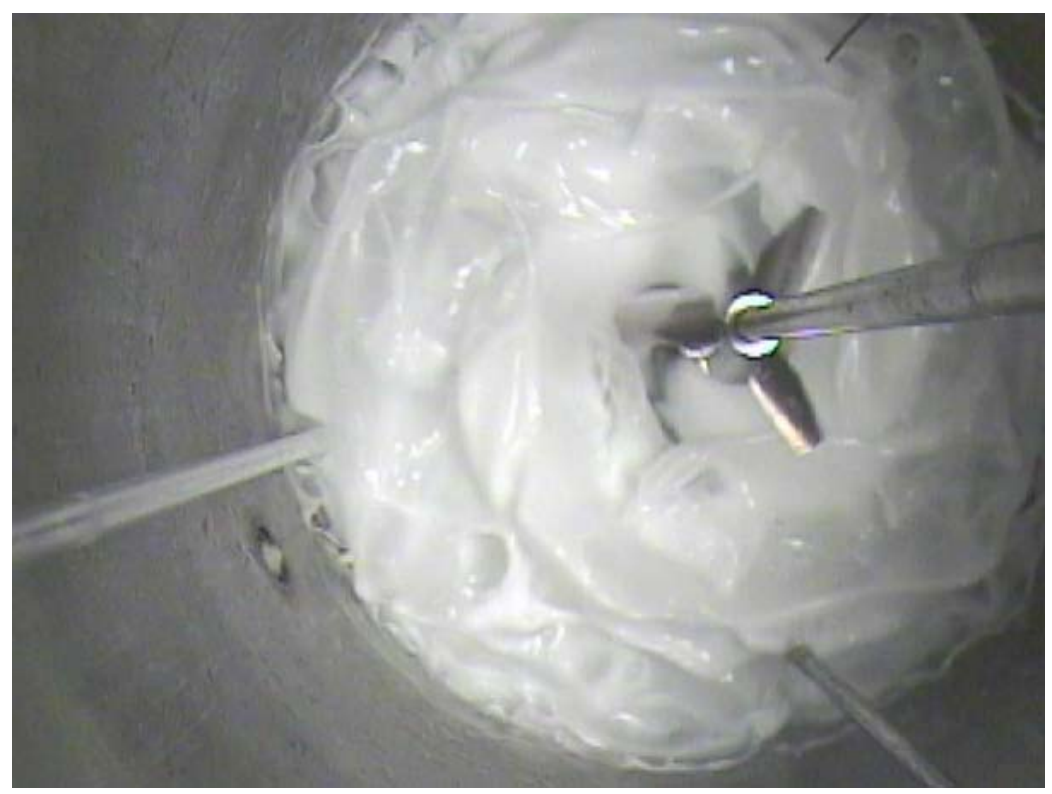

Figure 3-3. 6 Gallons, 10 Pa, Extreme Surface Motion At 330 RPM with Coils Out 


\subsection{Twenty Pascal Tests}

\section{Gallon Test Coils In}

No surface motion was visible with the exception of the area directly contacting the agitator shaft through out this entire test. Tests were conducted at 75 RPM, 100 RPM, 150 RPM, 200 RPM, 220 RPM, 250 RPM, 275 RPM, 300 RPM, 330 RPM, 420 RPM, and 450 RPM.

\section{Gallon Test Coils Out}

Testing was conducted at 75 RPM, 100 RPM, 150 RPM, 200 RPM, 220 RPM, 250 RPM, 300 RPM, 330 RPM, 350 RPM, 420 RPM, and 450 RPM. No surface motion was observed at any speed other than a slight oscillatory motion and no vortexing at 450 RPM.

\section{Gallon Test Coils In}

There was no surface movement outside the coils at both 75 RPM and 100 RPM. Significant motion occurred inside the coils at 150 RPM, with slight motion on the outside of the coils moving towards the tank center. Significant surface motion extended beyond the coils at 220 RPM, however, the wall areas remained stagnant. Also, no vortex was observed at 220 RPM. A slight vortex did appear around 275 RPM, although surface motion did not change significantly from that of 220 RPM. At approximately 288 RPM the vortex reversed from a depression in the slurry surface to an elevation. The flow around the agitator reversed and began pumping up and away from the agitator shaft rather than towards the shaft and down, see Figure 3-4. Significant motion occurred inside the coils at 330 RPM with some surface motion outside the coils, however, the wall areas remained stagnant. Again, at 330 RPM, a reverse vortex was pumping slurry up the center and away from the agitator shaft.

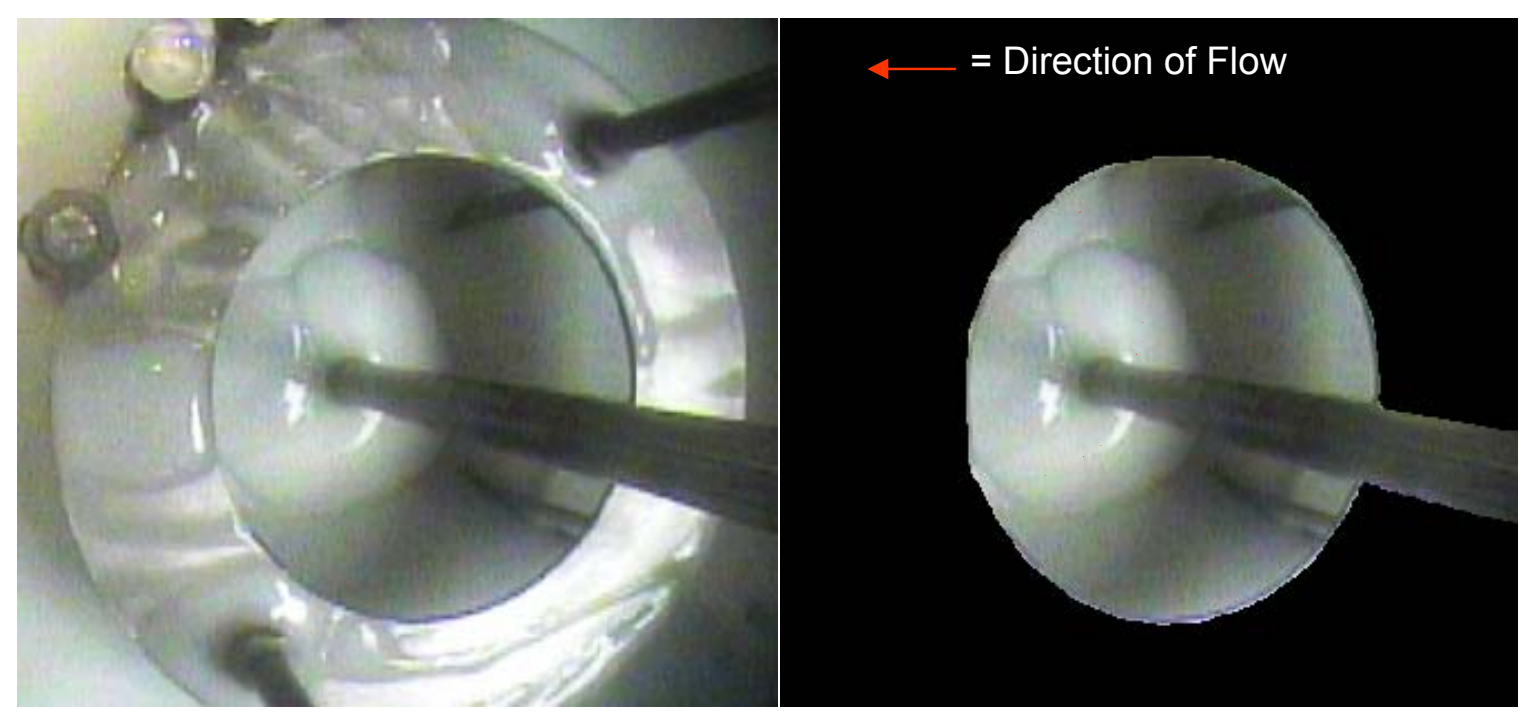

Figure 3-4. 25 Gallons, 20 Pa Reverse Vortex With Coils 


\section{Gallon Test Coils Out}

Surface motion is evident at 200 RPM, however, the outer perimeter of the tank remained stagnant. Motion increased slightly at 220 RPM, but motion ceased approximately four inches from the tank wall. At 330 RPM surface motion increased in both area and velocity. A small depression existed at 330 RPM, but the tank wall areas were still stagnant. There was very little change in surface motion characteristics when speed was increased to 345 RPM. There was very good motion over the whole surface at 420 RPM, and a very deep vortex.

\section{Gallon Test Coils In}

There was significant surface motion inside the coils at 75 RPM, 100 RPM, 150 RPM, and 200 RPM, but there was no notable movement outside the coils at these speeds. At 220 RPM, surface motion remained significant inside coils, and began oscillating outside the coils. At 300 RPM and 330 RPM the oscillatory motion outside the coils increased, but neither speed showed any swirling motion or lateral movement on the surface.

\section{Gallon Test Coils Out}

Cavern mixing occurred at 75 RPM, 100 RPM, 150 RPM, and 200 RPM with surface motion centered about the agitator, and no motion within six inches of the tank wall. Surface motion became more pronounced at 220 RPM with no vortex and nearly four inches from the tank wall was stagnant. At 275 RPM there was complete surface motion. Surface motion was more violent at 330 RPM with a deep vortex exposing the lower impeller hub and slurry slung to the tank wall. 
WSRC-TR-2004-00436

REVISION 0

\subsection{Discussion}

\subsubsection{Impact of Coils on Solids Suspension}

While mixing at specific agitator speeds during the Five Pascal Tests samples were taken with a Coliwasa (Composite Liquid Waste Sampler) at three different locations within the mixing vessel. All three locations were sampled in quadruplicate as designated in the technical task plan governing this study. ${ }^{4}$ The three sampling locations in the tank are; just below the surface of the slurry (Surface Level), at the measured depth equivalent to that of the surface level when mixing at 25 Gallons (25 Gallon Level), and at approximately three inches off the tank bottom (Tank Bottom). During the Five Pascal Testing, sampling was done after mixing for two hours at 220 RPM, and again after mixing at 330 RPM for two hours both with the coils in and with the coils removed. Sampling locations were maintained by a shaft guide fixed to the lid of the tank allowing very little room for movement, and only movement in a vertical direction. Markers on the side of the Coliwasa were used to designate the point at which sampling was to be done.

After sampling was completed, the individual samples were analyzed for weight percent total solids and density. The mixing vessel was considered homogeneous if each set of samples (surface level, 25 gallon level and tank bottom) were within 5\% of the average value $^{3}$ of all samples extracted at a specific agitation speed. Table 3-1 contains the density, the weight percent total solids, and sample information for the samples taken prior to mixing with the Five Pascal fluid.

Table 3-1 Results for Initial Five Pascal Fluid Samples

\begin{tabular}{ccccccc}
\hline Sample & Location & $\begin{array}{c}\text { Wt.\% } \\
\text { Total } \\
\text { Solids }\end{array}$ & $\begin{array}{c}\text { Agitator } \\
\text { Speed } \\
\text { (RPM) }\end{array}$ & Coils & $\begin{array}{c}\text { Density } \\
\text { (g/mL) }\end{array}$ & $\begin{array}{c}\text { \% Deviation } \\
\text { Total Solids }\end{array}$ \\
\hline SMMS-0027-A & Tank Bottom & 53.07 & 0 & In & 1.44 & 95.90 \\
SMMS-0027-B & Tank Bottom & 54.66 & 0 & In & 1.44 & 101.77 \\
SMMS-0028-A & 25 Gallon Level & 20.74 & 0 & In & 1.12 & -23.44 \\
SMMS-0028-B & 25 Gallon Level & 23.24 & 0 & In & 1.14 & -14.21 \\
SMMS-0029-A & Surface Level & 4.22 & 0 & In & 1.00 & -84.42 \\
SMMS-0029-B & Surface Level & 6.61 & 0 & In & 1.03 & -75.60 \\
\hline
\end{tabular}

Figure 3-5 is a graphical representation of the results for sampling at $220 \mathrm{RPM}$ and at 330 RPM during the $5 \mathrm{~Pa}$ tests. The solids distribution was unevenly distributed at both 220 RPM with coils in and coils out and 330 RPM with coils in the mixing vessel, indicating that the vessel was not homogenous. However, with the coils removed and mixing at 330 RPM, the solids distribution was within the $\pm 5 \%$ uniformity requirement. As stated previously, during the Five Pascal Test, complete surface motion was not observed at 220 RPM with the coils in or out of the vessel. 

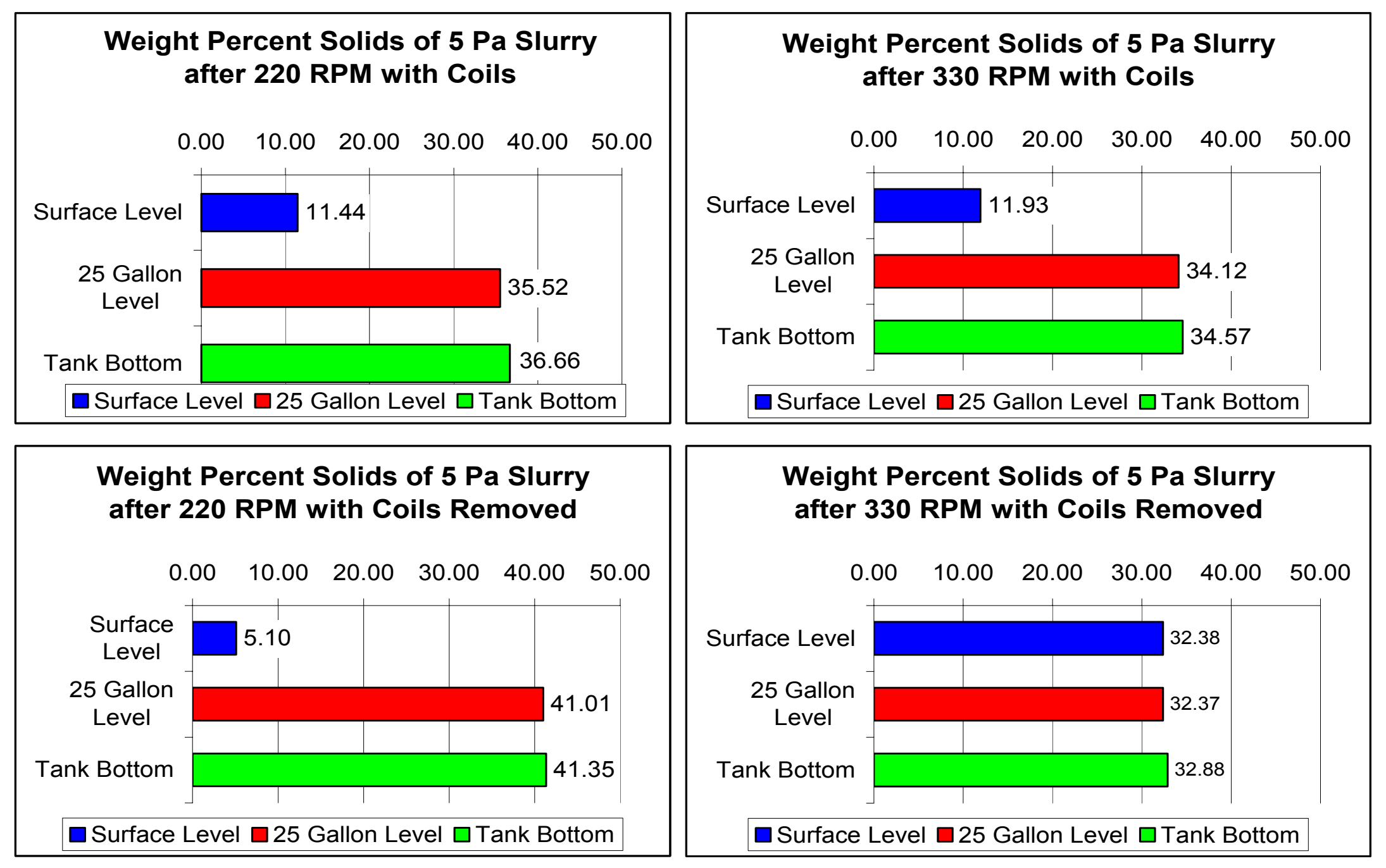

Figure 3-5. Histogram of Wt\% TS Distribution for Five Pascal Mixing Tests at 40 Gallons 
Table 3-2 contains all sample information and results of density and weight percent solids analysis for samples extracted after mixing at both 220 revolutions per minute and 330 revolutions per minute.

Table 3-2 Physical Properties from the 40 Gallon Five Pascal Fluid Mixing Tests

\begin{tabular}{|c|c|c|c|c|c|c|}
\hline Sample & Location & $\begin{array}{l}\text { Wt.\% } \\
\text { Total } \\
\text { Solids }\end{array}$ & $\begin{array}{l}\text { Agitator } \\
\text { Speed } \\
\text { (RPM) }\end{array}$ & Coils & $\begin{array}{l}\text { Density } \\
(\mathrm{g} / \mathrm{mL})\end{array}$ & $\begin{array}{l}\text { \% Deviation } \\
\text { Total Solids }\end{array}$ \\
\hline SMMS-0030-A & Surface Level & 7.63 & 220 & In & 1.04 & 72.63 \\
\hline SMMS-0030-B & Surface Level & 6.98 & 220 & In & 1.03 & 74.96 \\
\hline SMMS-0030-C & Surface Level & 18.00 & 220 & In & 1.08 & 35.42 \\
\hline SMMS-0030-D & Surface Level & 13.16 & 220 & In & 1.07 & 52.79 \\
\hline SMMS-0031-A & 25 Gallon Level & 35.25 & 220 & In & 1.27 & -26.46 \\
\hline SMMS-0031-B & 25 Gallon Level & 35.63 & 220 & In & 1.23 & -27.83 \\
\hline SMMS-0031-C & 25 Gallon Level & 35.42 & 220 & In & 1.24 & -27.07 \\
\hline SMMS-0031-D & 25 Gallon Level & 35.77 & 220 & In & 1.24 & -28.33 \\
\hline SMMS-0032-A & Tank Bottom & 37.31 & 220 & In & 1.25 & -33.86 \\
\hline SMMS-0032-B & Tank Bottom & 35.97 & 220 & In & 1.24 & -29.05 \\
\hline SMMS-0032-C & Tank Bottom & 36.82 & 220 & In & 1.25 & -32.10 \\
\hline SMMS-0032-D & Tank Bottom & 36.54 & 220 & In & 1.26 & -31.09 \\
\hline SMMS-0033-A & Surface Level & 11.34 & 330 & In & 1.08 & 57.80 \\
\hline SMMS-0033-B & Surface Level & 11.90 & 330 & In & 1.06 & 55.72 \\
\hline SMMS-0033-C & Surface Level & 12.56 & 330 & In & 1.05 & 53.26 \\
\hline SMMS-0033-D & Surface Level & 11.92 & 330 & In & 1.06 & 55.64 \\
\hline SMMS-0034-A & 25 Gallon Level & 33.83 & 330 & In & 1.25 & -25.89 \\
\hline SMMS-0034-B & 25 Gallon Level & 34.21 & 330 & In & 1.23 & -27.30 \\
\hline SMMS-0034-C & 25 Gallon Level & 34.22 & 330 & In & 1.22 & -27.34 \\
\hline SMMS-0034-D & 25 Gallon Level & 34.21 & 330 & In & 1.24 & -27.30 \\
\hline SMMS-0035-A & Tank Bottom & 34.75 & 330 & In & 1.24 & -29.31 \\
\hline SMMS-0035-B & Tank Bottom & 34.58 & 330 & In & 1.22 & -28.68 \\
\hline SMMS-0035-C & Tank Bottom & 34.35 & 330 & In & 1.19 & -27.83 \\
\hline SMMS-0035-D & Tank Bottom & 34.60 & 330 & In & 1.24 & -28.76 \\
\hline SMMS-0036-A & Surface Level & 6.94 & 220 & Out & 1.02 & 76.19 \\
\hline SMMS-0036-B & Surface Level & 6.94 & 220 & Out & 1.03 & 76.19 \\
\hline SMMS-0036-C & Surface Level & 3.32 & 220 & Out & 1.01 & 88.61 \\
\hline SMMS-0036-D & Surface Level & 3.18 & 220 & Out & 1.01 & 89.09 \\
\hline SMMS-0037-A & 25 Gallon Level & 40.77 & 220 & Out & 1.31 & -39.86 \\
\hline SMMS-0037-B & 25 Gallon Level & 41.35 & 220 & Out & 1.30 & -41.85 \\
\hline SMMS-0037-C & 25 Gallon Level & 40.92 & 220 & Out & 1.29 & -40.38 \\
\hline SMMS-0037-D & 25 Gallon Level & 40.98 & 220 & Out & 1.32 & -40.58 \\
\hline SMMS-0038-A & Tank Bottom & 41.08 & 220 & Out & 1.30 & -40.93 \\
\hline SMMS-0038-B & Tank Bottom & 41.02 & 220 & Out & 1.32 & -40.72 \\
\hline SMMS-0038-C & Tank Bottom & 41.97 & 220 & Out & 1.31 & -43.98 \\
\hline SMMS-0038-D & Tank Bottom & 41.33 & 220 & Out & 1.32 & -41.78 \\
\hline SMMS-0039-A & Surface Level & 32.62 & 330 & Out & 1.26 & -0.23 \\
\hline SMMS-0039-B & Surface Level & 32.20 & 330 & Out & 1.24 & 1.06 \\
\hline SMMS-0039-C & Surface Level & 32.97 & 330 & Out & 1.24 & -1.31 \\
\hline SMMS-0039-D & Surface Level & 31.73 & 330 & Out & 1.23 & 2.50 \\
\hline
\end{tabular}


WSRC-TR-2004-00436

REVISION 0

Table 3-2 Physical Properties from the 40 Gallon Five Pascal Fluid Mixing Tests

\begin{tabular}{ccccccc}
\hline Sample & Location & $\begin{array}{c}\text { Wt.\% } \\
\text { Total } \\
\text { Solids }\end{array}$ & $\begin{array}{c}\text { Agitator } \\
\text { Speed } \\
\text { (RPM) }\end{array}$ & Coils & $\begin{array}{c}\text { Density } \\
\text { (g/mL) }\end{array}$ & $\begin{array}{c}\text { \% Deviation } \\
\text { Total Solids }\end{array}$ \\
\hline SMMS-0040-A & 25 Gallon Level & 32.48 & 330 & Out & 1.23 & 0.20 \\
SMMS-0040-B & 25 Gallon Level & 32.18 & 330 & Out & 1.23 & 1.12 \\
SMMS-0040-C & 25 Gallon Level & 32.27 & 330 & Out & 1.22 & 0.84 \\
SMMS-0040-D & 25 Gallon Level & 32.56 & 330 & Out & 1.23 & -0.05 \\
SMMS-0041-A & Tank Bottom & 33.80 & 330 & Out & 1.23 & -3.86 \\
SMMS-0041-B & Tank Bottom & 32.88 & 330 & Out & 1.23 & -1.03 \\
SMMS-0041-C & Tank Bottom & 32.66 & 330 & Out & 1.24 & -0.35 \\
SMMS-0041-D & Tank Bottom & 32.19 & 330 & Out & 1.22 & 1.09 \\
\hline
\end{tabular}

It was expected that the Ten Pascal fluid would not settle throughout the duration of the agitator test, based on the settling tests performed in section 2.2. However, samples were taken during the 40 gallon, Ten Pascal Test. Each sample was analyzed for weight percent total solids and density. Solids sampling was not done, with the coils in or with the coils out, until the following day. Table 3-3 summarizes the physical properties of the Ten Pascal Test samples.

Table 3-3 Physical Properties from the 40 Gallon Ten Pascal Fluid Mixing Tests

\begin{tabular}{ccccccc}
\hline Sample & Location & $\begin{array}{c}\text { Wt.\% } \\
\text { Total } \\
\text { Solids }\end{array}$ & $\begin{array}{c}\text { Agitator } \\
\text { Speed } \\
\text { (RPM) }\end{array}$ & Coils & $\begin{array}{c}\text { Density } \\
\text { (g/mL) }\end{array}$ & $\begin{array}{c}\text { \% Deviation } \\
\text { Total Solids }\end{array}$ \\
\hline SMMS-0042-A & Surface Level & 31.35 & 330 & Out & 1.18 & 1.12 \\
SMMS-0042-B & Surface Level & 29.57 & 330 & Out & 1.19 & 6.73 \\
SMMS-0042-C & Surface Level & 30.75 & 330 & Out & 1.20 & 3.01 \\
SMMS-0042-D & Surface Level & 30.04 & 330 & Out & 1.19 & 5.25 \\
SMMS-0043-A & 25 Gallon Level & 32.05 & 330 & Out & 1.22 & -1.09 \\
SMMS-0043-B & 25 Gallon Level & 32.28 & 330 & Out & 1.22 & -1.82 \\
SMMS-0043-C & 25 Gallon Level & 32.1 & 330 & Out & 1.22 & -1.25 \\
SMMS-0043-D & 25 Gallon Level & 31.71 & 330 & Out & 1.22 & -0.02 \\
SMMS-0044-A & Tank Bottom & 32.54 & 330 & Out & 1.22 & -2.64 \\
SMMS-0044-B & Tank Bottom & 33.4 & 330 & Out & 1.22 & -5.35 \\
SMMS-0044-C & Tank Bottom & 32.73 & 330 & Out & 1.22 & -3.24 \\
SMMS-0044-D & Tank Bottom & 31.93 & 330 & Out & 1.22 & -0.71 \\
\hline SMMS-0045-A & Surface Level & 31.04 & 330 & In & 1.20 & 1.20 \\
SMMS-0045-B & Surface Level & 30.81 & 330 & In & 1.21 & 1.92 \\
SMMS-0045-C & Surface Level & 30.58 & 330 & In & 1.20 & 2.65 \\
SMMS-0045-D & Surface Level & 30.89 & 330 & In & 1.20 & 1.67 \\
SMMS-0046-A & 25 Gallon Level & 31.78 & 330 & In & 1.23 & -1.14 \\
SMMS-0046-B & 25 Gallon Level & 31.58 & 330 & In & 1.21 & -0.51 \\
SMMS-0046-C & 25 Gallon Level & 31.63 & 330 & In & 1.21 & -0.67 \\
SMMS-0046-D & 25 Gallon Level & 31.49 & 330 & In & 1.20 & -0.22 \\
SMMS-0047-A & Tank Bottom & 31.85 & 330 & In & 1.22 & -1.36
\end{tabular}


Table 3-3 Physical Properties from the 40 Gallon Ten Pascal Fluid Mixing Tests

\begin{tabular}{ccccccc}
\hline Sample & Location & $\begin{array}{c}\text { Wt.\% } \\
\text { Total } \\
\text { Solids }\end{array}$ & $\begin{array}{c}\text { Agitator } \\
\text { Speed } \\
\text { (RPM) }\end{array}$ & Coils & $\begin{array}{c}\text { Density } \\
\text { (g/mL) }\end{array}$ & $\begin{array}{c}\text { \% Deviation } \\
\text { Total Solids }\end{array}$ \\
\hline SMMS-0047-B & Tank Bottom & 31.61 & 330 & In & 1.21 & -0.60 \\
SMMS-0047-C & Tank Bottom & 31.88 & 330 & In & 1.21 & -1.45 \\
SMMS-0047-D & Tank Bottom & 31.89 & 330 & In & 1.21 & -1.49 \\
\hline
\end{tabular}

Three samples taken from the Ten Pascal slurry with coils-removed fell outside of the 5\% uniformity requirement. Sampling did not occur until 12 hours after the Ten Pascal Test was completed, which is a time lapse of greater than what is expected of normal DWPF operations. All sampling locations were identical to those of the Five Pascal Test samples. Samples were taken in quadruplicate for the Ten Pascal Test as well, and showed, as expected, very little variation in distribution. Figure 3-6 and Figure 3-7 is a graphical representation of solids distribution during the Ten Pascal Tests. Additionally, based on these results, mixing with the coils in seemed to provide a more homogenous distribution than that with the coils out. This could be due to the higher shear rates (bulk) which could have reduced the apparent viscosity to a point were the larger frit particles have settled and are not easily re-suspended through the mixing tank.

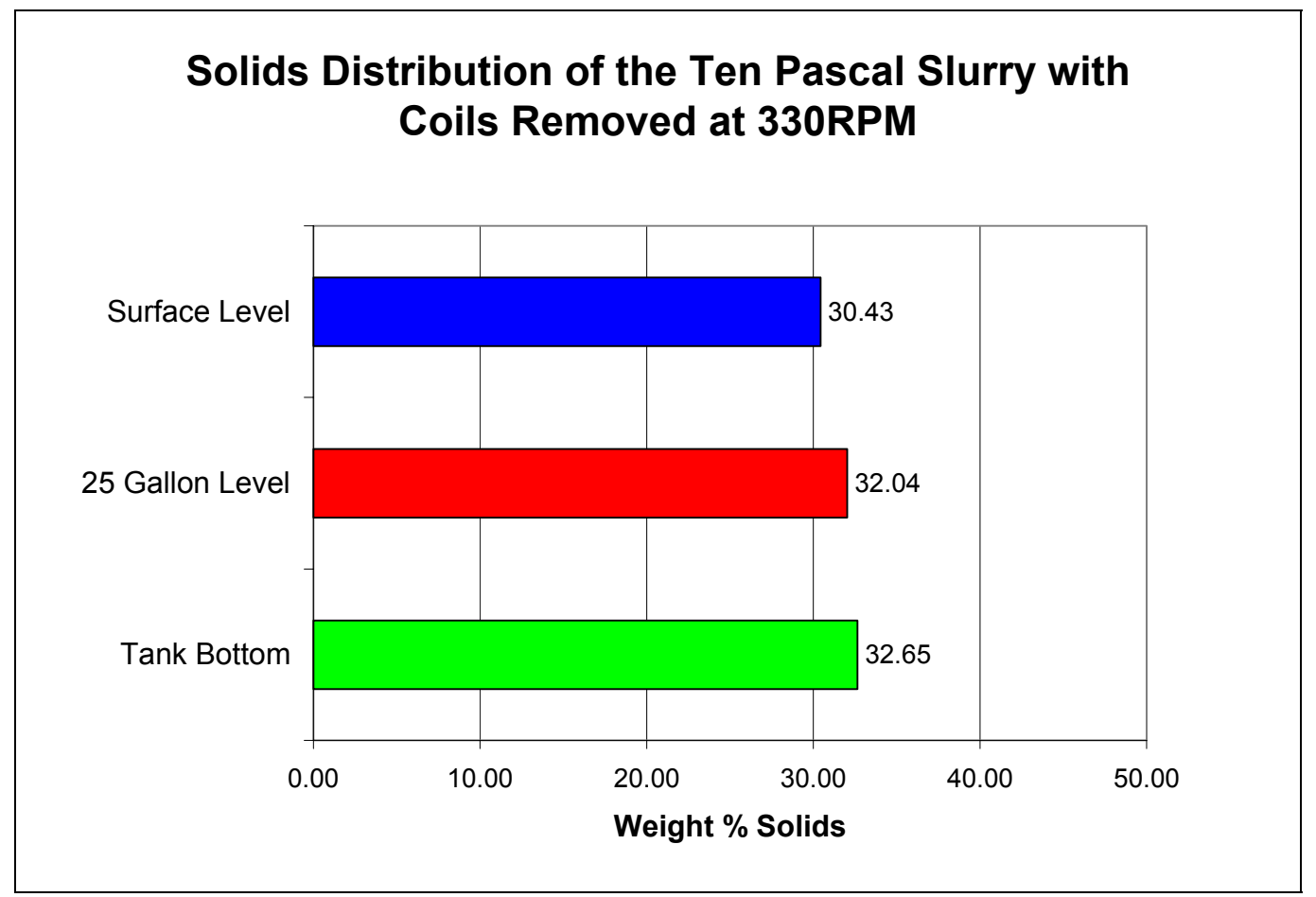

Figure 3-6. Histogram of Wt\% TS Distribution for Ten Pascal Mixing Tests with Coils Out at 40 Gallons 


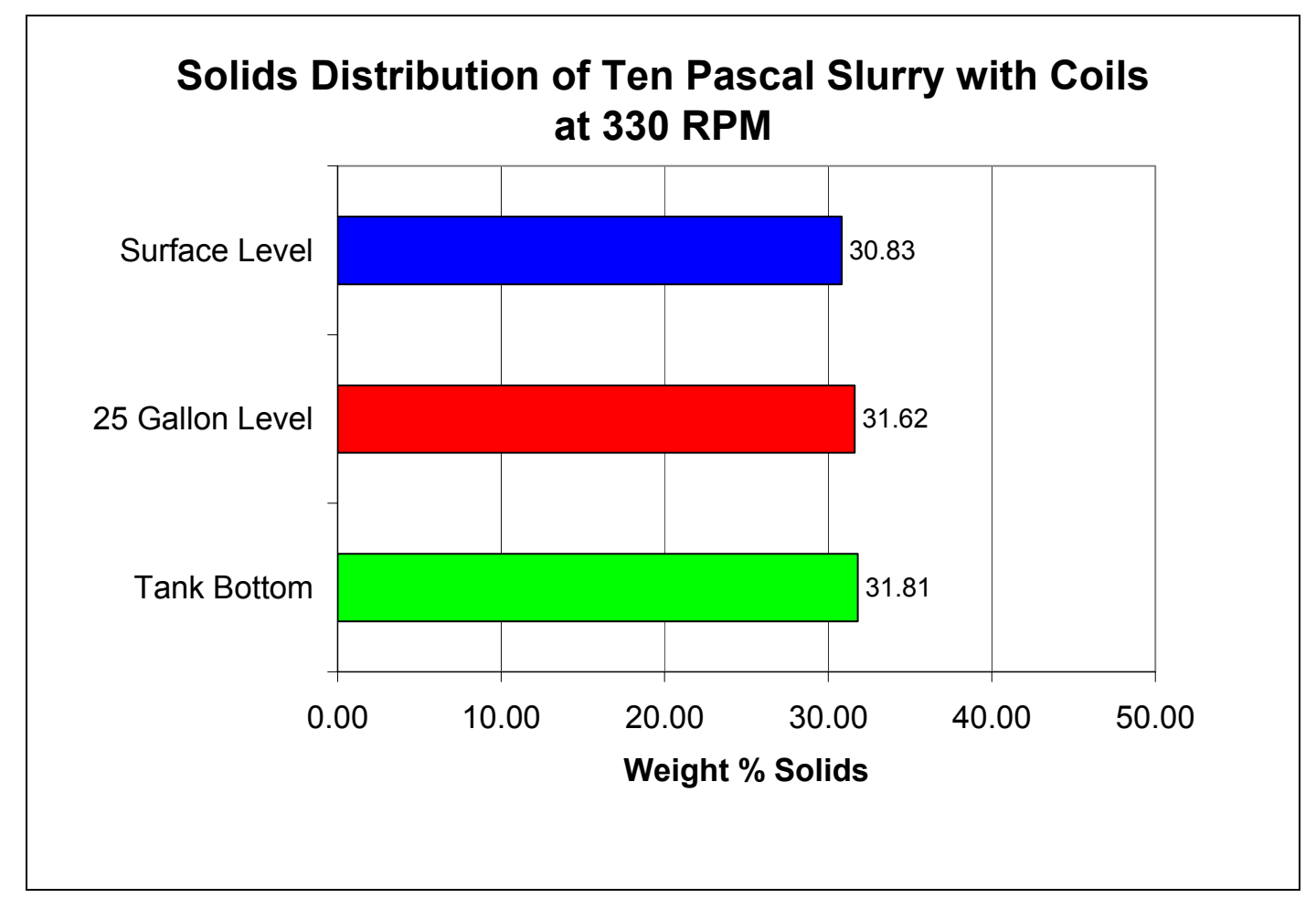

Figure 3-7. Histogram of Wt\% TS Distribution for Ten Pascal Mixing Tests with Coils In at 40 Gallons

Given that the frit in the Ten Pascal slurry settles faster than the frit in the Twenty Pascal slurry, coupled with the fact that the Ten Pascal slurry exhibited a fairly decent wt.\% solids distribution even after mixing cessation for over twelve hours, it was decided that no solids distribution sampling will be performed during testing with the Twenty Pascal slurry.

\subsubsection{Surface Phenomena}

To quantify the surface phenomena a Lieco Disto Pro $4^{\mathrm{a}}$ Laser Distance Meter was used to measure the surface to tank lid distance. Measurements were taken from Tank edge towards the tank middle at several measured increments creating a surface profile.

Surface profiles quantify the shape of the vortex and can be used to show the differences in the size of the vortex for a given agitator speed, with and without the coils. During testing of the Five Pascal slurry, significant vortex formation was noted at the 6 gallon level, the 25 gallon level, and the 40 gallon level, with the coils removed. For the 5 Pascal slurry a vortex was present with the coils in and with the coils out, at 220 RPM at the 25 gallon level. However, the vortex was slightly deeper with the coils out than with the coils in, as seen in Figure 3-8. When the coils were in, they seem to provide some natural baffling or the overall flow produced by the impellers is smaller with the coils in as compared to with the coils out. 


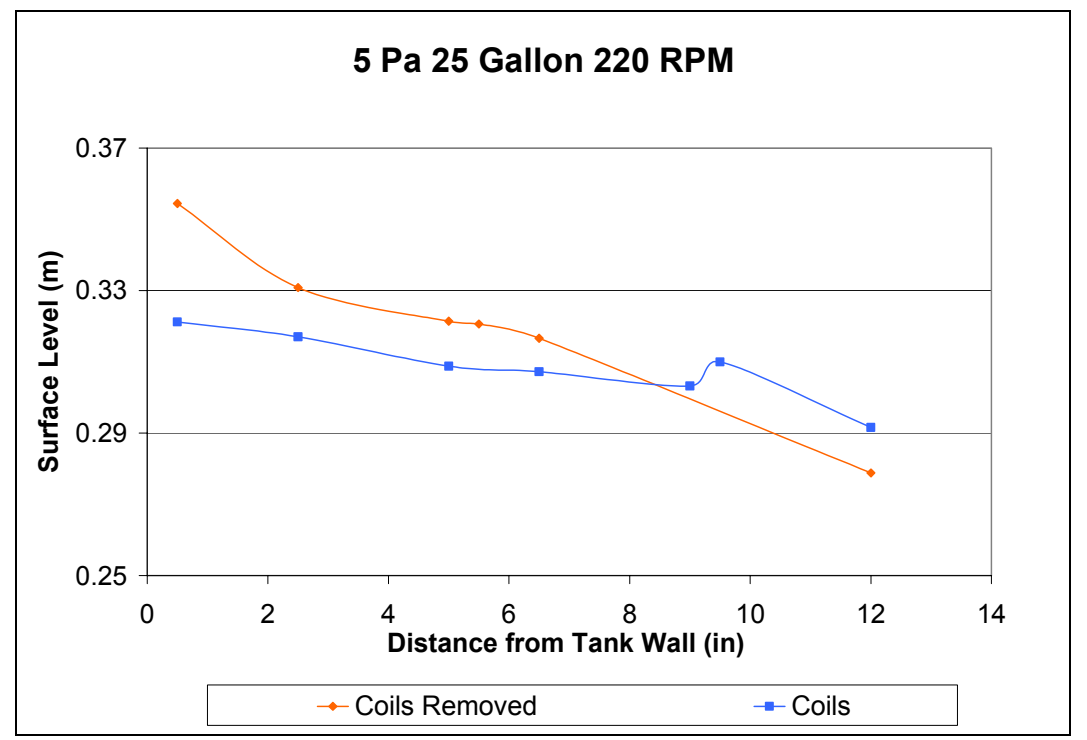

Figure 3-8. Impact of Coils on Vortex Depth at 220 RPM For 25 Gallon 5 Pa Slurry

While testing at the 40 gallon levels with the 5 Pascal slurry, a significant vortex was present when mixing at 360 RPM with the coils out and at 420 RPM with the coils in. No vortexing occurred during the 40 gallon tests with the 10 Pascal or the 20 Pascal slurries. Figure 3-9 shows, the vortex during the 25 gallon test of the Ten Pascal slurry was greater with the coils removed.

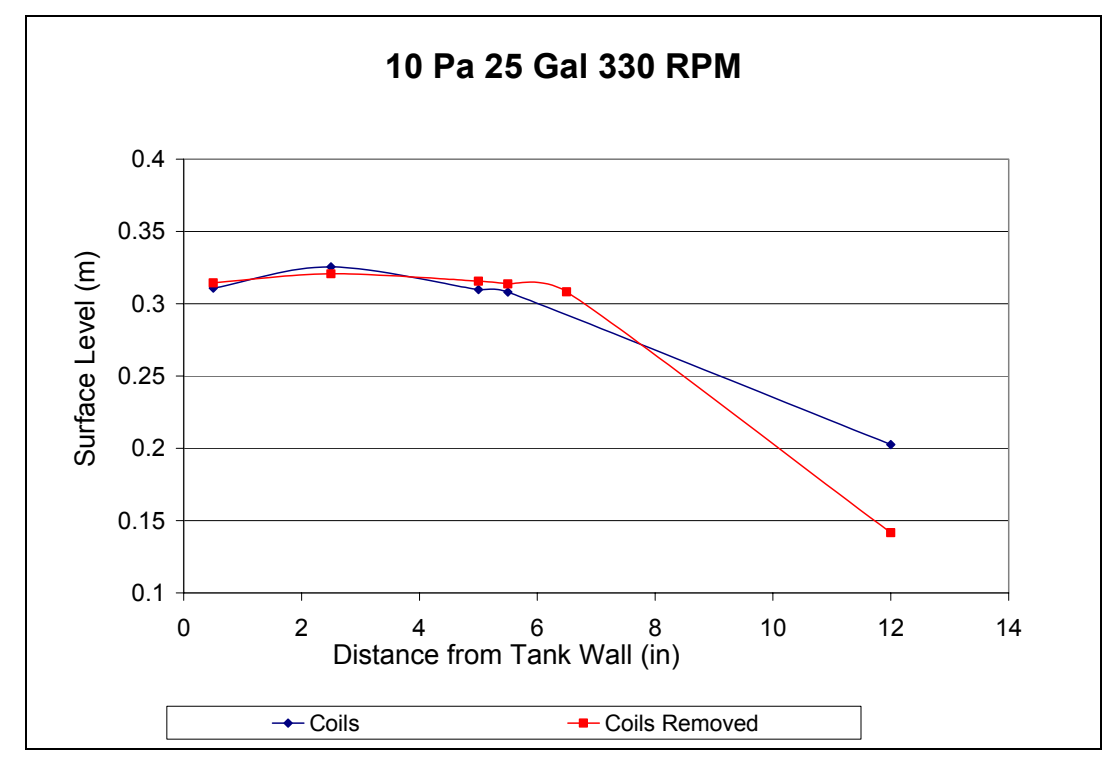

Figure 3-9. Impact of Coils on Vortex Depth at 330 RPM For 25 Gallon 10 Pa Slurry

The 20 Pascal slurry had very little vortexing for all test conditions. A slight vortex occurred in both the 25 Gallon test with and without the coils. However, as previously discussed, during the 25 Gallon test with the coils in, the center of the vortex was higher 
than the surrounding areas. The cause of this phenomenon was not investigated. During the 6 Gallon test with coils in, there was a slight vortex, however, with the coils out there was a deep vortex revealing the lower impeller hub.

The overall trend during testing was that the depth of the vortex increased for a given agitator speed with the coils out as compared with the coils in. Agitator speed also impacted the size and depth of the vortex in a proportionate manner, which has not been quantified in this task. In general, as the agitator speed increased for a given test condition, so did the size and depth of the vortex.

Several qualifiers must be mentioned with respect to the surface profile measurements. When the coils were in the vessel, the plate at the top of the coils assembly blocked the laser from measuring surface level between the 13 through 17 half-inch marks. The direct drive motor, and the gear reduced motor prevented measurements beyond the 15 half-inch mark. Another issue with measuring the vortex center (11.6 inches from the tank wall) was the tendency for the vortex to oscillate (the vortex would slightly collapse and then grow again), thus increasing the variance of surface level measurements taken near the agitator shaft. This caused very erratic readings, and when graphed the error bars increased significantly as measurements moved towards the center of the vortex. The inconsistency inherent in the data because of the above issue required that the data be treated in context with other information such as visual observations to accurately reflect test results.

Previous testing showed very similar results with respect to homogeneity of solids when mixing, and the ability to mix well at given speeds and volumes. ${ }^{7,8}$ Full mixing was noted at the 5Pa test with 25 gallons at 220 RPM, which compared well with the results seen in a full scale test of a $7 \mathrm{~Pa}$ fluid at 6000 gallons and 67 RPM performed during the Homogeneity Study. Although, the results in this report compare well with the results of that previous testing, the comparison is limited to mid-level and low level volumes. There was no apparent comparison for high volume testing (approximately 9500 gallons) done on mixing in the SME or the MFT.

\footnotetext{
${ }^{7}$ Jenkins, W.J., MFT Homogeneity Study at TNX - Preliminary Report on the High Weight Percent Solids Concentration (U). September 2, 1993. WSRC-RP-93-1229.

${ }^{8}$ Jenkins, W.J., MFT Homogeneity Study at TNX - Final Report on the Low Weight Percent Solids

Concentration (U). September 21, 1993. WSRC-RP-93-1271.
} 
WSRC-TR-2004-00436

REVISION 0

\subsection{SCALING METHODS}

There are many different methods available for scaling agitator speeds, each geared towards a specific aspect of mixing. Equal solids suspension and equal power per unit volume consumption are two examples of desired results that yield two different methods of scaling. It is important in agitator speed scaling (either up or down) that geometric similarity exists between the pilot scale vessel and the full scale vessel. However, even with geometrically similar vessels, scaling mixing processes can be unpredictable due to dynamic and kinematic dissimilarities. Scaling using dynamic/kinematic similarities for unique mixing conditions further complicates the problem, due to lack of available technical references supporting the use of the similarity. This problem can be further complicated, if multiple mixing requirements (equal solids suspension, similar surface phenomena, etc.) are required. When scaling mixing processes, it is pertinent to evaluate all the available scaling methods with regards to a specific situation (i.e. the $1 / 6^{\text {th }}$ Scale vessel to the DWPF Full Scale vessel) and use engineering judgment as to which method or hybrid of methods will result in the desired mixing process.

Ekato performed the initial testing to determine the speed and power requirements for the current DWPF vessels. The Ekato results were presented as a log-log plot of agitator speed versus vessel diameter. ${ }^{9}$ This diagram was the primary method for determining the scaled agitator speeds for this testing. As mentioned, there are many different ways to scale mixing tanks, however, each contains different limiting aspects depending on the intended outcome.

The agitator speed can be scaled using a geometric property, such as impeller diameter, tank diameter or volume. Geometric properties that have the same degree of freedom can be interchanged, for example, one can use tank diameter in place of impeller diameter, without causing a change in the exponents shown in equation 4.0, but would change the value of the constant $\mathrm{K}_{\mathrm{j}}$. The different scaling methods provided below can be represented in the form of:

$$
n_{i}^{v} \cdot D^{w}=K_{j}
$$

Where: $\mathrm{n}_{\mathrm{i}}=$ agitator speed (revolutions/second)

$\mathrm{K}_{\mathrm{j}}=$ constant for a given condition (having units of $n_{i}{ }^{v} \cdot D^{w}$ )

$\mathrm{D}=$ impeller diameter $(\mathrm{m})$

$\mathrm{v}=$ speed exponent (unitless)

$\mathrm{w}=$ diameter exponent (unitless)

Note that $\mathrm{Kj}$ is assumed constant when scaling between the two different sized scaled processes. For two different scales, where "1" denotes the full scale and "2" denotes the pilot scale, the above equation reduces to:

\footnotetext{
${ }^{9}$ Located in Appendix E.
} 
WSRC-TR-2004-00436

REVISION 0

$$
\frac{n_{2}}{n_{1}}=\left(\frac{D_{2}}{D_{1}}\right)^{-\frac{w}{v}}
$$

\subsection{Equal Reynolds Number}

A sizing method yielding one of the largest changes in agitator speed from one scale to another is equal Reynolds Number. The Reynolds Number $\left(\mathrm{N}_{\mathrm{RE}}\right)$ for a power-law fluid can be calculated using the following equation ${ }^{10}$ :

$$
N_{R E}=\frac{\rho n^{2-n^{\prime}} D^{2}}{K\left(k_{s}\right)^{n^{\prime}-1}}
$$

Where: $\rho=$ Density $\left(\mathrm{Kg} / \mathrm{m}^{3}\right)$

$\mathrm{n}=$ Rotational Speed (Revolutions/Second)

$\mathrm{D}=$ Impeller Diameter $(\mathrm{m})$

$\mathrm{k}_{\mathrm{s}}=$ Effective Shear Rate Constant (unitless)

n' = Flow Behavior Index of a Power Law Fluid (unitless)

$\mathrm{K}=$ Power Law Coefficient $\left(\mathrm{Pa}-\mathrm{Sec}^{\mathrm{n}}\right)$

Reconfiguring equation (4.2) into equation (4.1) and using equation (4.2) yields the following sizing correlation:

$$
\frac{n_{2}}{n_{1}}=\left(\frac{D_{2}}{D_{1}}\right)^{\frac{-2}{2-n^{\prime}}}
$$

Note that equation (4.3) is dependent on the flow behavior index (hence is fluid dependent) and in the case where the fluid is Newtonian $\left(n^{\prime}=1\right)$, equation (4.4) reduces to the Newtonian case, as expected. Using the DWPF Full Scale vessel low speed setting (67 RPM) and the $10 \mathrm{~Pa}$ slurry model as a Power Law fluid (where n' $=0.3576, \mathrm{~K}=7.162$ $\left.\mathrm{Pa} \cdot \mathrm{Sec}^{0.3576}\right)$, the agitator speed for the $1 / 6^{\text {th }}$ Scale vessel is shown below. Table $4-1$ contains all the results for the 5, 10 and 20 Pa fluids fitted with a Power Law model.

$$
n_{2}=67 R P M\left(\frac{5.8}{36}\right)^{-1.2177}=619 R P M
$$

\footnotetext{
${ }^{10}$ Wilkens, R.J., Henry, C., Gates, L.E., "How to Scale-Up Mixing Processes in Non-Newtonian Fluids", Chem. Eng. Prog., 100 (5), pp.44-52. May 2003.
} 
WSRC-TR-2004-00436

REVISION 0

Table 4-1 Scaling Agitator Speeds Using Equal Reynolds Number

\begin{tabular}{|c|c|c|c|}
\hline \multirow{3}{*}{$\begin{array}{c}\text { Full Scale } \\
\text { Agitator } \\
\text { Speed } \\
\text { (RPM) }\end{array}$} & \multicolumn{3}{|c|}{ Yield Stress (Pa) } \\
\hline & 5 & 10 & 20 \\
\hline & $\begin{array}{c}\mathrm{K}=\mathbf{1 . 0 5 7} \mathrm{Pa} \mathrm{sec}^{\mathrm{n}} \\
\mathbf{n}^{\prime}=\mathbf{0 . 4 1 3 3}\end{array}$ & $\begin{array}{c}K=2.774 \text { Pa sec }{ }^{n^{\prime}} \\
n^{\prime}=0.3576\end{array}$ & $\begin{array}{c}\mathrm{K}=7.162 \mathrm{~Pa} \mathrm{sec}^{\mathrm{n}^{\prime}} \\
\mathrm{n}^{\prime}=0.273\end{array}$ \\
\hline 67 & 669 & 619 & 555 \\
\hline 103 & 1029 & 952 & 853 \\
\hline 134 & 1338 & 1240 & 1110 \\
\hline
\end{tabular}

\subsection{Equal Cavern Diameter Ratio}

The cavern (area which has active mixing) can be estimated and the method for determining the cavern diameter ratio can be used for sizing. The size of the cavern diameter $\left(D_{c}\right)$ can be estimated using the impeller diameter, power number, fluid density, agitator speed, and the yield stress of the fluid. ${ }^{11,12}$ The cylindrical cavern relationship ${ }^{11}$, 12, equation (4.4) will be used. This correlation can be used to estimate the speed or impeller diameter for a required cavern size between the impeller and tank walls. Past this point, the cavern grows (in the $\mathrm{z}$ direction) directly proportional to the agitator speed.

$$
\left(\frac{D_{c}}{D}\right)^{3}=\left(\frac{1.36 N_{P}}{\pi^{2}}\right)\left(\frac{\rho n^{2} D^{2}}{\tau_{y}}\right)
$$

Where: $\mathrm{D}_{\mathrm{c}}=$ Cavern Diameter $(\mathrm{m})$

$\mathrm{N}_{\mathrm{P}}=$ Power Number (unitless)

$\tau_{\mathrm{y}}=$ Yield Stress $\left(\mathrm{N} / \mathrm{m}^{2}\right)$

Reconfiguring equation (4.4) into equation (4.1) and using equation (4.2) yields the following (this assumes that the power number, density, and yield stress do not change):

$$
\frac{n_{2}}{n_{1}}=\left(\frac{D_{2}}{D_{1}}\right)^{-1}
$$

To properly utilize these equations, a baseline condition must be determined (such as when the cavern reaches the tank wall $\mathrm{D}_{\mathrm{c}}=\mathrm{T}$ ) to determine an agitator speed. In this case, $\mathrm{D}_{\mathrm{C}} / \mathrm{D}=\mathrm{T} / \mathrm{D}=4$. Using a power number of $6^{13}$, yield stress of $10 \mathrm{~Pa}$ and a density of $1200 \mathrm{~kg} / \mathrm{m}^{3}$ for the DWPF full scale vessel, the agitator speed is:

\footnotetext{
${ }^{11}$ Solomon, J., Elson, T.P., Nienow, A.W., and Pace, G.W., Chemical Engineering Com. Vol. 11 pp143, 1981.

${ }^{12}$ Elson, T.P., Cheesman, D.J., Nienow, A.W., Chemical Engineering Science. Vol.41, No 10, pp.25552562, 1986.

${ }^{13}$ Power number taken from Ekato report, see Appendix E.
} 


$$
\begin{aligned}
n_{1} & =\sqrt{\left(\frac{D_{c}}{D}\right)^{3}\left(\frac{\pi^{2} \cdot \tau_{y}}{1.36 N_{P} \cdot \rho \cdot D^{2}}\right)}=\sqrt{\left(\frac{12}{3}\right)^{3} \cdot \frac{\pi^{2} \cdot 10 P a \cdot\left(\frac{\mathrm{kg} \cdot \mathrm{m}}{\mathrm{Pa} \cdot \mathrm{s}^{2}}\right)}{1.36 \cdot 6 \cdot 1200 \frac{\mathrm{kg}}{\mathrm{m}^{3}} \cdot(0.9144)^{2}}} \\
& =0.8784 \frac{\mathrm{rev}}{\mathrm{sec}}=52.7 \mathrm{RPM}
\end{aligned}
$$

For the $1 / 6^{\text {th }}$ Scale vessel agitator speed to have the same cavern condition (to the wall of the tanks), is:

$$
n_{2}=52.7\left(\frac{5.8}{36}\right)^{-1}=327 R P M
$$

The agitator speeds for the other fluids are shown in Table 4-2. Note the exponent using equal cavern diameter is -1.0 , slightly less than that of the Reynolds Number method for a given fluid. In general, the calculated $\mathrm{N}_{\mathrm{RE}}$ speeds are much higher than that of the equal cavern method.

Table 4-2 Scaling Agitator Speed Using Equal Cavern Diameter Method To Reach the Wall of the Mixing Tank

\begin{tabular}{ccccc}
\hline \multirow{2}{*}{ Process } & $\begin{array}{c}\text { Tank } \\
\text { Diameter } \\
\text { (inches) }\end{array}$ & \multicolumn{3}{c}{ Yield Stress (Pa) } \\
\cline { 3 - 5 } $1 / 6^{\text {th }}$ Scale & 5.8 & $231 \mathrm{RPM}$ & $327 \mathrm{RPM}$ & $463 \mathrm{RPM}$ \\
DWPF Scale & 36 & $37.3 \mathrm{RPM}$ & $52.7 \mathrm{RPM}$ & $74.5 \mathrm{RPM}$ \\
\hline
\end{tabular}

Note that this is the agitator speed required to have mixing to the walls of the tank, not necessarily throughout the vessel. The agitator speed past this point increases linearly after the cavern reaches the wall ${ }^{11,12}$, but is not calculated in this report. Note, that the minimum operating speed (67 RPM) for the full scale DWPF process with a 20 Pa fluid, there would be a cavern that does not reach the tank walls.

\subsection{Equal Tip Speed}

The impeller tip speed, $\mathrm{S}_{\mathrm{t}}$, is a relatively common method for scaling. Tip Speed scaling is generally associated with shear sensitive mixing phenomena, such as particle or droplet size control. ${ }^{10}$ Tip Speed can be calculated by:

$$
\mathrm{S}_{\mathrm{t}}=\pi \mathrm{nD}
$$

Reconfiguring equation (4.8) into equation (4.1) and using equation (4.2) yields the following: 


$$
\frac{n_{2}}{n_{1}}=\left(\frac{D_{2}}{D_{1}}\right)^{-1}
$$

Note that tip speed, equation (4.6), is independent of any physical property. The exponent for both the equal cavern diameter ratio and equal tip speed are the same. In reality, the speed for complete mixing as determined by the cavern method would yield a larger agitator speed, since the above equal cavern diameter ratio does not take into consideration additional speed for complete tank mixing. Equal Tip Speed should be used for scale-up only when small-scale studies have definitively shown that required process performance correlates with Tip Speed. Equal Tip Speed has been calculated for the $1 / 6^{\text {th }}$ Scale vessel at 67 RPM DWPF Full Scale and is shown below. Results for the other speeds are provided in Table 4-3.

$$
n_{2}=52.7\left(\frac{5.8}{36}\right)^{-1}=327 R P M
$$

Table 4-3 Scaling Agitator Speed Using Equal Tip Speed Method

\begin{tabular}{cc}
\hline \multicolumn{2}{c}{ Agitator Speed (RPM) } \\
DWPF Scale & $\mathbf{1 / 6}^{\text {th }}$ Scale \\
\hline 67 & 416 \\
103 & 639 \\
134 & 832 \\
\hline
\end{tabular}

\subsection{Equal Power Per Unit Volume}

Scale-up utilizing the Power Per Unit Volume $(\mathrm{P} / \mathrm{V})$ is one of more common and acceptable methods for sizing. The advantage to $\mathrm{P} / \mathrm{V}$ scaling is three fold; this method is well established and documented, easily measured on a pilot scale, and typically conservative (providing adequate mixing in the full scale processes) when scaling from pilot to full scale equipment. To calculate $\mathrm{P} / \mathrm{V}$ in turbulent flow, the following equation can be used:

$$
\frac{P}{V}=\frac{\left(N_{p} \rho n^{3} D^{5}\right)}{\left(\frac{\pi T^{2} Z}{4}\right)}
$$

Where: $\mathrm{P}=$ Impeller Power $(\mathrm{W})$

$\mathrm{V}=$ Volume $\left(\mathrm{m}^{3}\right)$

$\mathrm{T}=$ Tank Diameter $(\mathrm{m})$

$\mathrm{Z}=$ Depth of Liquid in Vessel (m)

From geometric similarities, equation (4.8) can be written as: 


$$
\frac{P}{V} \alpha \frac{N_{p} \rho n^{3} D^{5}}{D^{3}}=N_{p} \rho n^{3} D^{2}
$$

Reconfiguring equation (4.9) into equation (4.1) and using equation (4.2) yields the following:

$$
\frac{n_{2}}{n_{1}}=\left(\frac{D_{2}}{D_{1}}\right)^{-\frac{2}{3}}
$$

Power per Unit Volume is generally used for scale-up unless there are specific agitation requirements such as particle dispersion, solids distribution, or surface phenomena. Unlike tip speed, power per unit volume is dependent on many variables. Equal $\mathrm{P} / \mathrm{V}$ has been calculated for the $1 / 6^{\text {th }}$ Scale vessel at 67 RPM DWPF Full Scale and is shown below. Results for the other DPWF agitator speeds are provided in Table 4-4.

$$
n_{2}=67\left(\frac{5.8}{36}\right)^{-\frac{2}{3}}=226 R P M
$$

Table 4-4 Scaling Agitator Speed Using Equal Power Per Unit Volume

\begin{tabular}{cc}
\hline \multicolumn{2}{c}{ Agitator Speed (RPM) } \\
DWPF Scale & $\mathbf{1 / 6}^{\text {th }}$ Scale \\
\hline 67 & 226 \\
103 & 348 \\
134 & 453 \\
\hline
\end{tabular}

\subsection{Ekato Method}

Ekato was the agitator vendor who performed the original agitator testing to determine the agitator speed, motor size, and agitator shaft for the DWPF processes. Ekato used two different scales and then interpolated the test results to determine the agitator speed that would provide adequate mixing, given the dimensions of the full scale mixing processes at DWPF. The Ekato test conditions and results are shown in Appendix E. A summary of their testing is provided below:

- The fluids used had the following approximate fluid properties: yield stress of 7 $\mathrm{Pa}$, and consistency of $0.025 \mathrm{~Pa} \cdot \mathrm{s}$.

- The top of the bottom flat blade impeller was located just below the draft tube, discharging its flow into the bulk of the tank. This is different from that of the DWPF and the $1 / 6^{\text {th }}$ scale, where the bottom impeller partially discharges some of its flow directly into the coils.

- The two scales used by Ekato are not geometrically similar.

The small vessel and pilot vessel results that provided adequate visual mixing (speed and tank diameter) and the speed recommended by Ekato for DWPF are shown in Figure 4-1. 
These three data points were fitted to a power law model and the exponent of -0.6386 was determined and shown in Figure 4-1.

The Ekato speed has been calculated for the $1 / 6^{\text {th }}$ Scale vessel at 67 RPM DWPF Full Scale and is shown below. Results for the other DPWF agitator speeds are provided in Table 4-5. The results are very similar to the power per unit volume results in the previous section.

$$
n_{2}=67\left(\frac{5.8}{36}\right)^{-0.6386}=215 R P M
$$

Table 4-5 Scaling Agitator Speed Using Ekato Method

\begin{tabular}{cc}
\hline \multicolumn{2}{c}{ Agitator Speed (RPM) } \\
DWPF Scale & $\mathbf{1 / 6}^{\text {th }}$ Scale \\
\hline 67 & 215 \\
103 & 330 \\
134 & 420 \\
\hline
\end{tabular}

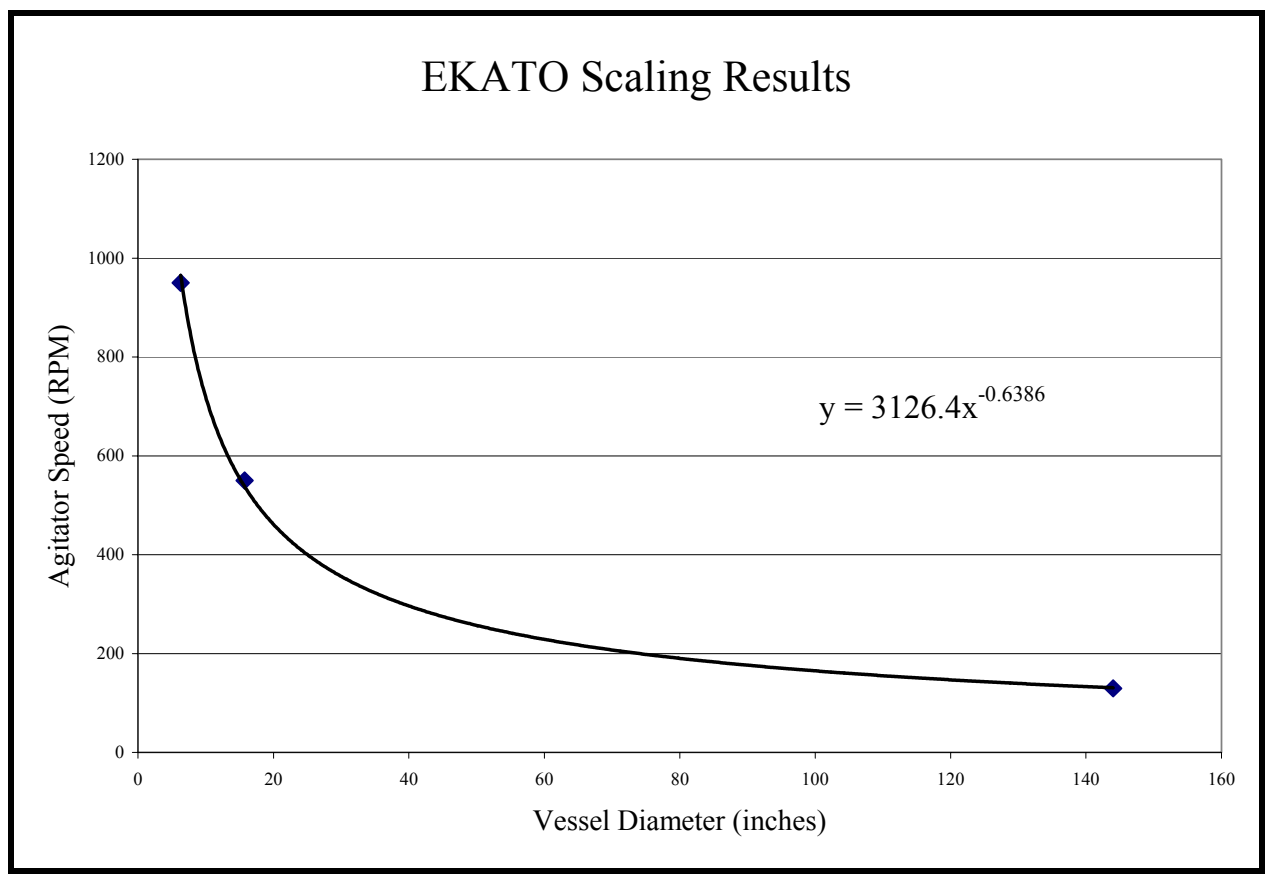

Figure 4-1. Ekato Test Results

\subsection{Equal Froude Number}

The Froude Number method, $\mathrm{N}_{\mathrm{Fr}}$, is among the most conservative of scale up methods. Often Equal Froude Number is disregarded because it results in a high (in some cases, 
impossibly high) rotational speed at full scale conditions. The $\mathrm{N}_{\mathrm{Fr}}$ is defined as the ratio of the inertial force over the gravitational force of agitation in a mixing vessel:

$$
\mathrm{N}_{\mathrm{Fr}}=\frac{n^{2} D}{g}
$$

Where: $\mathrm{g}=$ gravity, $\mathrm{m} / \mathrm{s}^{2}$

Reconfiguring equation (4.11) into equation (4.1) and using equation (4.2) yields the following:

$$
\frac{n_{2}}{n_{1}}=\left(\frac{D_{2}}{D_{1}}\right)^{-\frac{1}{2}}
$$

The Froude Number is most appropriate for scaling when trying to maintain similar surface phenomena as it accounts for gravitational effects with respect to significant vortexing. ${ }^{14}$ Equal Froude number has been calculated for the $1 / 6^{\text {th }}$ scale vessel at 67 RPM DWPF full scale and is shown below. Results for the other DPWF agitator speeds are provided in Table 4-6. Note that the results in Table 4-6 assume that a visual verification of the phenomena occurred, which is not the case, since there is no data to state the condition of the agitated surface and to compare this to the scaled system.

$$
n_{2}=67\left(\frac{5.8}{36}\right)^{-\frac{1}{2}}=167 R P M
$$

Table 4-6 Scaling Agitator Speed Using Equal Froude Number

\begin{tabular}{cc}
\hline \multicolumn{2}{c}{ Agitator Speed (RPM) } \\
DWPF Scale & $\mathbf{1 / 6}^{\text {th }}$ Scale \\
\hline 67 & 167 \\
103 & 257 \\
134 & 324 \\
\hline
\end{tabular}

\subsection{Comparison of $1 / 6^{\text {th }}$ Scaled Mixing to TNX Homogeneity Study}

A comparison was made between the $1 / 6^{\text {th }}$ Scaled mixing vessel test results and the Homogeneity Studies. ${ }^{7,8}$ At 6000 Gallons and 100 RPM the Homogeneity Studies showed complete mixing with uniform solids suspension. Complete mixing and solids suspension was seen in the $1 / 6^{\text {th }}$ Scale tests at 25 Gallons (6000 gallon equivalent) and 330 RPM. The rheology of the fluids used in both test were similar, but not identical. The fluid used in the homogeneity testing was approximately 7 Pascals, where as, the comparable fluid in the $1 / 6^{\text {th }}$ Scale testing was 5 Pascals. Utilizing those two points a power-law regression was performed and the results are shown in Figure 4-2. Thus, the

${ }^{14}$ Skelland, A.H.P., Non-Newtonian Flow and Heat Transfer. pp.310-311, 1967. John Wiley \& Sons, Inc. New York. 
Power per Unit Volume method may be too conservative (not yielding adequate agitator speed) when scaling from the $1 / 6^{\text {th }}$ Scale vessel to the DWPF Full Scale vessel.

However, error is inherent with just two points, and therefore the results should be used with caution.

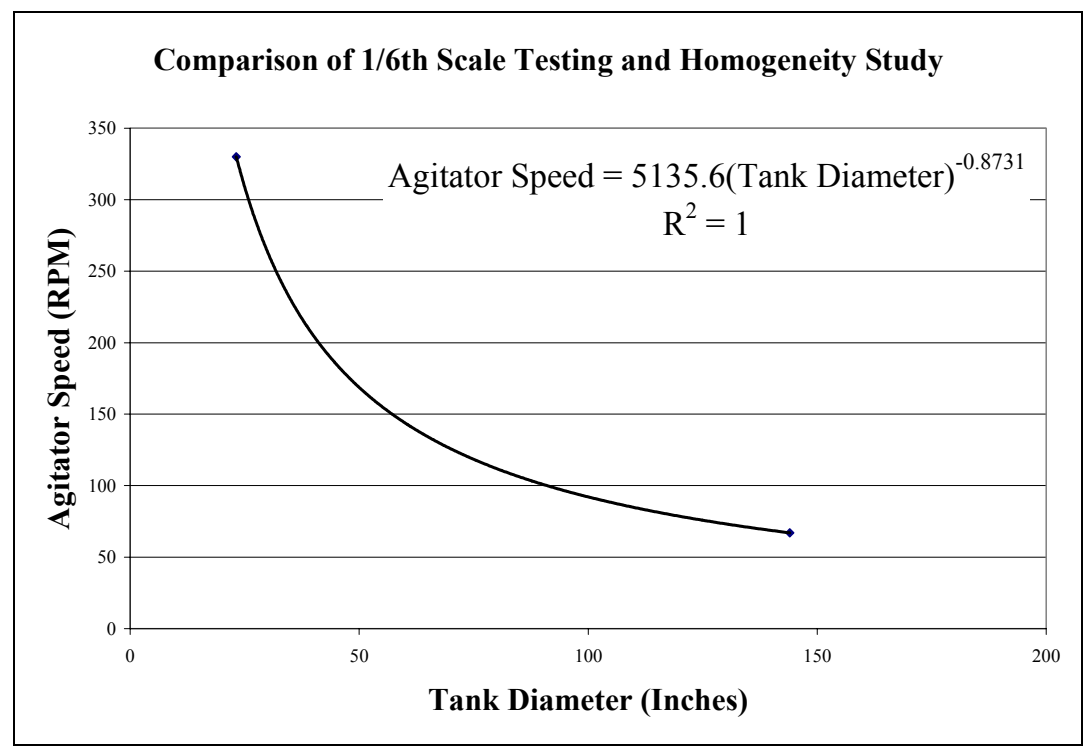

Figure 4-2. Comparison to TNX Homogeneity Study

Given the DWPF scale, the $1 / 6^{\text {th }}$ Scale dynamic/kinematic properties used in the above sections were calculated for the three different fluids and the 67 RPM and 130 RPM Full Scale speeds and the results are shown in Table 4-7 through Table 4-12. In all these calculations, it was assumed that the power number is constant for the condition of flow and the effective shear rate constant is applicable throughout all Reynolds numbers. Using the DWPF design parameters to determine the mixing properties of the $1 / 6^{\text {th }}$ Scale clearly indicate that $\mathrm{N}_{\mathrm{RE}}$ predicts the highest agitator speed and the $\mathrm{N}_{\mathrm{Fr}}$ predicts the lowest. The Reynolds number indicates that if other scaling methods are used other than equal $\mathrm{N}_{\mathrm{RE}}$, the Reynolds number for the $1 / 6^{\text {th }}$ Scale could be an order of magnitude lower than that of the DWPF scale, resulting in inappropriate utilization of the power number. If Cavern mixing exists on the $1 / 6^{\text {th }}$ Scale, it may not necessarily exist on the Full Scale. In most cases the cavern ratio for the Full Scale is greater than those of the $1 / 6^{\text {th }}$ Scale, indicating that there would be less of a chance to have cavern mixing.

The scaling methods discussed here are based upon scaling of vessels of standard mixing geometries that are geometrically similar and are not all inclusive. These scaling methods do not account for mixing vessels that have heating and cooling coils surrounding the impellers nor do they consider having the bottom impeller located very near the bottom of the mixing vessel. These issues add more uncertainty when sizing. Another issue, such as wall surface area per volume has a greater effect on a small scale mixing vessel than it would on a large scale mixing vessel. Finally, the number of coils columns in the mixing vessel could also impact sizing. 
WSRC-TR-2004-00436

REVISION 0

Table 4-7 Dynamic/Kinematic Properties of $1 / 6^{\text {th }}$ Scale Using Various Sizing Methods - 5 Pa Fluid, 130 RPM

\begin{tabular}{|c|c|c|}
\hline \multicolumn{2}{|c}{ Input Da } \\
\hline Fluid Density: & 1200.0 & $\mathrm{~kg} / \mathrm{m}^{3}$ \\
\hline Yield Stress: & 5 & $\mathrm{~Pa}\left(\mathrm{~N} / \mathrm{m}^{2}\right)$ \\
\hline Power Law Coef: & 1.057 & $\mathrm{~Pa} \cdot \mathrm{s}^{\mathrm{n}}$ \\
\hline Flow index: & 0.4133 & unitless \\
\hline Impeller shear ratio: & 11 & unitless \\
\hline Impeller Power Number: & 6 & unitless \\
\hline
\end{tabular}

\begin{tabular}{|c|c|c|c|}
\hline & Full Scale & Pilot & Units \\
\hline Tank Dia.: & 144 & 23.2 & inches \\
\hline Tank Vol.: & 9500 & 40 & gallons \\
\hline Impeller Dia.: & 36 & 5.8 & inches \\
\hline
\end{tabular}

\begin{tabular}{|c|c|c|c|c|c|c|c|}
\hline \multirow{2}{*}{ Property } & \multirow{2}{*}{ Units } & \multirow{2}{*}{ Full Scale } & \multicolumn{5}{|c|}{$\begin{array}{c}\text { Scaling Method Used To Determine Pilot Scale } \\
\text { Properties }\end{array}$} \\
\hline & & & $\mathbf{N}_{\mathrm{RE}}$ & $\begin{array}{l}\text { Caver } \\
\mathbf{n} / \mathbf{N}_{\mathrm{TS}}\end{array}$ & $\mathbf{P} / \mathbf{V}$ & Ekato & $\mathbf{N}_{\mathrm{Fr}}$ \\
\hline Rotational Speed & RPM & 130 & 1298 & 807 & 439 & 382 & 324 \\
\hline $\mathrm{N}_{\mathrm{RE}}$ & unitless & 211488 & 211488 & 99447 & 37865 & 30315 & 23365 \\
\hline Cavern Ratio & unitless & 9.20 & 12.63 & 9.20 & 6.13 & 5.59 & 5.01 \\
\hline Tip Speed & $\mathrm{m} / \mathrm{s}$ & 6.22 & 10.01 & 6.22 & 3.39 & 2.94 & 2.50 \\
\hline Power & Watts & 46859 & 5065 & 1216 & 196 & 129 & 79 \\
\hline PV & $\mathrm{W} / \mathrm{m}^{3}$ & 1303 & 33458 & 8034 & 1294 & 850 & 520 \\
\hline Froude Number & unitless & 0.44 & 7.03 & 2.72 & 0.80 & 0.61 & 0.44 \\
\hline
\end{tabular}

Table 4-8 Dynamic/Kinematic Properties of $1 / 6^{\text {th }}$ Scale Using Various Sizing Methods - 5 Pa Fluid, 67 RPM

\begin{tabular}{|c|c|c|}
\hline \multicolumn{2}{|c}{ Input Da } \\
\hline Fluid Density: & 1200.0 & $\mathrm{~kg} / \mathrm{m}^{3}$ \\
\hline Yield Stress: & 5 & $\mathrm{~Pa}\left(\mathrm{~N} / \mathrm{m}^{2}\right)$ \\
\hline Power Law Coef: & 1.057 & $\mathrm{~Pa} \cdot \mathrm{s}^{\mathrm{n}}$ \\
\hline Flow index: & 0.4133 & unitless \\
\hline Impeller shear ratio: & 11 & unitless \\
\hline Impeller Power Number: & 6 & unitless \\
\hline
\end{tabular}

\begin{tabular}{|c|c|c|c|}
\hline & Full Scale & Pilot & Units \\
\hline Tank Dia.: & 144 & 23.2 & inches \\
\hline Tank Vol.: & 9500 & 40 & gallons \\
\hline Impeller Dia.: & 36 & 5.8 & inches \\
\hline
\end{tabular}

\begin{tabular}{|c|c|c|c|c|c|c|c|}
\hline \multirow{2}{*}{ Property } & \multirow{2}{*}{ Units } & \multirow{2}{*}{ Full Scale } & \multicolumn{5}{|c|}{$\begin{array}{c}\text { Scaling Method Used To Determine Pilot Scale } \\
\text { Properties }\end{array}$} \\
\hline & & & $\mathbf{N}_{\mathbf{R E}}$ & $\begin{array}{l}\text { Caver } \\
\text { n } / \mathbf{N}_{\text {TS }}\end{array}$ & $\mathbf{P} / \mathbf{V}$ & Ekato & $\mathbf{N}_{\mathrm{Fr}}$ \\
\hline Rotational Speed & RPM & 67 & 669 & 416 & 226 & 197 & 167 \\
\hline $\mathrm{N}_{\mathrm{RE}}$ & unitless & 73880 & 73880 & 34740 & 13227 & 10590 & 8162 \\
\hline Cavern Size & unitless & 5.91 & 8.12 & 5.91 & 3.94 & 3.59 & 3.22 \\
\hline Tip Speed & $\mathrm{m} / \mathrm{s}$ & 3.21 & 5.16 & 3.21 & 1.75 & 1.52 & 1.29 \\
\hline Power & Watts & 6415 & 693 & 167 & 27 & 18 & 11 \\
\hline PV & $\mathrm{W} / \mathrm{m}^{3}$ & 178 & 4580 & 1100 & 177 & 116 & 71 \\
\hline Froude Number & unitless & 0.12 & 1.87 & 0.72 & 0.21 & 0.16 & 0.12 \\
\hline
\end{tabular}


WSRC-TR-2004-00436

REVISION 0

Table 4-9 Dynamic/Kinematic Properties of $1 / 6^{\text {th }}$ Scale Using Various Sizing Methods - 10 Pa Fluid, 130 RPM

\begin{tabular}{|c|c|c|}
\hline \multicolumn{2}{|c}{ Input Da } \\
\hline Fluid Density: & 1200.0 & $\mathrm{~kg} / \mathrm{m}^{3}$ \\
\hline Yield Stress: & 10 & $\mathrm{~Pa}\left(\mathrm{~N} / \mathrm{m}^{2}\right)$ \\
\hline Power Law Coef: & 2.774 & $\mathrm{~Pa} \cdot \mathrm{s}^{\mathrm{n}}$ \\
\hline Flow index: & 0.3576 & unitless \\
\hline Impeller shear ratio: & 11 & unitless \\
\hline Impeller Power Number: & 6 & unitless \\
\hline
\end{tabular}

\begin{tabular}{|c|c|c|c|}
\hline & Full Scale & Pilot & Units \\
\hline Tank Dia.: & 144 & 23.2 & inches \\
\hline Tank Vol.: & 9500 & 40 & gallons \\
\hline Impeller Dia.: & 36 & 5.8 & inches \\
\hline
\end{tabular}

\begin{tabular}{|c|c|c|c|c|c|c|c|}
\hline \multirow{2}{*}{ Property } & \multirow{2}{*}{ Units } & \multirow{2}{*}{ Full Scale } & \multicolumn{5}{|c|}{$\begin{array}{c}\text { Scaling Method Used To Determine Pilot Scale } \\
\text { Properties }\end{array}$} \\
\hline & & & $\mathbf{N}_{\mathbf{R E}}$ & $\begin{array}{l}\text { Caver } \\
\mathbf{n} / \mathbf{N}_{\mathrm{TS}}\end{array}$ & $\mathbf{P} / \mathbf{V}$ & Ekato & $\mathbf{N}_{\mathrm{Fr}}$ \\
\hline Rotational Speed & RPM & 130 & 1201 & 807 & 439 & 382 & 324 \\
\hline $\mathrm{N}_{\mathrm{RE}}$ & unitless & 96153 & 96153 & 50053 & 18423 & 14635 & 11177 \\
\hline Cavern Size & unitless & 7.30 & 9.52 & 7.30 & 4.87 & 4.43 & 3.97 \\
\hline Tip Speed & $\mathrm{m} / \mathrm{s}$ & 6.22 & 9.26 & 6.22 & 3.39 & 2.94 & 2.50 \\
\hline Power & Watts & 46859 & 4008 & 1216 & 196 & 129 & 79 \\
\hline PV & $\mathrm{W} / \mathrm{m}^{3}$ & 1303 & 26474 & 8034 & 1294 & 850 & 520 \\
\hline Froude Number & unitless & 0.44 & 6.01 & 2.72 & 0.80 & 0.61 & 0.44 \\
\hline
\end{tabular}

Table 4-10 Dynamic/Kinematic Properties of $1 / 6^{\text {th }}$ Scale Using Various Sizing Methods - 10 Pa Fluid, 67 RPM

\begin{tabular}{|c|c|c|c|c|c|c|}
\hline \multicolumn{7}{|c|}{ Input Data } \\
\hline Fluid Density: & 1200.0 & $\mathrm{~kg} / \mathrm{m}^{3}$ & & & & \\
\hline Yield Stress: & 10 & $\mathrm{~Pa}\left(\mathrm{~N} / \mathrm{m}^{2}\right)$ & & & & \\
\hline Power Law Coef: & 2.774 & $\mathrm{~Pa} \cdot \mathrm{s}^{\mathrm{n} \prime}$ & & Full Scale & Pilot & Units \\
\hline Flow index: & 0.3576 & unitless & Tank Dia.: & 144 & 23.2 & inches \\
\hline Impeller shear ratio: & 11 & unitless & Tank Vol.: & 9500 & 40 & gallons \\
\hline Impeller Power Number: & 6 & unitless & Impeller Dia.: & 36 & 5.8 & inches \\
\hline
\end{tabular}

\begin{tabular}{cccccccc}
\hline & & \multicolumn{7}{c}{ Scaling Method Used To Determine Pilot Scale } \\
Property & Units & Full Scale & \multicolumn{3}{c}{ Properties } \\
& & & $\mathbf{N}_{\mathbf{R E}}$ & $\begin{array}{c}\text { Caver } \\
\mathbf{n} / \mathbf{N}_{\mathbf{T S}}\end{array}$ & $\mathbf{P} / \mathbf{V}$ & Ekato & $\mathbf{N}_{\mathbf{F r}}$ \\
\hline Rotational Speed & RPM & 67 & 619 & 416 & 226 & 197 & 167 \\
$N_{\text {RE }}$ & unitless & 32372 & 32372 & 16851 & 6202 & 4927 & 3763 \\
Cavern Size & unitless & 4.69 & 6.12 & 4.69 & 3.13 & 2.85 & 2.55 \\
Tip Speed & m/s & 3.21 & 4.77 & 3.21 & 1.75 & 1.52 & 1.29 \\
Power & Watts & 6415 & 549 & 167 & 27 & 18 & 11 \\
PV & W/m & 178 & 3624 & 1100 & 177 & 116 & 71 \\
Froude Number & unitless & 0.12 & 1.60 & 0.72 & 0.21 & 0.16 & 0.12 \\
\hline
\end{tabular}


WSRC-TR-2004-00436

REVISION 0

Table 4-11 Dynamic/Kinematic Properties of $1 / 6^{\text {th }}$ Scale Using Various Sizing Methods - 20 Pa Fluid, 130 RPM

\begin{tabular}{|c|c|c|}
\hline \multicolumn{2}{|c}{ Input Da } \\
\hline Fluid Density: & 1200.0 & $\mathrm{~kg} / \mathrm{m}^{3}$ \\
\hline Yield Stress: & 20 & $\mathrm{~Pa}\left(\mathrm{~N} / \mathrm{m}^{2}\right)$ \\
\hline Power Law Coef: & 7.162 & $\mathrm{~Pa} \cdot \mathrm{s}^{\mathrm{n}}$ \\
\hline Flow index: & 0.273 & unitless \\
\hline Impeller shear ratio: & 11 & unitless \\
\hline Impeller Power Number: & 6 & unitless \\
\hline
\end{tabular}

\begin{tabular}{|c|c|c|c|}
\hline & Full Scale & Pilot & Units \\
\hline Tank Dia.: & 144 & 23.2 & inches \\
\hline Tank Vol.: & 9500 & 40 & gallons \\
\hline Impeller Dia.: & 36 & 5.8 & inches \\
\hline
\end{tabular}

\begin{tabular}{cccccccc}
\hline & & & \multicolumn{5}{c}{ Scaling Method Used To Determine Pilot Scale } \\
Property & Units & Full Scale & \multicolumn{5}{c}{$\begin{array}{c}\text { Caver } \\
\text { Properties }\end{array}$} \\
& & & $\mathbf{N}_{\mathbf{R E}}$ & $\begin{array}{c}\mathbf{n}_{\mathbf{~}} \mathbf{N}_{\mathbf{T S}} \\
\text { P/V }\end{array}$ & Ekato & $\mathbf{N}_{\mathbf{F r}}$ \\
\hline Rotational Speed & $\mathrm{RPM}$ & 130 & 1077 & 807 & 439 & 382 & 324 \\
$\mathbf{N}_{\text {RE }}$ & unitless & 48702 & 48702 & 29586 & 10343 & 8120 & 6116 \\
Cavern Size & unitless & 5.80 & 7.03 & 5.80 & 3.86 & 3.52 & 3.15 \\
Tip Speed & $\mathrm{m} / \mathrm{s}$ & 6.22 & 8.31 & 6.22 & 3.39 & 2.94 & 2.50 \\
Power & Watts & 46859 & 2891 & 1216 & 196 & 129 & 79 \\
PV & W/m & 1303 & 19095 & 8034 & 1294 & 850 & 520 \\
Froude Number & unitless & 0.44 & 4.84 & 2.72 & 0.80 & 0.61 & 0.44 \\
\hline
\end{tabular}

Table 4-12 Dynamic/Kinematic Properties of $1 / 6^{\text {th }}$ Scale Using Various Sizing Methods - 20 Pa Fluid, 67 RPM

\begin{tabular}{|c|c|c|}
\hline \multicolumn{2}{|c}{ Input Da } \\
\hline Fluid Density: & 1200.0 & $\mathrm{~kg} / \mathrm{m}^{3}$ \\
\hline Yield Stress: & 20 & $\mathrm{~Pa}\left(\mathrm{~N} / \mathrm{m}^{2}\right)$ \\
\hline Power Law Coef: & 7.162 & $\mathrm{~Pa} \cdot \mathrm{s}^{\mathrm{n}^{\prime}}$ \\
\hline Flow index: & 0.273 & unitless \\
\hline Impeller shear ratio: & 11 & unitless \\
\hline Impeller Power Number: & 6 & unitless \\
\hline
\end{tabular}

\begin{tabular}{|c|c|c|c|}
\hline & Full Scale & Pilot & Units \\
\hline Tank Dia.: & 144 & 23.2 & inches \\
\hline Tank Vol.: & 9500 & 40 & gallons \\
\hline Impeller Dia.: & 36 & 5.8 & inches \\
\hline
\end{tabular}

\begin{tabular}{cccccccc}
\hline & & \multicolumn{7}{c}{ Scaling Method Used To Determine Pilot Scale } \\
Property & Units & Full Scale & \multicolumn{3}{c}{ Properties } \\
& & & $\mathbf{N}_{\mathbf{R E}}$ & $\begin{array}{c}\text { Caver } \\
\mathbf{n} / \mathbf{N}_{\mathbf{T S}}\end{array}$ & $\mathbf{P} / \mathbf{V}$ & Ekato & $\mathbf{N}_{\mathbf{F r}}$ \\
\hline Rotational Speed & RPM & 67 & 555 & 416 & 226 & 197 & 167 \\
N $_{\text {RE }}$ & unitless & 15502 & 15502 & 9418 & 3292 & 2585 & 1947 \\
Cavern Size & unitless & 3.73 & 4.52 & 3.73 & 2.48 & 2.26 & 2.03 \\
Tip Speed & m/s & 3.21 & 4.28 & 3.21 & 1.75 & 1.52 & 1.29 \\
Power & Watts & 6415 & 396 & 167 & 27 & 18 & 11 \\
PV & W/m & 178 & 2614 & 1100 & 177 & 116 & 71 \\
Froude Number & unitless & 0.12 & 1.28 & 0.72 & 0.21 & 0.16 & 0.12 \\
\hline
\end{tabular}


WSRC-TR-2004-00436

REVISION 0

\subsection{CONCLUSIONS}

Vortex formation increased significantly when the coil was removed, especially for the 5 Pa test fluid. Vortex formation can cause process upsets by entraining air into the process ${ }^{15}$ and can cause uneven mechanical loading on the agitator shaft and subsequent failure. It should be noted that scaling of the vortex phenomena is extremely uncertain and the $1 / 6^{\text {th }}$ scale results may not accurately reflect the severity of the problems that will occur in the full scale tank. However, removal of the coil did improve surface motion and solids distribution.

The $1 / 6^{\text {th }}$ Scale test results showed good surface motion for the $5 \mathrm{~Pa}$ and $10 \mathrm{~Pa}$ fluids at 25 gallons for the 330 RPM tests (scales to 6000 gallons and 103 RPM), but the $20 \mathrm{~Pa}$ fluid indicated borderline results with small areas of stagnation around the wall. Cavern formation was noted for all fluids at 40 gallons (9500 gallons) at this speed. Sample results from the homogeneity samples did not indicate that the $5 \mathrm{~Pa}$ fluid was uniform at 40 gallons and 330 RPM with the coils in the tank.

Laboratory Scale test utilizing power per unit volume as the scaling parameters had significant cavern formation at higher volumes and at lower volumes with high yield stress materials. Comparisons of sizing methods indicate a variety of results, where sizing using the Reynolds number or Froude number are not recommended. The other sizing methods discussed may be suitable, however, additional testing may be required.

It should be noted that the DWPF MFT agitator is currently configured with a high speed setting of 103 RPM and that no operational difficulties have been noted. Sample results from the MFT have agreed with sample results from the SME, indicating that adequate mixing has been maintained in the MFT at the lower agitator speed. In addition, scale up of the $1 / 6^{\text {th }}$ scale mixing test results to full scale process is very difficult and a variety of different methods that yield very different results are available.

\footnotetext{
${ }^{15}$ Stone, M.E., Marinik. A.R., Small Scale Mixing Tests for the DWPF Chemical Process Cell Vessels (U). March 2004. WSRC-TR-2004-00074.
} 
WSRC-TR-2004-00436

REVISION 0

\subsection{RECOMMENDATIONS}

A plan should be developed to address vortex formation prior to removal of the MFT coil assembly.

The CFD models developed for the MFT and SME vessels should be validated versus the $1 / 6^{\text {th }}$ scale results. Validation of the model will lead to improved results from the model and will allow better representation of the DWPF process by the model.

The rheological properties of actual DWPF process slurries should be measured. A flow curve that would allow yield stress and consistency to be determined would be ideal, but even a single point measurement of apparent viscosity would lead to valuable insight into process conditions and aid in the evaluation of process upsets. The amount of variability in the process could be determined if the analysis is performed on routine process samples.

The MFT and SME agitators should not operate continuously at the low speed setting (67 RPM) when the vessels are above 6000 gallons to reduce the potential for cavern formation.

Alternative means of reducing the erosion rate on the cooling/heating coils due to the irregular shaped frit are:

- Conversion of irregular shaped frit to spherical shaped frit which is processed from the irregular shaped frit.

- Raising the lower section of the cooling/heating coils above the discharge of the bottom impeller. Raising the coils would likely improve mixing in the vessel. 
WSRC-TR-2004-00436

REVISION 0

\section{APPENDIX A. Mixing Data for all Tests}

\section{Coils}

\section{Pascal}

\begin{tabular}{|l|l|l|l|l|l|l|l|}
\hline Time & Agitator Speed & Tank Level & Density Meter & Temperature & Air Flow & Agitator Power & Power/Volume \\
\hline
\end{tabular}

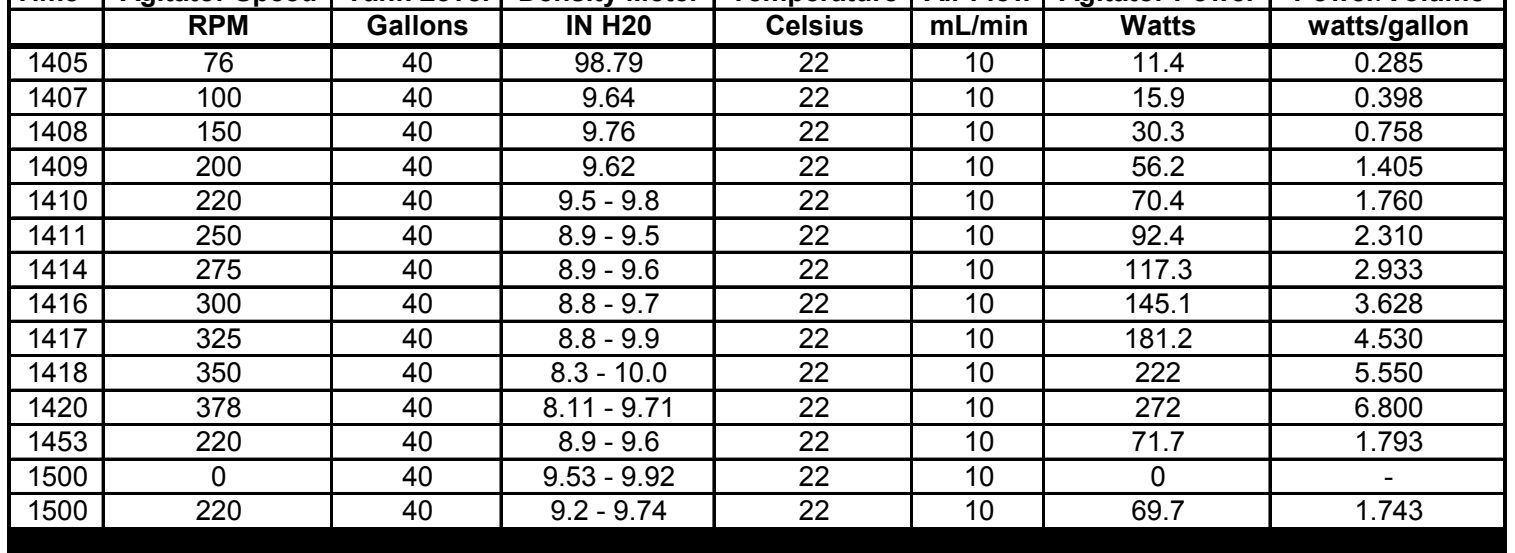

\begin{tabular}{|l|c|c|c|c|c|c|c|}
\hline 800 & 0 & 25 & 10.4 & 23 & 10 & - & \\
\hline 926 & 60 & 25 & 9.6 & 23 & 10 & 8.7 & 0.35 \\
\hline 947 & 150 & 25 & 9.6 & 23 & 10 & 29.9 & 1.20 \\
\hline 951 & 220 & 25 & 9.49 & 23 & 10 & 63.5 & 2.54 \\
\hline 800 & 300 & 25 & $8.7-9.5$ & 22 & 10 & 188.7 & 7.55 \\
\hline 954 & 330 & 25 & $8.8-10.0$ & 23 & 10 & 171.6 & 6.86 \\
\hline 959 & 390 & 25 & $8.8-9.9$ & 23 & 10 & 275 & 11.00 \\
\hline
\end{tabular}

\begin{tabular}{|c|c|c|c|c|c|c|c|}
\hline Time & Agitator Speed & Tank Level & Density Meter & Temperature & Air Flow & Agitator Power & Power/Volume \\
\hline
\end{tabular}

\begin{tabular}{|c|c|c|c|c|c|c|c|}
\hline & RPM & Gallons & IN H2O & Celsius & $\mathrm{mL} / \mathrm{min}$ & Watts & watts/gallon \\
\hline 1050 & 74 & 25 & 9.7 & 21 & 10 & 25.9 & 1.04 \\
\hline 1051 & 100 & 25 & 9.7 & 21 & 10 & 36.7 & 1.47 \\
\hline 1052 & 150 & 25 & 9.62 & 21 & 10 & 60.9 & 2.44 \\
\hline 1054 & 175 & 25 & 9.52 & 21 & 10 & 75.1 & 3.00 \\
\hline 1055 & 200 & 25 & 9.5 & 21 & 10 & 92.1 & 3.68 \\
\hline 1059 & 220 & 25 & 9.56 & 21 & 10 & 107.2 & 4.29 \\
\hline 1105 & 300 & 25 & 9.69 & 21 & 10 & 178.5 & 7.14 \\
\hline 1107 & 330 & 25 & 9.45 & 21 & 10 & 207 & 8.28 \\
\hline 1110 & 345 & 25 & 9.45 & 21 & 10 & 218 & 8.72 \\
\hline 1124 & 75 & 25 & 9.43 & 21 & 10 & 13.5 & 0.54 \\
\hline 1125 & 100 & 25 & 9.83 & 21 & 10 & 15.8 & 0.63 \\
\hline 1126 & 150 & 25 & 9.5 & 21 & 10 & 23.1 & 0.92 \\
\hline 1127 & 200 & 25 & 9.6 & 21 & 10 & 36.8 & 1.47 \\
\hline 1129 & 220 & 25 & 9.81 & 21 & 10 & 43.3 & 1.73 \\
\hline 1131 & 250 & 25 & 9.55 & 21 & 10 & 55.5 & 2.22 \\
\hline 1133 & 300 & 25 & 9.26 & 21 & 10 & 85.4 & 3.42 \\
\hline 1135 & 330 & 25 & 9.03 & 21 & 10 & 111 & 4.44 \\
\hline 1139 & 375 & 25 & 8.88 & 21 & 10 & 162 & 6.48 \\
\hline 1140 & 400 & 25 & 10.51 & 21 & 10 & 196 & 7.84 \\
\hline 1141 & 420 & 25 & 8.54 & 21 & 10 & 226 & 9.04 \\
\hline 1145 & 445 & 25 & 10.6 & 21 & 10 & 267 & 10.68 \\
\hline
\end{tabular}


WSRC-TR-2004-00436

REVISION 0

\begin{tabular}{|c|c|c|c|c|c|c|c|}
\hline Time & Agitator Speed & Tank Level & Density Meter & Temperature & Air Flow & Agitator Power & Power/Volume \\
\hline & RPM & Gallons & IN H20 & Celsius & mL/min & Watts & watts/gallon \\
\hline 1445 & 75 & 38 & 9.38 & 21 & 10 & 12.5 & 0.33 \\
\hline 1449 & 100 & 38 & 9.37 & 21 & 10 & 14.8 & 0.39 \\
\hline 1450 & 150 & 38 & 9.44 & 21 & 10 & 22.7 & 0.60 \\
\hline 1451 & 200 & 38 & 9.52 & 21 & 10 & 37.6 & 0.99 \\
\hline 1452 & 220 & 38 & 9.2 & 21 & 10 & 46 & 1.21 \\
\hline 1500 & 250 & 38 & 9.12 & 21 & 10 & 59.6 & 1.57 \\
\hline 1501 & 300 & 38 & 8.49 & 21 & 10 & 92.43 & 2.43 \\
\hline 1502 & 330 & 38 & 8.67 & 21 & 10 & 117.4 & 3.09 \\
\hline 1508 & 375 & 38 & 9.22 & 21 & 10 & 169.9 & 4.47 \\
\hline 1509 & 400 & 38 & 8.99 & 21 & 10 & 199 & 5.24 \\
\hline 1510 & 420 & 38 & 8.4 & 21 & 10 & 226 & 5.95 \\
\hline 1514 & 437 & 38 & 6.54 & 21 & 10 & 261 & 6.87 \\
\hline
\end{tabular}

10 Pascal

\begin{tabular}{|c|c|c|c|c|c|c|c|}
\hline Time & Agitator Speed & Tank Level & Density Meter & Temperature & Air Flow & Agitator Power & Power/Volume \\
\hline & RPM & Gallons & IN H2O & Celsius & $\mathrm{mL} / \mathrm{min}$ & Watts & watts/gallon \\
\hline 1432 & 220 & 40 & 9.65 & 21 & 10 & 111.7 & 2.7925 \\
\hline 1455 & 220 & 40 & 9.57 & 22 & 10 & 104.5 & 2.6125 \\
\hline 1456 & 75 & 40 & 9.64 & 22 & 10 & 24 & 0.6 \\
\hline 1457 & 100 & 40 & 9.49 & 22 & 10 & 33.2 & 0.83 \\
\hline 1500 & 150 & 40 & 9.83 & 22 & 10 & 56.6 & 1.415 \\
\hline 1501 & 200 & 40 & 9.52 & 22 & 10 & 86.2 & 2.155 \\
\hline 1502 & 250 & 40 & 9.07 & 22 & 10 & 124.5 & 3.1125 \\
\hline 1502 & 275 & 40 & 9.52 & 22 & 10 & 147.5 & 3.6875 \\
\hline 1503 & 300 & 40 & 9.3 & 22 & 10 & 174.5 & 4.3625 \\
\hline 1503 & 330 & 40 & 8.59 & 22 & 10 & 202 & 5.05 \\
\hline 1504 & 350 & 40 & 10.81 & 22 & 10 & 227 & 5.675 \\
\hline 1347 & 220 & 25 & 9.57 & 22 & 10 & 111 & 4.44 \\
\hline 1410 & 220 & 25 & 9.72 & 22 & 10 & 100.3 & 4.012 \\
\hline 1417 & 220 & 25 & 9.55 & 22 & 10 & 97.3 & 3.892 \\
\hline 1421 & 75 & 25 & 9.83 & 22 & 10 & 22.5 & 0.9 \\
\hline 1425 & 100 & 25 & 9.38 & 22 & 10 & 31.6 & 1.264 \\
\hline 1426 & 150 & 25 & 9.74 & 22 & 10 & 53.6 & 2.144 \\
\hline 1427 & 200 & 25 & 9.54 & 22 & 10 & 82.6 & 3.304 \\
\hline 1428 & 250 & 25 & 9.65 & 22 & 10 & 119.2 & 4.768 \\
\hline 1429 & 275 & 25 & 9.49 & 22 & 10 & 140 & 5.6 \\
\hline 1430 & 300 & 25 & 9.43 & 22 & 10 & 166.6 & 6.664 \\
\hline 1431 & 330 & 25 & 9.3 & 22 & 10 & 195.3 & 7.812 \\
\hline 1432 & 352 & 25 & 8.88 & 22 & 10 & 215 & 8.6 \\
\hline 1023 & 75 & 6 & 3.66 & 20 & 10 & 27.8 & 4.63 \\
\hline 1023 & 100 & 6 & 3.81 & 20 & 10 & 39 & 6.50 \\
\hline 1024 & 150 & 6 & 3.59 & 20 & 10 & 60.5 & 10.08 \\
\hline 1025 & 200 & 6 & 3.61 & 20 & 10 & 86.3 & 14.38 \\
\hline 1026 & 220 & 6 & 3.75 & 20 & 10 & 97.9 & 16.32 \\
\hline 1027 & 250 & 6 & 3.73 & 20 & 10 & 116.1 & 19.35 \\
\hline 1028 & 275 & 6 & 3.94 & 20 & 10 & 129.8 & 21.63 \\
\hline 1029 & 300 & 6 & 3.67 & 20 & 10 & 143.5 & 23.92 \\
\hline 1030 & 330 & 6 & 3.72 & 20 & 10 & 160.2 & 26.70 \\
\hline 1031 & 354 & 6 & 3.81 & 20 & 10 & 175.2 & 29.20 \\
\hline
\end{tabular}


WSRC-TR-2004-00436

REVISION 0

\begin{tabular}{|c|c|c|c|c|c|c|c|}
\hline Time & Agitator Speed & Tank Level & Torque & Temperature & Air Flow & Agitator Power & Power/Volume \\
\hline & RPM & Gallons & N-cm & Celsius & mL/min & Watts & watts/gallon \\
\hline 1438 & 330 & 40 & 196 & 21 & 10 & 120 & 3 \\
\hline 1440 & 360 & 40 & 232 & 21 & 10 & 153 & 3.825 \\
\hline 1441 & 420 & 40 & 324 & 21 & 10 & 235 & 5.875 \\
\hline 1508 & 330 & 25 & 182 & 21 & 10 & 114 & 4.56 \\
\hline 1514 & 420 & 25 & 295 & 21 & 10 & 217 & 8.68 \\
\hline 1517 & 450 & 25 & 342 & 21 & 10 & 270 & 10.8 \\
\hline
\end{tabular}

\section{Pascal}

\begin{tabular}{|l|l|l|l|l|l|l|l} 
Time & Agitator Speed & Tank Level & Density Meter & Temperature & Air Flow & Agitator Power & Power/ Volume \\
\hline
\end{tabular}

\begin{tabular}{|c|c|c|c|c|c|c|c|}
\hline & RPM & Gallons & IN H20 & Celsius & $\mathbf{~ m L / m i n}$ & Watts & Watts/Gallon \\
\hline 1634 & 75 & 40 & 9.69 & 22 & 10 & 20.9 & 0.52 \\
\hline 1635 & 100 & 40 & 9.22 & 22 & 10 & 29.9 & 0.75 \\
\hline 1636 & 150 & 40 & 9.29 & 22 & 10 & 48.9 & 1.22 \\
\hline 1637 & 200 & 40 & 9.39 & 22 & 10 & 77.7 & 1.94 \\
\hline 1638 & 220 & 40 & 10.01 & 22 & 10 & 91.2 & 2.28 \\
\hline 1639 & 250 & 40 & 9.68 & 22 & 10 & 114.2 & 2.86 \\
\hline 1640 & 275 & 40 & 9.44 & 22 & 10 & 135.6 & 3.39 \\
\hline 1641 & 300 & 40 & 9.02 & 22 & 10 & 161.1 & 4.03 \\
\hline 1642 & 330 & 40 & 9.79 & 22 & 10 & 193.6 & 4.84 \\
\hline 1643 & 352 & 40 & 9.5 & 22 & 10 & 214 & 5.35 \\
\hline
\end{tabular}

\begin{tabular}{|c|c|c|c|c|c|c|c|}
\hline 931 & 75 & 25 & 10.08 & 21 & 10 & 24.2 & 0.97 \\
\hline 934 & 100 & 25 & 9.92 & 21 & 10 & 33.9 & 1.36 \\
\hline 936 & 150 & 25 & 9.53 & 21 & 10 & 56.3 & 2.25 \\
\hline 938 & 200 & 25 & 9.25 & 21 & 10 & 87 & 3.48 \\
\hline 926 & 222 & 25 & 9.66 & 21 & 10 & 108 & 4.32 \\
\hline 940 & 251 & 25 & 9.23 & 21 & 10 & 125.7 & 5.03 \\
\hline 942 & 275 & 25 & 9.79 & 21 & 10 & 147.8 & 5.91 \\
\hline 944 & 300 & 25 & 9.44 & 21 & 10 & 172.6 & 6.90 \\
\hline 948 & 330 & 25 & 9.28 & 21 & 10 & 195 & 7.80 \\
\hline 951 & 347 & 25 & 9.88 & 21 & 10 & 209 & 8.36 \\
\hline 1358 & 75 & 6 & 4.79 & 21 & 10 & 26.2 & 4.37 \\
\hline 1400 & 100 & 6 & 4.83 & 21 & 10 & 36.9 & 6.15 \\
\hline 1402 & 150 & 6 & 4.84 & 21 & 10 & 59.6 & 9.93 \\
\hline 1403 & 200 & 6 & 4.88 & 21 & 10 & 85.6 & 14.27 \\
\hline 1404 & 220 & 6 & 4.46 & 21 & 10 & 97.5 & 16.25 \\
\hline 1405 & 250 & 6 & 4.7 & 21 & 10 & 115.7 & 19.28 \\
\hline 1406 & 275 & 6 & 4.84 & 21 & 10 & 130.7 & 21.78 \\
\hline 1407 & 300 & 6 & 5.04 & 21 & 10 & 148.3 & 24.72 \\
\hline 1408 & 330 & 6 & 4.59 & 21 & 10 & 162.5 & 27.08 \\
\hline 1409 & 357 & 6 & 5.09 & 21 & 10 & 184 & 30.67 \\
\hline
\end{tabular}

\begin{tabular}{|c|c|c|c|c|c|c|c|}
\hline Time & Agitator Speed & Tank Level & Torque & Temperature & Air Flow & Agitator Power & Power/ Volume \\
\hline & RPM & Gallons & N-cm & Celsius & mL/min & Watts & Watts/Gallon \\
\hline 1222 & 420 & 40 & 300 & 22 & 10 & 220 & 5.5 \\
\hline 1227 & 450 & 40 & 338 & 22 & 10 & 265 & 6.625 \\
\hline 1300 & 330 & 40 & 189 & 22 & 10 & 113 & 2.825 \\
\hline 1310 & 420 & 40 & 313 & 22 & 10 & 228 & 5.7 \\
\hline
\end{tabular}

\begin{tabular}{|c|c|c|c|c|c|c|c|}
\hline Time & Agitator Speed & Tank Level & Torque & Temperature & Air Flow & Agitator Power & Power/Volume \\
\hline & RPM & Gallons & N-cm & Celsius & mL/min & Watts & watts/gallon \\
\hline 1438 & 330 & 40 & 196 & 21 & 10 & 120 & 3 \\
\hline 1440 & 360 & 40 & 232 & 21 & 10 & 153 & 3.825 \\
\hline 1441 & 420 & 40 & 324 & 21 & 10 & 235 & 5.875 \\
\hline 1508 & 330 & 25 & 182 & 21 & 10 & 114 & 4.56 \\
\hline 1514 & 420 & 25 & 295 & 21 & 10 & 217 & 8.68 \\
\hline 1517 & 450 & 25 & 342 & 21 & 10 & 270 & 10.8 \\
\hline
\end{tabular}


WSRC-TR-2004-00436

REVISION 0

\begin{tabular}{|c|c|c|c|c|c|c|c|}
\hline \multicolumn{8}{|c|}{$\begin{array}{c}\text { Coils Removed } \\
5 \text { Pascal }\end{array}$} \\
\hline Time & $\begin{array}{c}\text { Agitator Speed } \\
\text { RPM }\end{array}$ & $\begin{array}{l}\text { Tank Level } \\
\text { Gallons }\end{array}$ & $\begin{array}{c}\text { Density Meter } \\
\text { IN H2O }\end{array}$ & $\begin{array}{c}\text { Temperature } \\
\text { Celsius }\end{array}$ & $\begin{array}{l}\text { Air Flow } \\
\mathrm{mL} / \mathrm{min}\end{array}$ & $\begin{array}{c}\text { Agitator Power } \\
\text { Watts }\end{array}$ & $\begin{array}{c}\text { Power/Volume } \\
\text { Watts/Gallon }\end{array}$ \\
\hline 1205 & 0 & 6 & 3.25 & 25 & 10 & 0.2 & 0.03 \\
\hline 1215 & 150 & 6 & 3.4 & 23 & 10 & 59.0 & 9.83 \\
\hline 1218 & 220 & 6 & 3.3 & 23 & 10 & 88.3 & 14.72 \\
\hline 1224 & 330 & 6 & 3.4 & 23 & 10 & 151.6 & 25.27 \\
\hline 1226 & 190 & 6 & 3.4 & 23 & 10 & 68.7 & 11.45 \\
\hline 1437 & 98 & 25 & 9.8 & 22 & 10 & 34.1 & 1.36 \\
\hline 1440 & 150 & 25 & 9.5 & 22 & 10 & 59.0 & 2.36 \\
\hline 1504 & 150 & 25 & 9.4 & 22 & 10 & 49.2 & 1.97 \\
\hline 1444 & 220 & 25 & 9.35 & 22 & 10 & 100.4 & 4.02 \\
\hline 1449 & 330 & 25 & 9.3 & 22 & 10 & 179.2 & 7.17 \\
\hline 1457 & 360 & 25 & 9.2 & 22 & 10 & 186.9 & 7.48 \\
\hline 754 & 0 & 40 & 10.4 & 22 & 10 & 0.1 & 0.00 \\
\hline 810 & 220 & 40 & 10.0 & 22 & 10 & 112.9 & 2.82 \\
\hline 1010 & 220 & 40 & 9.9 & 22 & 10 & 85.8 & 2.15 \\
\hline 1027 & 330 & 40 & 10.0 & 22 & 10 & 166.5 & 4.16 \\
\hline 1220 & 360 & 40 & 9.4 & 23 & 10 & 185.0 & 4.63 \\
\hline
\end{tabular}

\begin{tabular}{|c|c|c|c|c|c|c|c|}
\hline \multicolumn{8}{|c|}{10 Pascal } \\
\hline Time & $\begin{array}{c}\text { Agitator Speed } \\
\text { RPM }\end{array}$ & $\begin{array}{c}\text { Tank Level } \\
\text { Gallons }\end{array}$ & $\begin{array}{c}\text { Density Meter } \\
\text { IN H20 }\end{array}$ & $\begin{array}{c}\text { Temperature } \\
\text { Celsius }\end{array}$ & $\begin{array}{l}\text { Air Flow } \\
\mathrm{mL} / \mathrm{min}\end{array}$ & $\begin{array}{c}\text { Agitator Power } \\
\text { Watts }\end{array}$ & $\begin{array}{c}\text { Power/Volume } \\
\text { Watts/Gallon }\end{array}$ \\
\hline 1014 & 0 & 6 & 6.34 & 21 & 10 & -0.2 & - \\
\hline 1049 & 75 & 6 & 3.76 & 22 & 10 & 23.2 & 3.87 \\
\hline 1050 & 150 & 6 & 3.71 & 22 & 10 & 51.9 & 8.65 \\
\hline 1054 & 190 & 6 & 3.68 & 22 & 10 & 66.6 & 11.10 \\
\hline 1017 & 220 & 6 & 3.75 & 22 & 10 & 92.2 & 15.37 \\
\hline 1028 & 220 & 6 & 3.87 & 22 & 10 & 90.6 & 15.10 \\
\hline 1047 & 220 & 6 & 3.73 & 22 & 10 & 82.7 & 13.78 \\
\hline 1051 & 330 & 6 & 3.69 & 22 & 10 & 143.3 & 23.88 \\
\hline 1318 & 100 & 25 & 9.62 & 22 & 10 & 31.3 & 1.25 \\
\hline 1319 & 150 & 25 & 9.54 & 22 & 10 & 51.6 & 2.06 \\
\hline 1247 & 220 & 25 & 9.5 & 22 & 10 & 105.2 & 4.21 \\
\hline 1322 & 330 & 25 & 8.7 & 22 & 10 & 187.5 & 7.50 \\
\hline 1326 & 360 & 25 & 9.3 & 22 & 10 & 199.0 & 7.96 \\
\hline 827 & 220 & 40 & 9.71 & 22 & 10 & 113.0 & 2.83 \\
\hline 855 & 220 & 40 & 9.82 & 22 & 10 & 101.6 & 2.54 \\
\hline 917 & 220 & 40 & 9.98 & 22 & 10 & 92.0 & 2.30 \\
\hline 924 & 220 & 40 & 9.7 & 22 & 10 & 96.9 & 2.42 \\
\hline 924 & 330 & 40 & 8.64 & 22 & 10 & 189.6 & 4.74 \\
\hline 925 & 348 & 40 & 8.37 & 22 & 10 & 204.0 & 5.10 \\
\hline Time & $\begin{array}{c}\text { Agitator Speed } \\
\text { RPM }\end{array}$ & $\begin{array}{l}\text { Tank Level } \\
\text { Gallons }\end{array}$ & $\begin{array}{c}\text { Torque } \\
\mathrm{N}-\mathrm{cm}\end{array}$ & $\begin{array}{c}\text { Temperature } \\
\text { Celsius }\end{array}$ & $\begin{array}{l}\text { Air Flow } \\
\mathrm{mL} / \mathrm{min}\end{array}$ & $\begin{array}{l}\text { Agitator Power } \\
\text { Watts }\end{array}$ & $\begin{array}{l}\text { Power/Volume } \\
\text { Watts/Gallon }\end{array}$ \\
\hline 1540 & 330 & 25 & 154 & 20 & 10 & 100.0 & 4.00 \\
\hline 1545 & 420 & 25 & 227 & 20 & 10 & 170.0 & 6.80 \\
\hline 1550 & 450 & 25 & 242 & 20 & 10 & 200.0 & 8.00 \\
\hline 1608 & 420 & 40 & 283 & 20 & 10 & 208.0 & 5.20 \\
\hline 1609 & 330 & 40 & 182 & 20 & 10 & 113.0 & 2.83 \\
\hline 1610 & 350 & 40 & 201 & 21 & 10 & 130.0 & 3.25 \\
\hline 1612 & 380 & 40 & 243 & 21 & 10 & 162.4 & 4.06 \\
\hline 1613 & 420 & 40 & 282 & 21 & 10 & 205.0 & 5.13 \\
\hline 1615 & 450 & 40 & 309 & 21 & 10 & 243.0 & 6.08 \\
\hline
\end{tabular}


WSRC-TR-2004-00436

REVISION 0

\begin{tabular}{|c|c|c|c|c|c|c|c|}
\hline \multicolumn{8}{|c|}{20 Pascal } \\
\hline Time & $\begin{array}{c}\text { Agitator Speed } \\
\text { RPM }\end{array}$ & $\begin{array}{c}\text { Tank Level } \\
\text { Gallons }\end{array}$ & $\begin{array}{c}\text { Density Meter } \\
\text { IN H2O }\end{array}$ & $\begin{array}{c}\text { Temperature } \\
\text { Celsius }\end{array}$ & $\begin{array}{c}\text { Air Flow } \\
\mathrm{mL} / \mathrm{min}\end{array}$ & $\begin{array}{c}\text { Agitator Power } \\
\text { Watts }\end{array}$ & $\begin{array}{l}\text { Power/Volume } \\
\text { Watts/Gallon }\end{array}$ \\
\hline 817 & 75 & 6 & 4.39 & 21 & 10 & 28.4 & 4.73 \\
\hline 819 & 100 & 6 & 4.54 & 21 & 10 & 40.0 & 6.67 \\
\hline 820 & 150 & 6 & 4.52 & 21 & 10 & 64.8 & 10.80 \\
\hline 821 & 200 & 6 & 4.49 & 21 & 10 & 92.5 & 15.42 \\
\hline 823 & 220 & 6 & 4.42 & 21 & 10 & 104.9 & 17.48 \\
\hline 825 & 250 & 6 & 4.51 & 21 & 10 & 116.1 & 19.35 \\
\hline 826 & 275 & 6 & 4.82 & 21 & 10 & 131.5 & 21.92 \\
\hline 827 & 300 & 6 & 4.72 & 21 & 10 & 146.8 & 24.47 \\
\hline 827 & 330 & 6 & 4.59 & 21 & 10 & 167.9 & 27.98 \\
\hline 829 & 350 & 6 & 4.50 & 21 & 10 & 176.7 & 29.45 \\
\hline 924 & 75 & 25 & 9.63 & 21 & 10 & 28.1 & 1.12 \\
\hline 925 & 100 & 25 & 9.5 & 21 & 10 & 38.8 & 1.55 \\
\hline 926 & 150 & 25 & 9.52 & 21 & 10 & 61.8 & 2.47 \\
\hline 928 & 200 & 25 & 9.48 & 21 & 10 & 95.0 & 3.80 \\
\hline 929 & 220 & 25 & 9.32 & 21 & 10 & 109.7 & 4.39 \\
\hline 931 & 250 & 25 & 9.22 & 21 & 10 & 132.1 & 5.28 \\
\hline 933 & 275 & 25 & 9.64 & 21 & 10 & 153.1 & 6.12 \\
\hline 934 & 300 & 25 & 10.03 & 21 & 10 & 180.4 & 7.22 \\
\hline 936 & 330 & 25 & 9.14 & 21 & 10 & 207.0 & 8.28 \\
\hline 938 & 346 & 25 & 9.47 & 21 & 10 & 217.0 & 8.68 \\
\hline 941 & 330 & 25 & - & 21 & 10 & 196.0 & 7.84 \\
\hline 942 & 345 & 25 & 9.74 & 21 & 10 & 210.0 & 8.40 \\
\hline 1155 & 75 & 40 & 9.94 & 21 & 10 & 23.2 & 0.58 \\
\hline 1159 & 100 & 40 & 9.64 & 21 & 10 & 31.7 & 0.79 \\
\hline 1159 & 150 & 40 & 9.57 & 21 & 10 & 54.9 & 1.37 \\
\hline 1200 & 200 & 40 & 10.04 & 21 & 10 & 82.1 & 2.05 \\
\hline 1201 & 220 & 40 & 10.08 & 21 & 10 & 94.7 & 2.37 \\
\hline 1203 & 250 & 40 & 9.92 & 21 & 10 & 115.8 & 2.90 \\
\hline 1204 & 275 & 40 & 9.32 & 21 & 10 & 138.3 & 3.46 \\
\hline 1205 & 300 & 40 & 9.42 & 21 & 10 & 163.0 & 4.08 \\
\hline 1206 & 330 & 40 & 10 & 21 & 10 & 197.0 & 4.93 \\
\hline 1209 & 351.8 & 40 & 9.87 & 21 & 10 & 217.0 & 5.43 \\
\hline Time & $\begin{array}{c}\text { Agitator Speed } \\
\text { RPM }\end{array}$ & $\begin{array}{c}\text { Tank Level } \\
\text { Gallons }\end{array}$ & $\begin{array}{c}\text { Torque } \\
\mathrm{N}-\mathrm{cm}\end{array}$ & $\begin{array}{c}\text { Temperature } \\
\text { Celsius }\end{array}$ & $\begin{array}{l}\text { Air Flow } \\
\mathrm{mL} / \mathrm{min}\end{array}$ & $\begin{array}{c}\text { Agitator Power } \\
\text { Watts }\end{array}$ & $\begin{array}{l}\text { Power/Volume } \\
\text { Watts/Gallon }\end{array}$ \\
\hline 1010 & 420 & 25 & 288 & 21 & 10 & 213.0 & 8.52 \\
\hline 1017 & 330 & 25 & 166 & 21 & 10 & 102.0 & 4.08 \\
\hline 1035 & 330 & 40 & 170 & 21 & 10 & 111.0 & 2.78 \\
\hline 1037 & 420 & 40 & 310 & 21 & 10 & 210.0 & 5.25 \\
\hline 1043 & 450 & 40 & 310 & 21 & 10 & 250.0 & 6.25 \\
\hline
\end{tabular}


WSRC-TR-2004-00436

REVISION 0

\section{APPENDIX B. Composition of Simulant Samples}

\begin{tabular}{|c|c|c|c|c|c|c|c|}
\hline & \multicolumn{2}{|c|}{5 Pascals } & \multicolumn{2}{|c|}{10 Pascals } & 10 Pascals & \multicolumn{2}{|c|}{20 Pascals } \\
\hline Firt $418(\mathrm{~g})$ & 75.00 & 0.00 & 75.00 & 0.00 & & 75.00 & 0.00 \\
\hline Xanthan Gum (g) & 0.88 & 1.25 & 2.63 & 3.75 & & 3.50 & 5.00 \\
\hline Kathon $(\mathrm{g})$ & 0.35 & 0.50 & 0.35 & 0.49 & & 0.35 & 0.49 \\
\hline $\mathrm{DI} \mathrm{H} 2 \mathrm{O}(\mathrm{g})$ & 173.78 & 248.25 & 172.03 & 245.76 & & 171.15 & 244.51 \\
\hline Sample Number & SMMS-0006 & SMMS-0007 & SMMS-0008 & SMMS-0009 & & SMMS-0010 & SMMS-0011 \\
\hline Firt $418(\mathrm{~g})$ & 75.03 & 0.00 & 75.00 & 0.00 & 0.00 & 75.00 & 0.00 \\
\hline Xanthan Gum (g) & 0.44 & 0.63 & 1.05 & 1.75 & 3.75 & 1.58 & 3.25 \\
\hline Kathon $(\mathrm{g})$ & 0.36 & 0.51 & 0.36 & 0.50 & 0.00 & 0.35 & 0.50 \\
\hline $\mathrm{DI} \mathrm{H} 2 \mathrm{O}(\mathrm{g})$ & 174.22 & 248.90 & 173.61 & 247.80 & 246.23 & 173.11 & 246.30 \\
\hline Sample Number & SMMS-0012 & SMMS-0013 & SMMS-0014 & SMMS-0015 & SMMS-0018 & SMMS-0016 & SMMS-0017 \\
\hline Frit (g) & 75.00 & 0.00 & 75.00 & 0.00 & & 0.00 & \\
\hline X.G. (g) & 0.60 & 0.98 & 0.96 & 1.63 & & 3.00 & \\
\hline Kathon $(\mathrm{g})$ & 0.35 & 0.50 & 0.35 & 0.50 & & 0.50 & \\
\hline Water (g) & 174.10 & 248.50 & 173.70 & 247.90 & & 246.50 & \\
\hline Sample Number & SMMS-0019 & SMMS-0020 & SMMS-0021 & SMMS-0022 & & SMMS-0023 & \\
\hline
\end{tabular}




\section{APPENDIX C. Rheograms of Simulant Preparation}
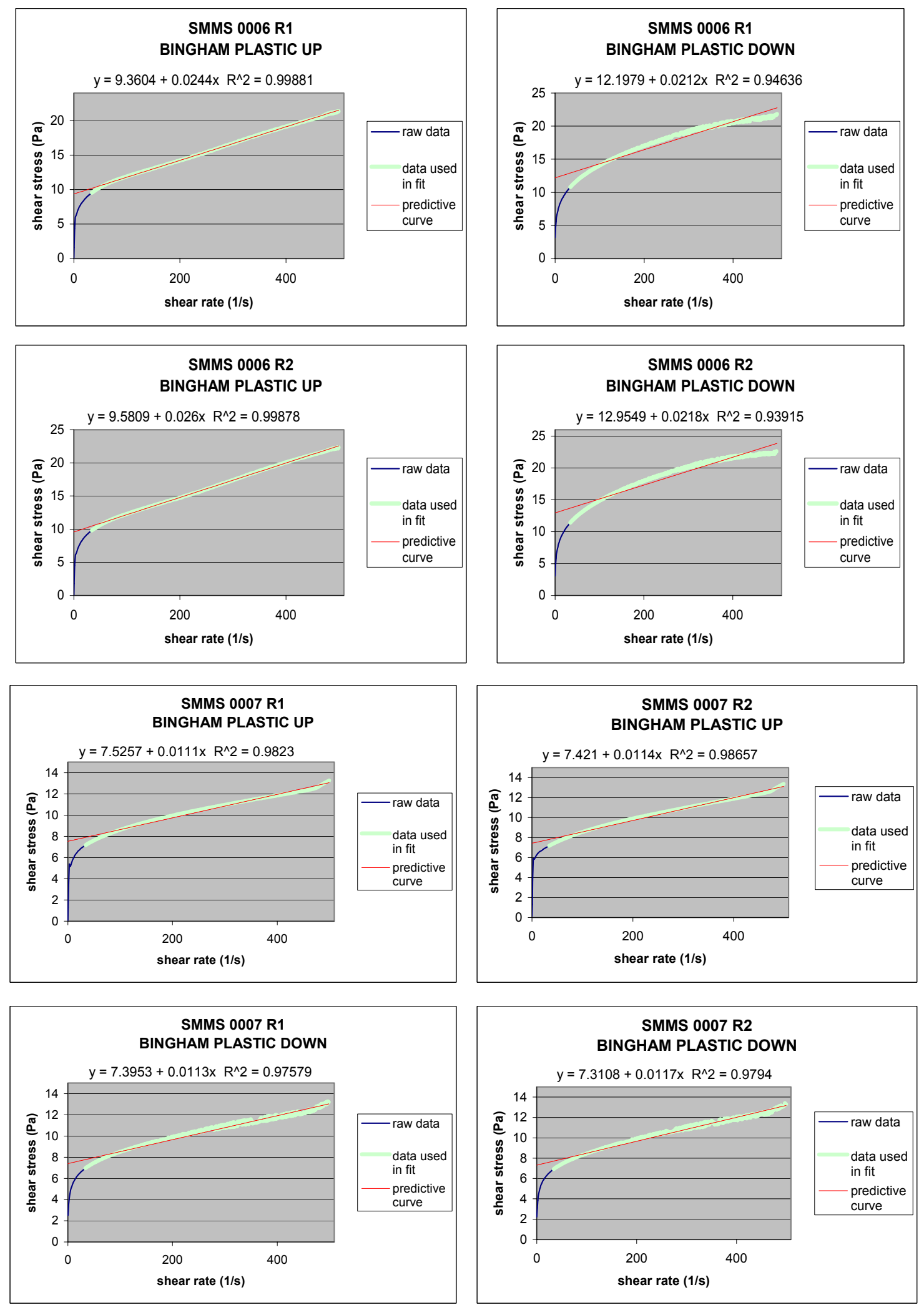

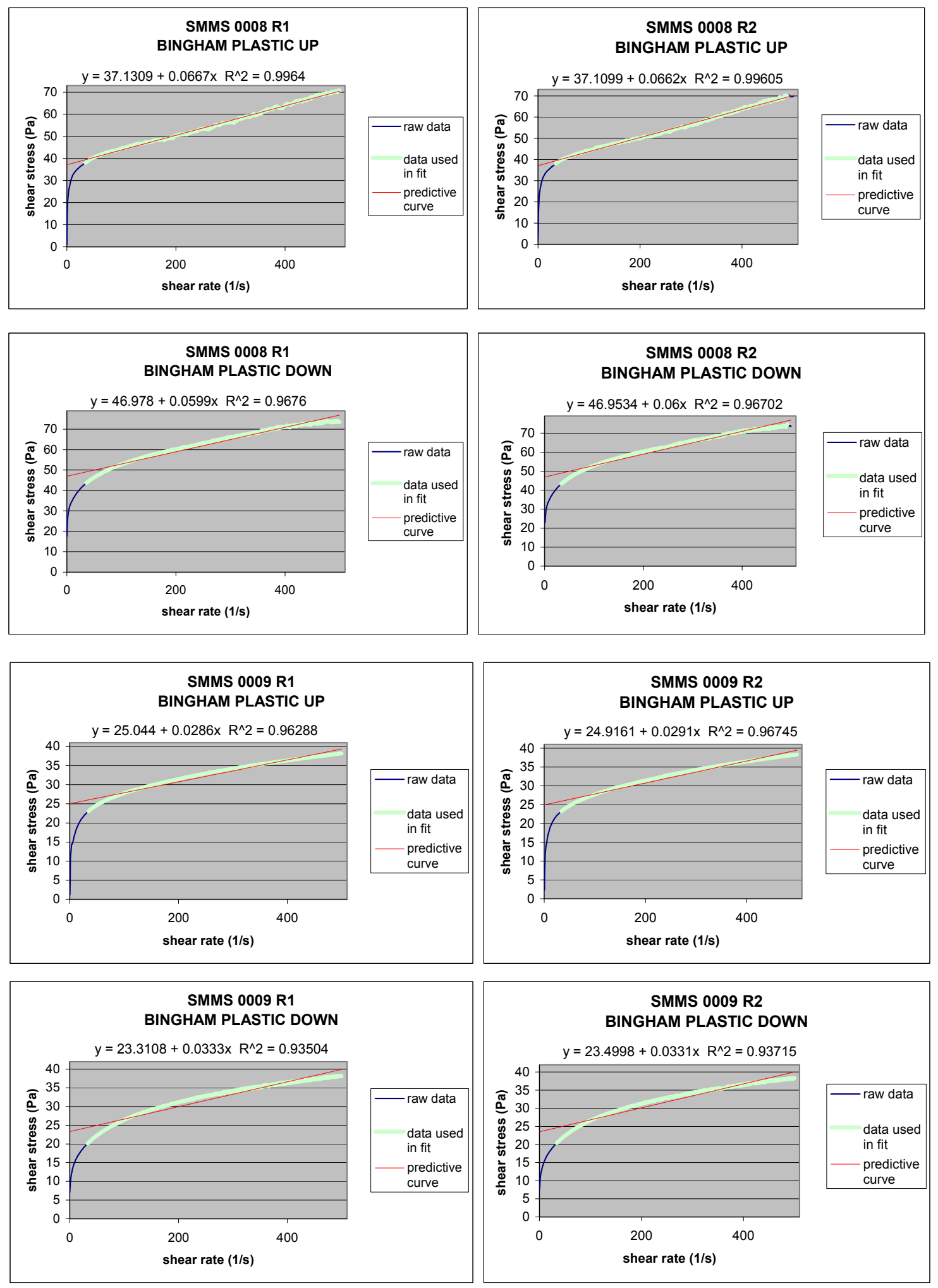

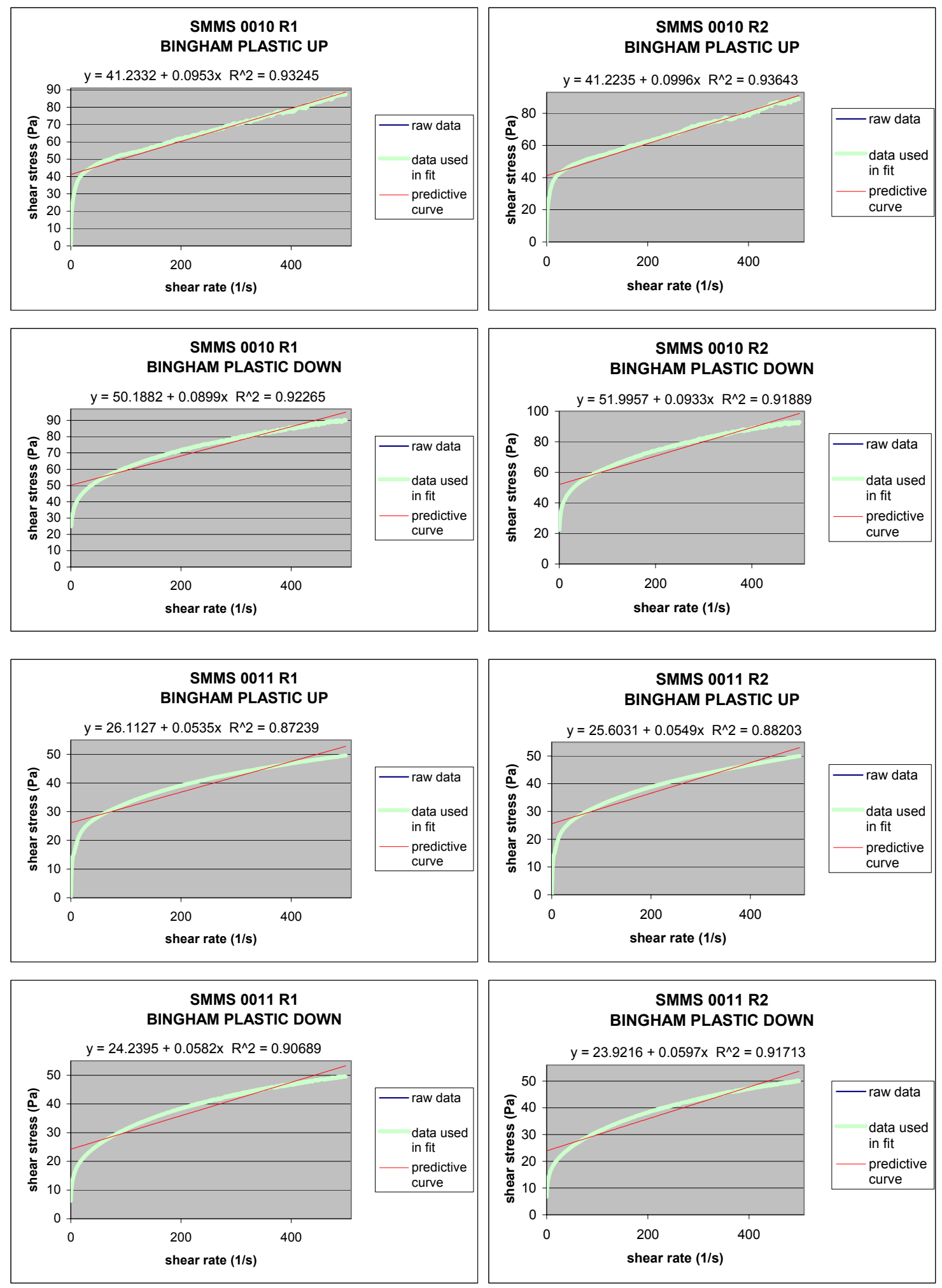

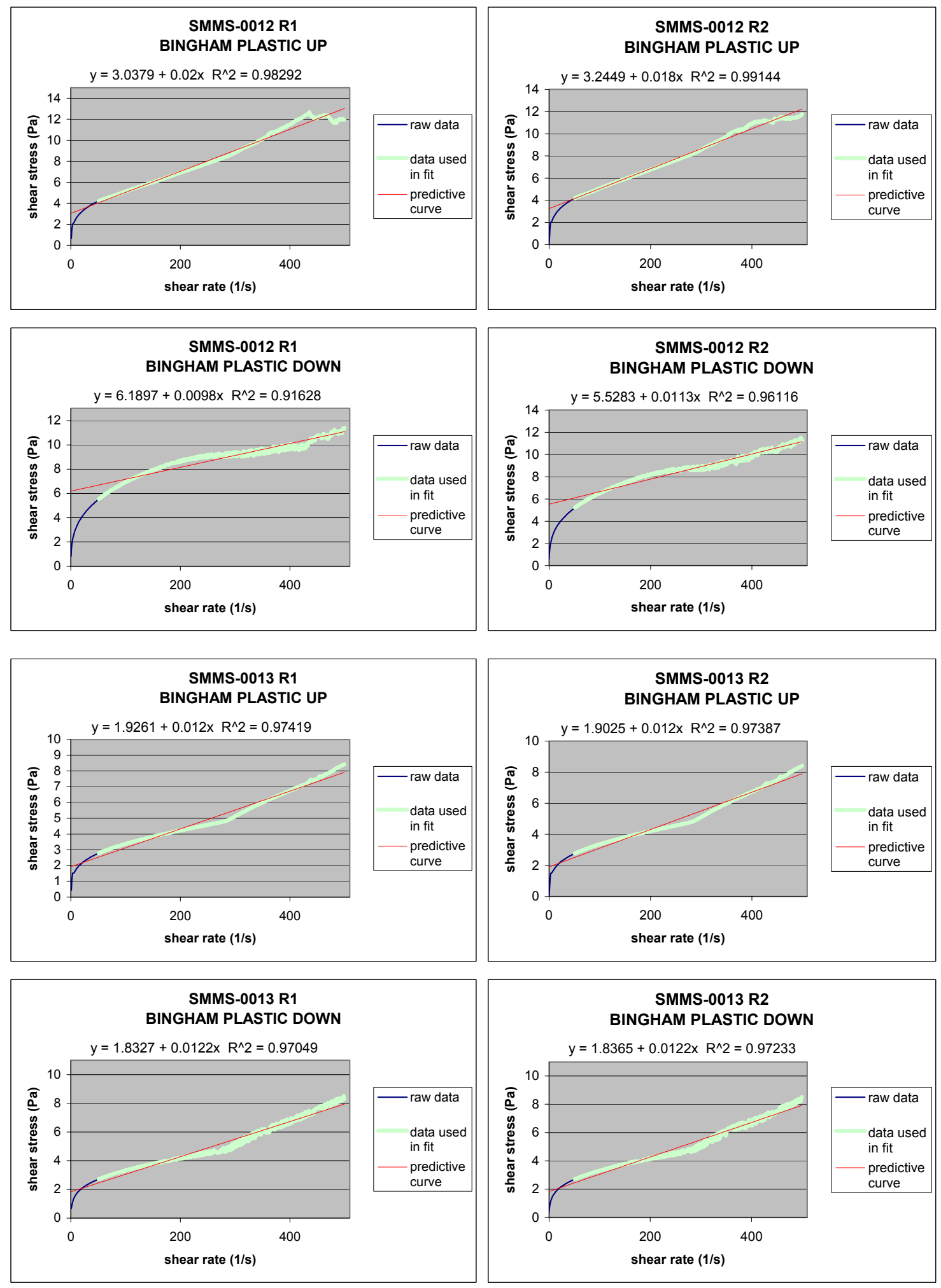

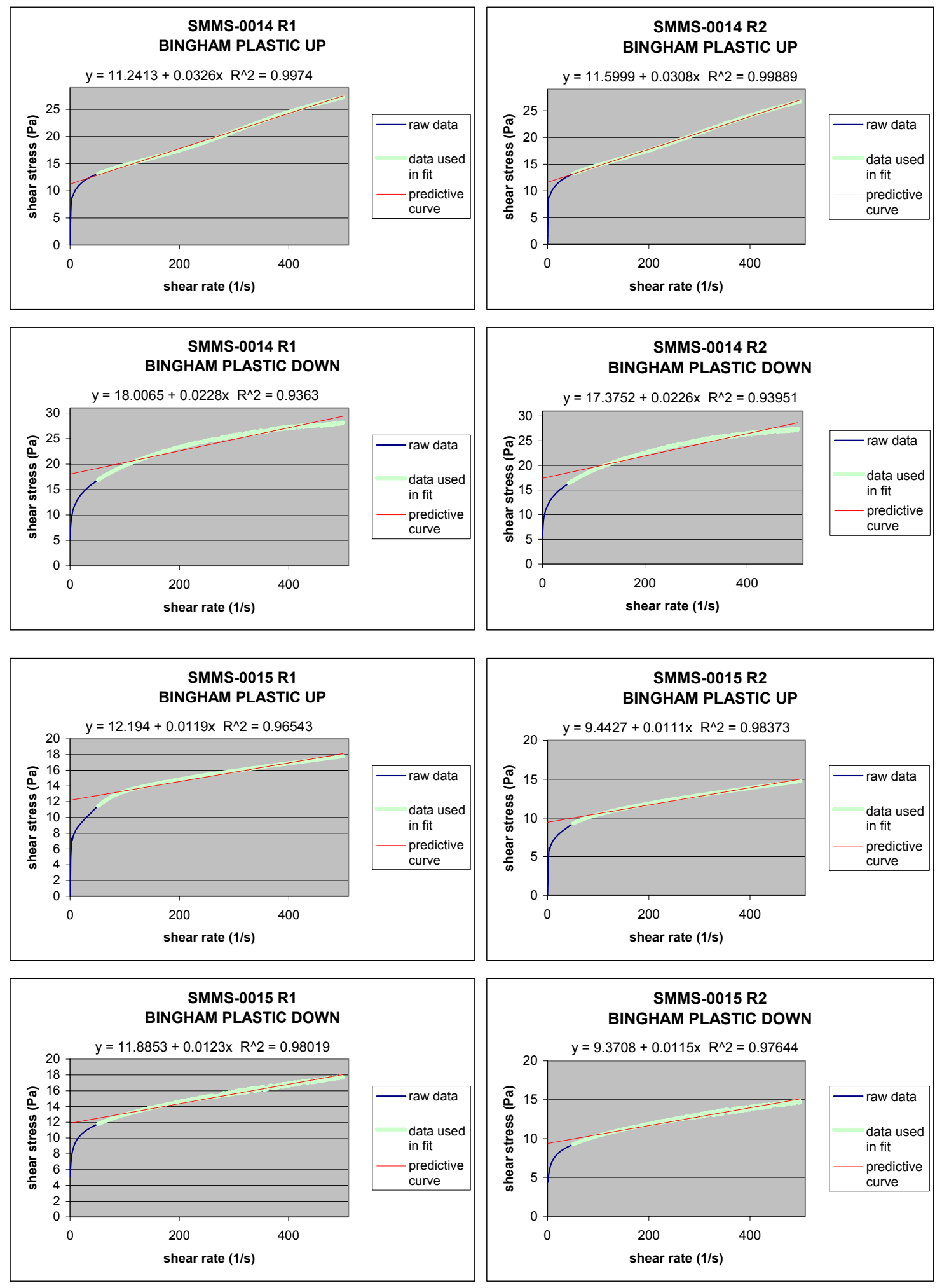

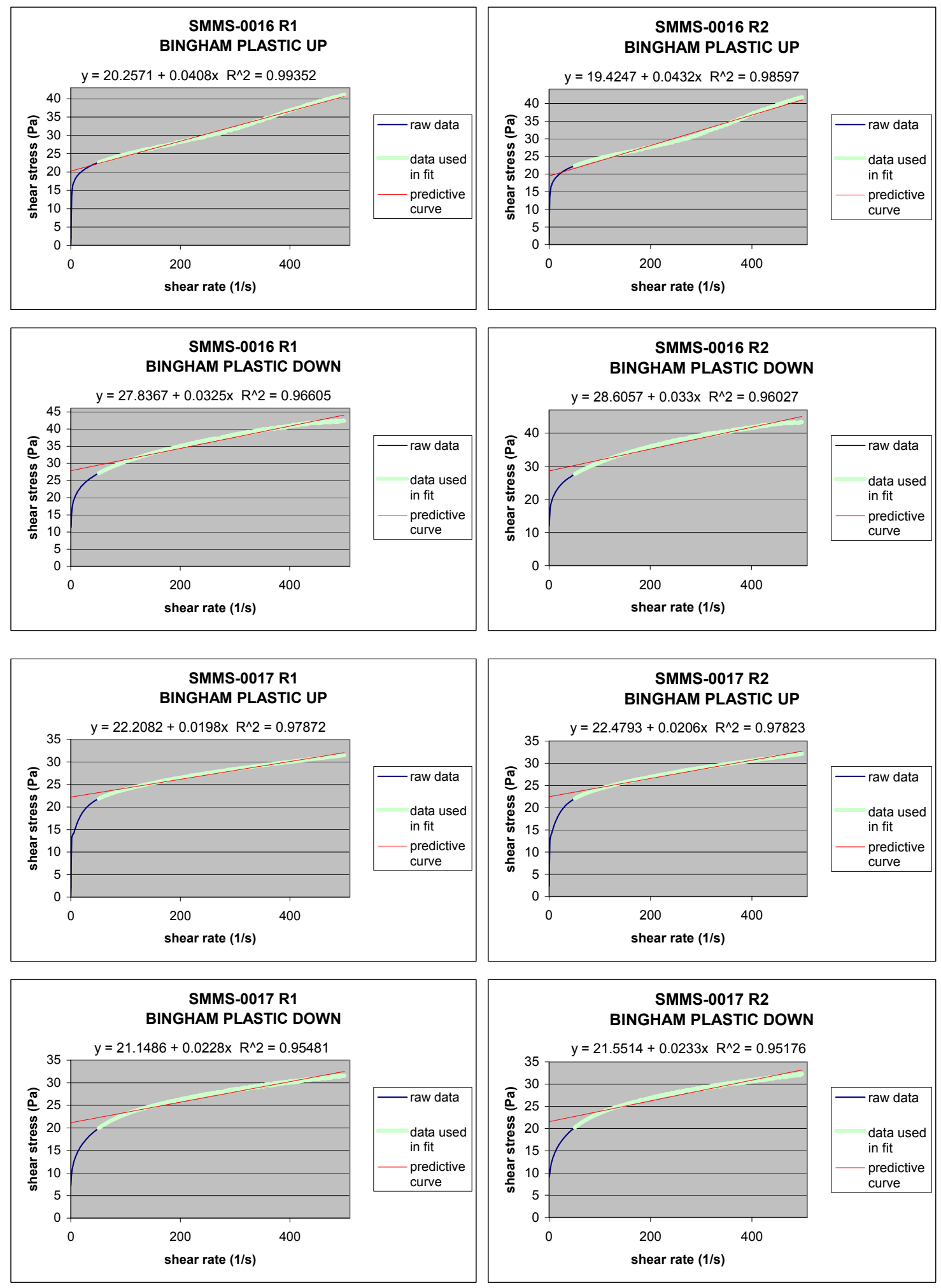
WSRC-TR-2004-00436

REVISION 0
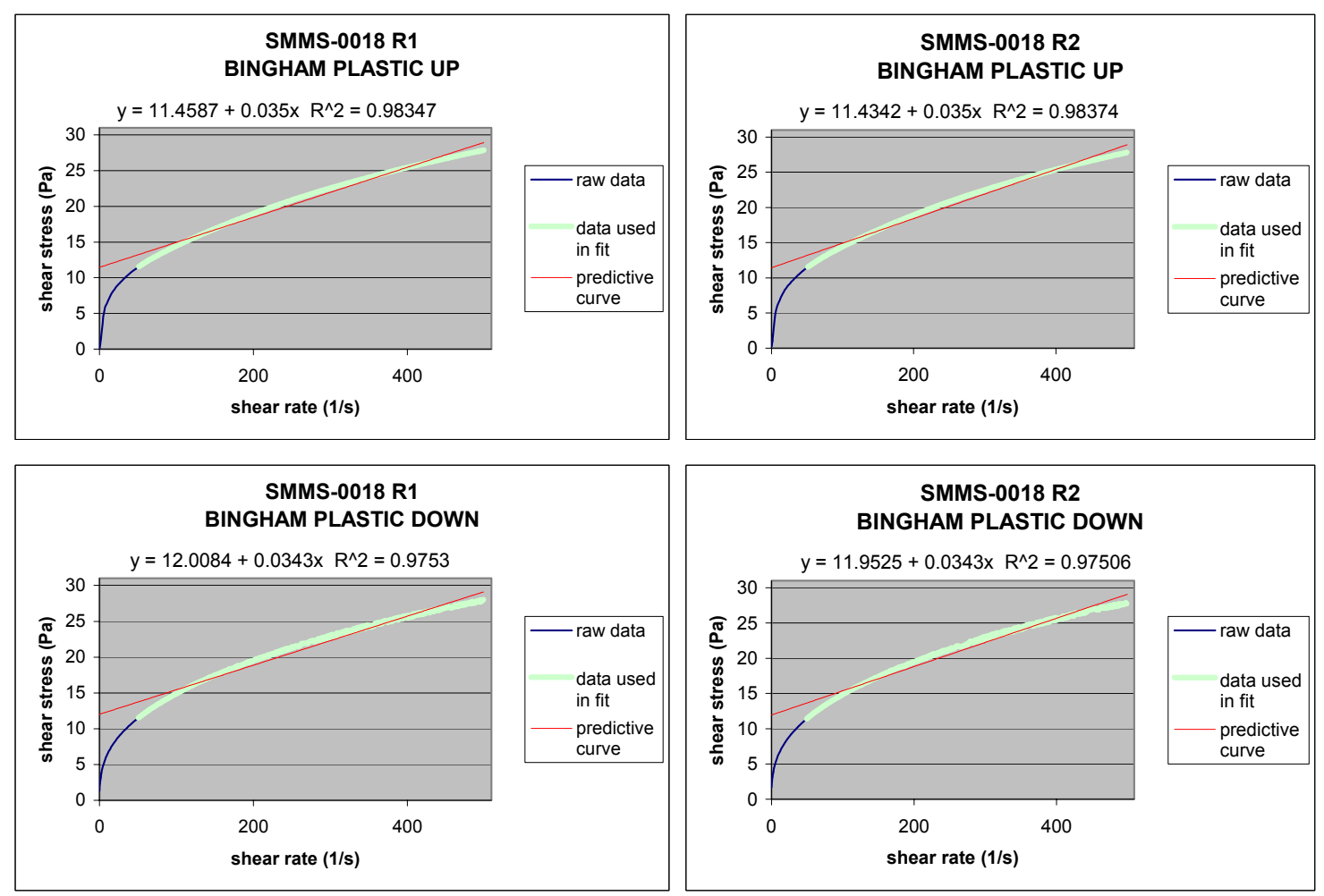


\section{APPENDIX D. EQUIPMENT AND INSTRUMENTATION}

Table 1. Equipment List: $1 / 6^{\text {th }}$ Scaled SRAT/SME/MFT Vessel

\begin{tabular}{||l|l||}
\hline Component & Make / Model \\
\hline Tank & Custom Fabrication per drawing EES-22729-PV-005 \\
\hline Agitator & Lightnin EV1P50M \\
\hline Impellers & Custom Fabrication per drawing EES-22729-R4-003 \\
\hline Video Camera & Cannon XL1 \\
\hline "Lipstick" Camera & Toshiba IK-CU44A \\
\hline Video Recorder & Sony MiniDV GV-D1000 NTSC \\
\hline Bubbler Assembly & Custom Fabrication \\
\hline Coil Assembly & Custom Fabrication \\
\hline Fiber Optic Light & Cole Parmer Illuminator 41720 \\
\hline Pump Dip Legs & Custom Fabrication \\
\hline $\begin{array}{l}\text { Supports for bubbler, pump dip } \\
\text { legs and sampler }\end{array}$ & Custom Fabrication \\
\hline Sampler & Drumstick Coliwasa \\
\hline \hline
\end{tabular}


WSRC-TR-2004-00436

REVISION 0

Table 2. Instrumentation List: $1 / 6^{\text {th }}$ Scale SRAT/SME/MFT Vessel

\begin{tabular}{|c|c|c|c|c|}
\hline $\begin{array}{l}\text { Measured } \\
\text { Parameter }\end{array}$ & Instrument Type & $\begin{array}{l}\text { Instrument } \\
\text { Model }\end{array}$ & $\begin{array}{l}\text { Instrument } \\
\text { M\&TE } \\
\text { Number }\end{array}$ & Comments \\
\hline $\begin{array}{l}\text { Agitator } \\
\text { Speed }\end{array}$ & PhotoTachometer & Extech & ITS-DI001 & $\begin{array}{l}\text { Instrument mounted } \\
\text { on tank top and } \\
\text { monitoring agitator } \\
\text { shaft through set } \\
\text { screw opening }\end{array}$ \\
\hline $\begin{array}{l}\text { Agitator } \\
\text { Power Draw }\end{array}$ & $\begin{array}{l}\text { True RMS Power } \\
\text { Analyzer }\end{array}$ & Extech 380803 & PA-5555 & $\begin{array}{l}\text { Agitator powered } \\
\text { through instrument }\end{array}$ \\
\hline \multirow{2}{*}{$\begin{array}{l}\text { Vessel } \\
\text { Temperature }\end{array}$} & $\begin{array}{l}\text { Type K } \\
\text { Thermocouple } \\
\text { Meter }\end{array}$ & $\begin{array}{l}\mathrm{I}^{2} \mathrm{R} \\
\text { Thermowatch } \\
\text { TOW-VOVC }\end{array}$ & TV003K & \\
\hline & $\begin{array}{l}\text { Type K } \\
\text { Thermocouple } \\
\text { Probe }\end{array}$ & $\begin{array}{l}\text { Omega } 1 / 8 " \\
\text { diameter probe, } \\
\text { Inconel cladding }\end{array}$ & ITS-TC001 & \\
\hline \multirow{4}{*}{$\begin{array}{l}\text { Slurry } \\
\text { Density via } \\
\text { Bubbler }\end{array}$} & $\begin{array}{l}\text { Differential } \\
\text { Pressure Meter }\end{array}$ & $\begin{array}{l}\text { Meriam Smart } \\
\text { Gauge - } 2100 \\
\text { series: } \\
0-200 \text { INWC }\end{array}$ & ITS-PT001 & $\begin{array}{l}\text { Bubbler tube mounted } \\
\text { above sump and is } \\
\text { flush with top of sump } \\
\text { with } 77 / 8 \text { " separation } \\
\text { between taps }\end{array}$ \\
\hline & Flow Controller & $\begin{array}{l}\text { MKS } 100 \\
\mathrm{ml} / \mathrm{min} \\
1179 \mathrm{~A} 12 \mathrm{CS} 1 \mathrm{BV}\end{array}$ & FC10011 & $\begin{array}{l}\text { Flow will be } 25 \\
\mathrm{ml} / \mathrm{min}\end{array}$ \\
\hline & Flow Controller & $\begin{array}{l}\text { MKS } 100 \\
\mathrm{ml} / \mathrm{min} \\
1179 \mathrm{~A} 12 \mathrm{CS} 1 \mathrm{BV}\end{array}$ & FC10010 & $\begin{array}{l}\text { Flow will be } 25 \\
\mathrm{ml} / \mathrm{min}\end{array}$ \\
\hline & Flow Computer & MKS & N/A & \\
\hline $\begin{array}{l}\text { Vortex } \\
\text { Depth }\end{array}$ & $\begin{array}{l}\text { Laser Distance } \\
\text { Gauge }\end{array}$ & Leica Disto Pro4 & $\begin{array}{l}\text { ITS- } \\
\text { LM001 }\end{array}$ & \\
\hline Time & $\begin{array}{l}\text { Stopwatch / } \\
\text { Clock }\end{array}$ & $\begin{array}{l}\text { Cole Parmer } \\
\text { 100-Hr Triple } \\
\text { Display } \\
\text { Clock/Timer } \\
\end{array}$ & $\mathrm{N} / \mathrm{A}$ & $\begin{array}{l}\text { Instrument was } \\
\text { ordered with NIST } \\
\text { certification }\end{array}$ \\
\hline
\end{tabular}




\section{APPENDIX E. Ekato Report}

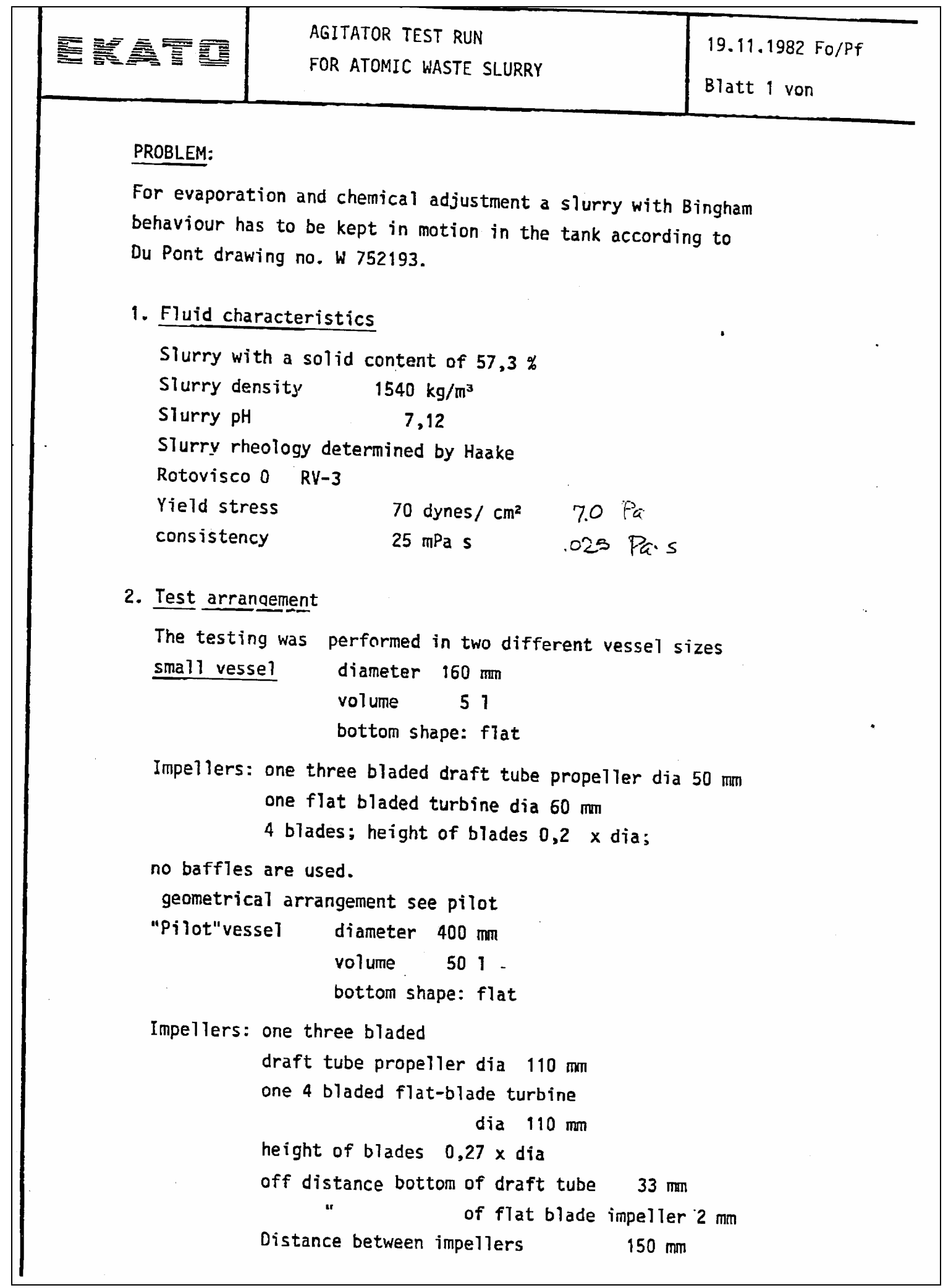




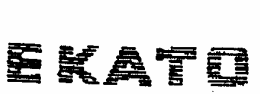

19.11.1982 Fo/Pf

Blatt 2 von

\begin{abstract}
draft tube dia $\quad 125 \mathrm{~mm}$
length draft tube $168 \mathrm{~mm}$
\end{abstract}

to simulate the process sample pump a solid shaft of dia $25 \mathrm{~mm}$ is attached $45 \mathrm{~mm}$ from tank wall.

liquid height: $400 \mathrm{~mm}$

The agitators are equipped with Speed variators. torque- and speed measurement devices.

3. Tests

Two series of tests are performeds

- with slurry

- with a transparent liquid having the same flow curve.

3.1 Description of transparent liquid.

The liquid consists of three components.

$77.4 \%$ w Polyisobutylen

$178 \% w$ Benzene

$4,8 \%$ Aerosil (Degussa) (fine dispersed $\mathrm{SiO}_{2}$ )

the flow behaviour can be influenced by variation of the composition.

Flow curve see figure 1.

3.2 Results with transparent liquid.

Snall vessel:

a speed of $n=950 \min ^{-1}$ is necessary to produce an overall motion in the vessel.

Pflot vessel

a speed of $n=550 \min ^{-1}$ is necessary for good motion.

3.3 Results with SME product.

A confirmation of the speeds. mentioned under

3.2 can be made. 
WSRC-TR-2004-00436

REVISION 0

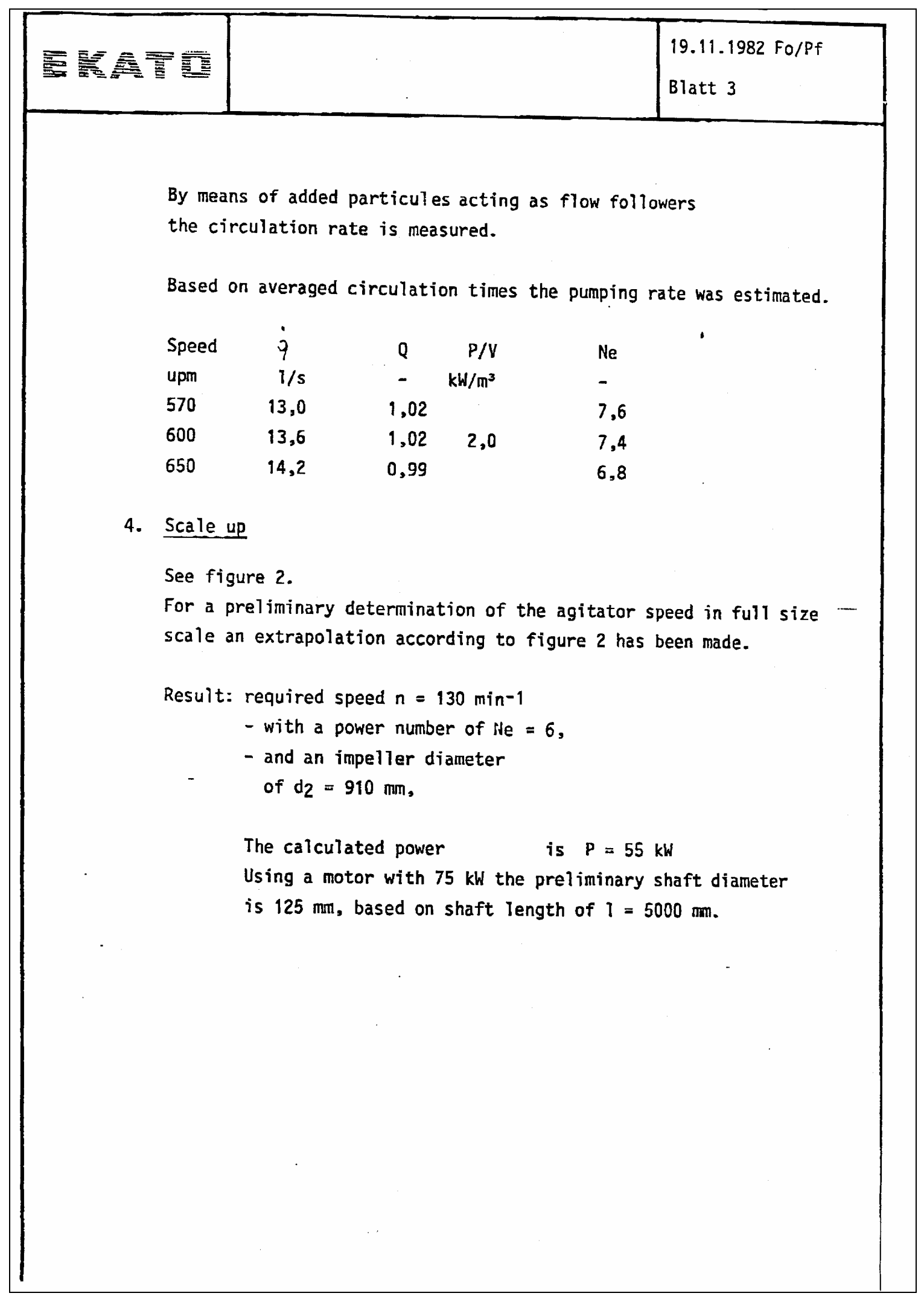


WSRC-TR-2004-00436

REVISION 0

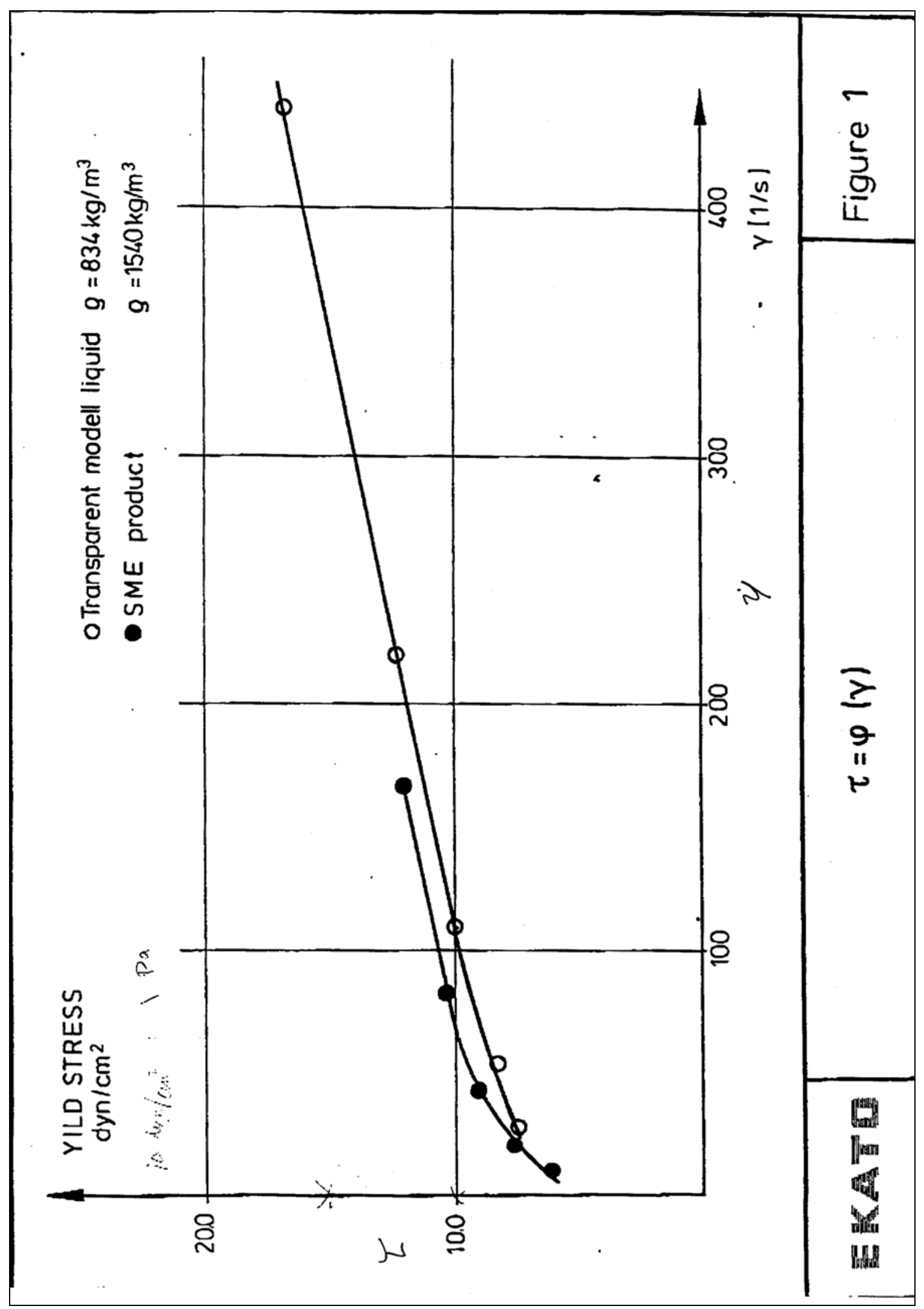


WSRC-TR-2004-00436

REVISION 0

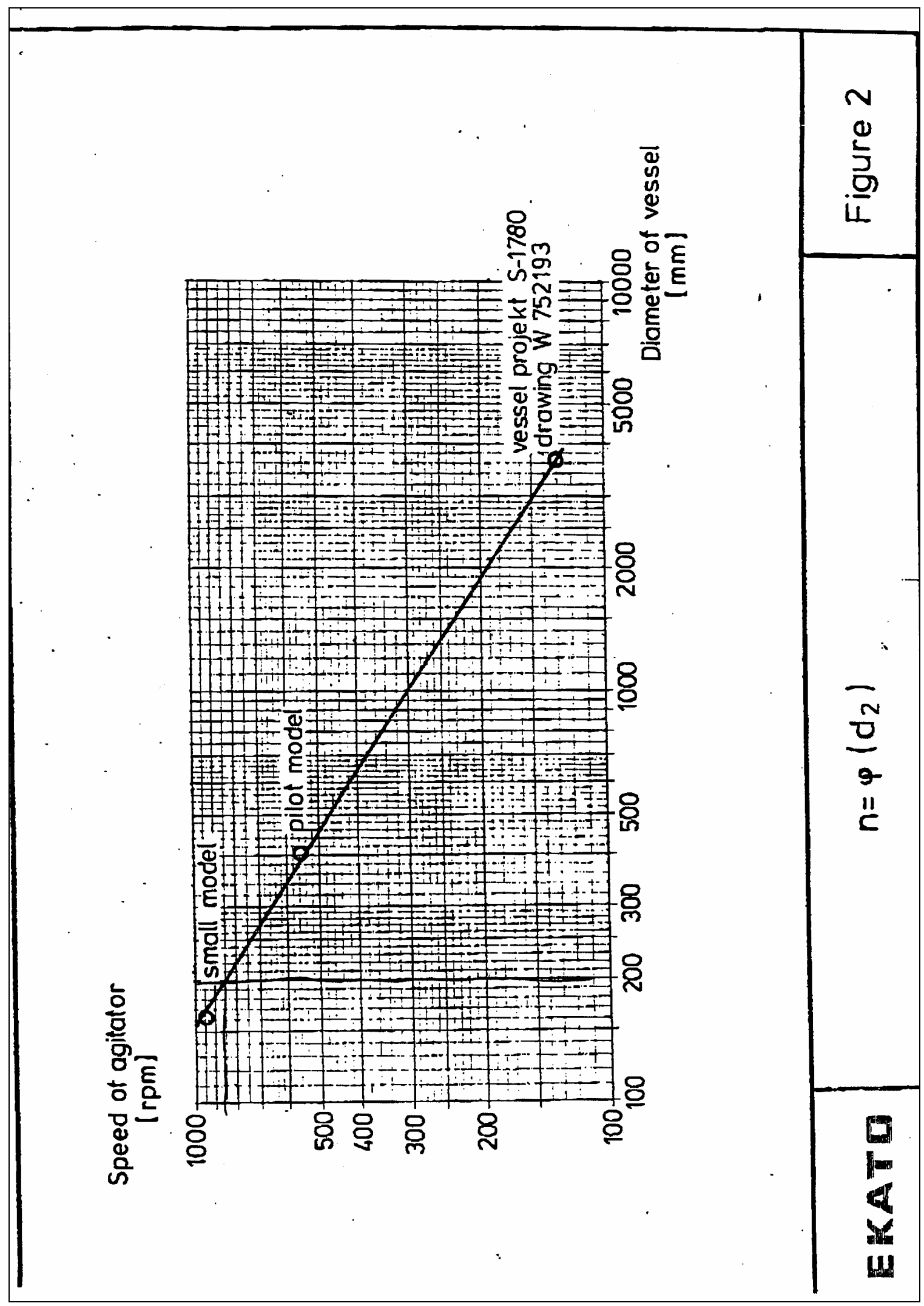


WSRC-TR-2004-00436

REVISION 0

\title{
APPENDIX F. Run Plan for Frit 418 Settling Tests
}

\author{
Westinghouse \\ Savannah River Company \\ Aiken, SC 29808
}

WESTINGHOUSE SAVANNAH RIVER COMPANY

\section{INTEROFFICE MEMORANDUM}

June 3, 2004

\author{
To: $\quad$ S. L. Marra \\ From: A.R. Marinik
}

Technical Review:

$$
\text { Signature }
$$$$
\text { Date }
$$

SRT-GPD-2004-00075

\section{$\underline{\text { Run Plan for Frit } 418 \text { Settling Tests }}$}

Task Plan: WSRC-RP-2004-00407

$\begin{array}{llll}\text { Researcher in Charge: } & \text { A. R. Marinik } & 819-8435 & 19391 \\ \text { Task Lead: } & \text { M. E. Stone } & 819-8410 & 17749\end{array}$

The Defense Waste Processing Facility (DWPF) is evaluating the removal of the cooling coils from the Melter Feed Tank (MFT). A Computational Fluid Dynamics (CFD) model has been developed by DWPF Engineering to perform this evaluation. As validation for this model a $1 / 6^{\text {th }}$ linear scale test will be performed by Savannah River National Laboratory. In order to perform these tests preparatory work must be done to determine the settling rates of Frit 418 , both in water, and Xanthan Gum slurry.

To determine the settling rates of Frit 418, three tests will be performed. The first test (Test \# 1) will consist of Frit 418 in water. $1.0 \mathrm{wt} \%$ Frit 418 will be added to $50 \mathrm{~mL}$ of water and filmed by a time lapse video camera as it settles to the bottom. The second test will consist of Frit 418 in a Xanthan Gum slurry. The Xanthan Gum slurry contains the Kathon as defined by SRT-GPD-2004-00070. 1.0wt\% Frit 418 will be added to each of three $50 \mathrm{~mL}$ samples of Xanthan Gum slurry. The first slurry will have a yield stress of $5 \mathrm{~Pa}$ (Test \# 2.1), the second will have a yield stress of $10 \mathrm{~Pa}$ (Test \# 2.2), and the third will have a yield stress of $20 \mathrm{~Pa}$ (Test \# 2.3). Again, in the $1.0 \mathrm{wt} \%$ Frit 418/Xanthan Gum tests the frit will be added to the sample and filmed by a time lapse video camera. The third test will consist of $30 \mathrm{wt} \%$ Frit 418 which has already been added to each of three Xanthan Gum slurries with yield stresses of $5 \mathrm{~Pa}$ (Test \# 3.1), $10 \mathrm{~Pa}$ (Test \# 3.2), and $20 \mathrm{~Pa}$ (Test \# 3.3). The following table summarizes the tests and components thereof.

\begin{tabular}{|c|c|c|c|c|c|}
\hline Test \# & Frit 418 (wt\%) & Frit 418 $(\mathrm{g})$ & Slurry Yield Stress & Slurry Mass $(\mathrm{g})$ & Sample \# \\
\hline 1.0 & 1.0 & 0.5 & $0 \mathrm{~Pa}$ & 50 & Water \\
\hline 2.1 & 1.0 & 0.5 & $5 \mathrm{~Pa}$ & 50 & SMMS-0020 \\
\hline 2.2 & 1.0 & 0.5 & $10 \mathrm{~Pa}$ & 50 & SMMS-0022 \\
\hline 2.3 & 1.0 & 0.5 & $20 \mathrm{~Pa}$ & 50 & SMMS-0023 \\
\hline 3.1 & 30 & $\mathrm{~N} / \mathrm{A}^{1}$ & $5 \mathrm{~Pa}$ & 50 & SMMS-0019 \\
\hline 3.2 & 30 & $\mathrm{~N} / \mathrm{A}^{1}$ & $10 \mathrm{~Pa}$ & 50 & SMMS-0021 \\
\hline 3.3 & 30 & $\mathrm{~N} / \mathrm{A}^{1}$ & $20 \mathrm{~Pa}$ & 50 & SMMS-0016 \\
\hline
\end{tabular}

${ }^{1}$ The Frit has already been added to this slurry.

THE WSRC TEAM

Westinghouse Savannah River Company LLC · Bechtel Savannah River, Inc. · BNFL Savannah River Corporation BWXT Savannah River Company · CH2 Savannah River Company· Polestar Savannah River Company 
WSRC-TR-2004-00436

REVISION 0

S. L. Marra

SRT-GPD-2004-00067

May 21,2004

Page 2 of 3

In Test \# 1 through Test \# 2.3 the Xanthan Gum slurry will first be added to the cylinder, and then the Frit 418 will be added on top. In Test \#3.1 through Test \# 3.3 the Xanthan Gum/Frit 418 slurry will be mixed well before being added to the cylinder. The camera will begin recording before the slurry is added to the container, and the camera will be stopped after complete settling occurs. Complete settling is defined as the point at which all frit has settled upon the bottom of the container. All three tests will be run side by side and filmed simultaneously. Sample placements during the testing/filming are as seen in the following figure.

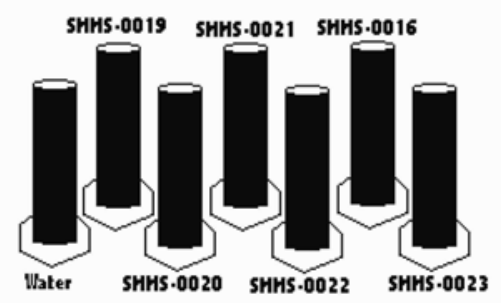

THE WSRC TEAM

Westinghouse Savannah River Company LLC · Bechtel Savannah River, Inc. · BNFL Savannah River Corporation BWXT Savannah River Company · CH2 Savannah River Company· Polestar Savannah River Company 